\title{
GEISA DE ANGELIS
}

Estudo comparativo entre a percepção da qualidade do sono, Qualidade de Vida, sintomas depressivos e de ansiedade em portadores do transtorno bipolar na fase eutímica

Dissertação apresentada à Faculdade de Medicina da Universidade de São Paulo para obtenção do título de mestre em Ciências

Área de concentração: Neurologia Orientador: Professor Dr. Rubens Nelson Amaral de Assis Reimão

Apoio da Coordenação de Aperfeiçoamento de Pessoal de Nível Superior (CAPES)

\author{
São Paulo
}




\section{UNIVERSIDADE DE SÃO PAULO \\ DEPARTAMENTO DE NEUROLOGIA}

\section{GEISA DE ANGELIS}

Estudo comparativo entre a percepção da qualidade do sono e Qualidade de Vida, sintomas depressivos e de ansiedade em portadores do transtorno bipolar na fase eutímica

São Paulo 2009 


\title{
Dados Internacionais de Catalogação na Publicação (CIP)
}

\author{
Preparada pela Biblioteca da
}

Faculdade de Medicina da Universidade de São Paulo

Oreprodução autorizada pelo autor

\section{Angelis, Geisa de}

Estudo comparativo entre a percepção da qualidade do sono, qualidade de vida, sintomas depressivos e de ansiedade em portadores do transtorno bipolar na fase eutímica / Geisa de Angelis. -- São Paulo, 2009.

Dissertação(mestrado)--Faculdade de Medicina da Universidade de São Paulo. Departamento de Neurologia.

Área de concentração: Neurologia.

Orientador: Rubens Nelson Amaral de Assis Reimão.

Descritores: 1.Transtorno bipolar 2.Transtornos do sono 3.Qualidade de vida 4.Sintomas afetivos 5.Sono

USP/FM/SBD-375/08 


\section{Dedicatória}

A minha mãe, Maria Antonia, pelo amor, carinho, apoio e incentivo.

A meu pai, Laércio (in memoriam), por semear o desejo de conhecer, a curiosidade e a perseverança

A meu marido, Jefferson, por estar presente em todos os momentos da minha vida 


\section{Agradecimentos}

Ao meu orientador, Dr. Rubens Reimão, pela orientação, disponibilidade, pela grande competência como pesquisador e profissional, pela confiança em meu trabalho e por compartilhar seus conhecimentos;

À amiga e professora Dra. Sueli Rossini, minha eterna gratidão pela amizade, incentivo e apoio incondicional. Por tudo o que representa para mim como pessoa, profissional e pesquisadora;

Ao Dr. Rafael Sanches, pela amizade, pela oportunidade que me deu de participar dos grupos de psicoeducação, pela colaboração, pelo incentivo, por ter-me ensinado muito sobre transtorno bipolar e por representar um modelo de psicoterapeuta com o jeito humano de ser que admiro muito;

Ao Jefferson, meu marido, pelo carinho, incentivo, apoio, pela dedicação, pela confiança e pelas contribuições práticas e teóricas;

A Maria Antonia, minha mãe querida, pelo amor incondicional, pelo cuidado, pela paciência e pelo grande apoio;

A Rosa Maria Grecco, minha prima, pelo acolhimento, carinho e apoio;

A todas as pessoas com transtorno bipolar do grupo de psicoeducação do Hospital Dia da FMRP/USP e seus familiares, que compartilharam com carinho e disponibilidade suas experiências de vida;

Ao Professor Geraldo Cássio, do Departamento de Neurologia da Faculdade de Medicina de Ribeirão Preto da Universidade de São Paulo, pela paciência nas aulas de estatística; 
À Ilza Garcia Gerônimo, funcionária do Grupo de Avaliação de Desempenho do Hospital das Clínicas da Faculdade de Medicina de Ribeirão Preto, pela disponibilidade e pela grande ajuda;

A todas as pessoas que gentilmente participaram desta pesquisa;

À Coordenação de Aperfeiçoamento de Pessoal de Nível Superior (CAPES) pela bolsa de estudo concedida;

A todos os colegas, professores e funcionários da Divisão de Clínica Neurológica do Hospital das Clínicas da Faculdade de Medicina da Universidade de São Paulo, pela colaboração e amizade. 


\section{SUMÁRIO}

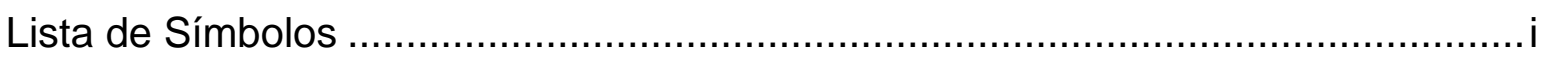

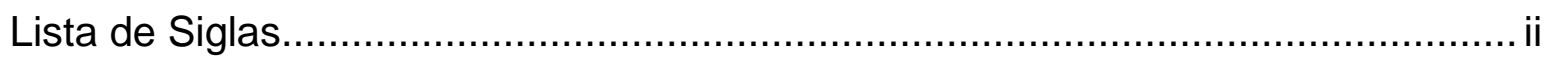

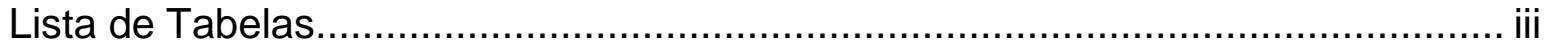

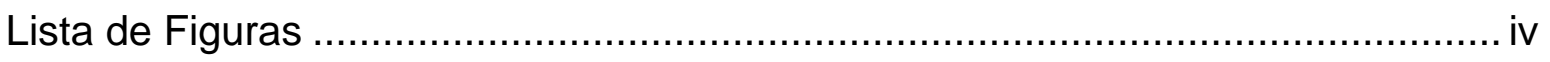

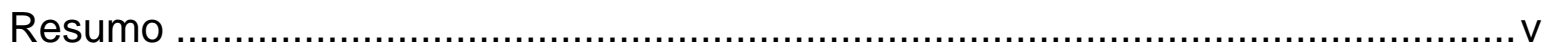

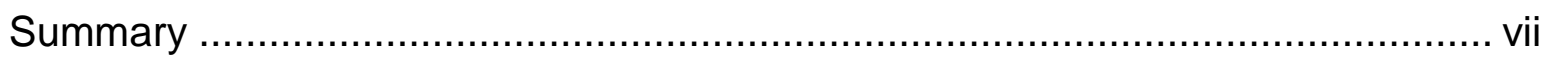

1 INTRODUÇÃO

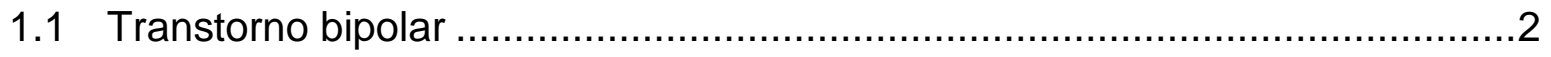

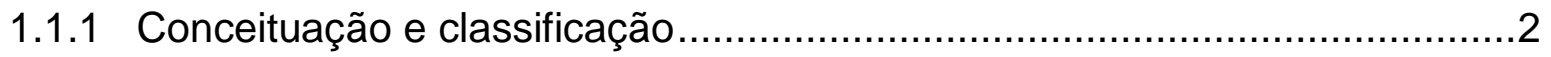

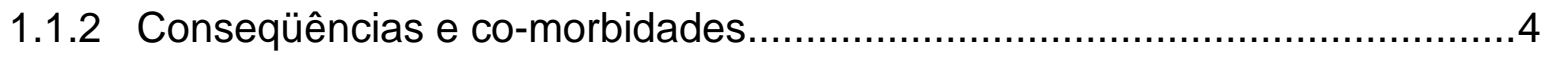

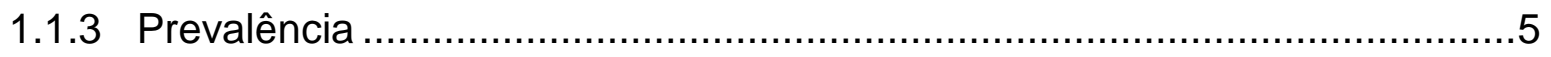

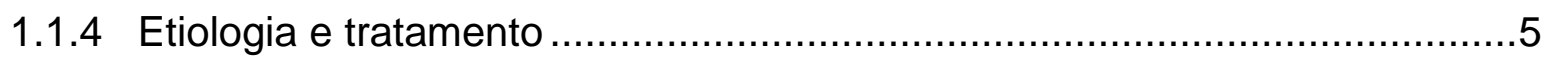

1.2 O papel da psicoeducação no tratamento do transtorno bipolar .....................6

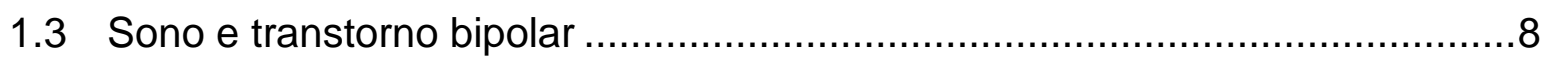

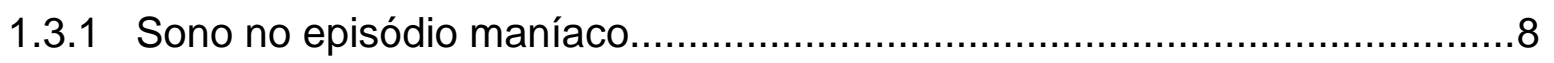

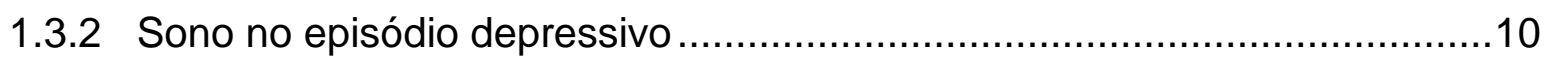

1.3.3 Sono no período eutímico ……………............................................12

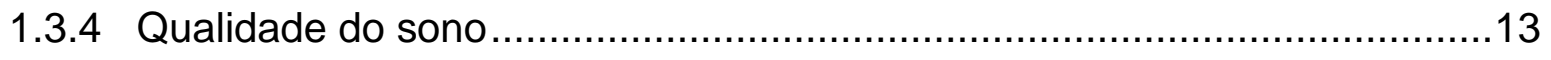

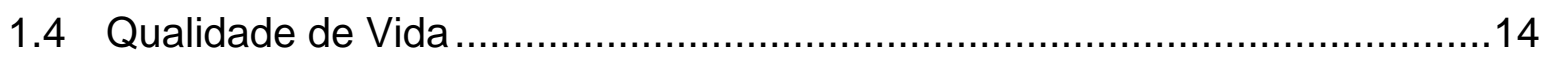

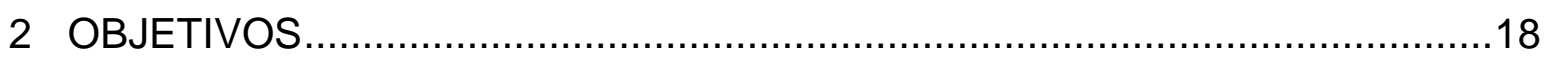

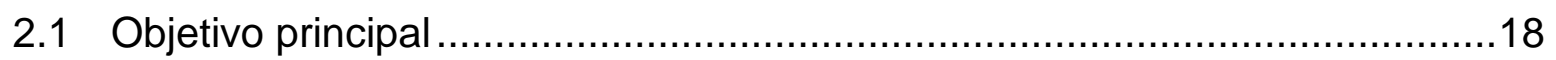

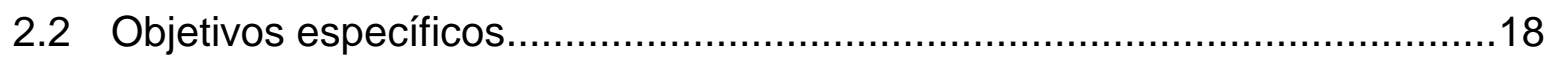

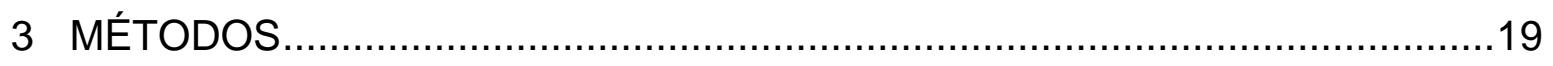

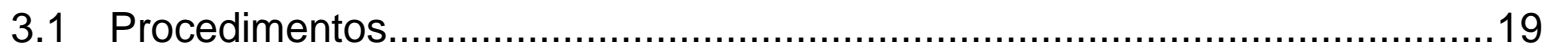

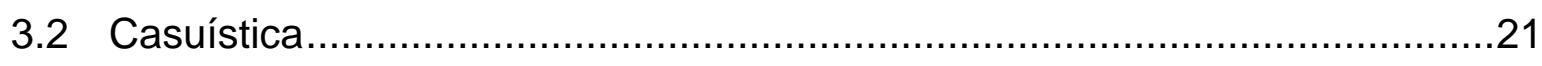

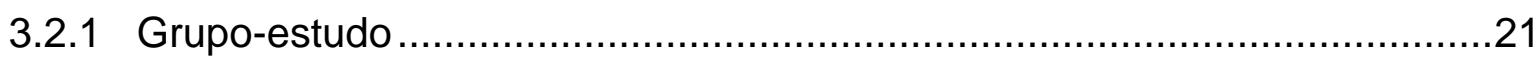




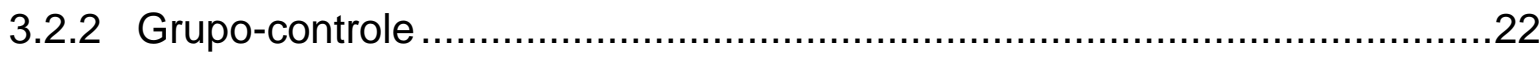

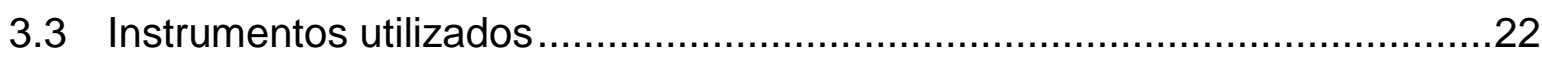

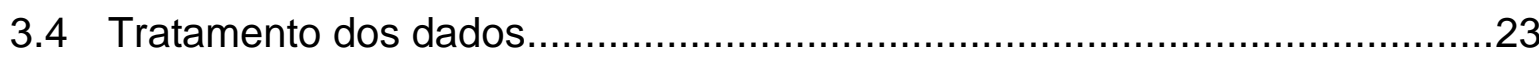

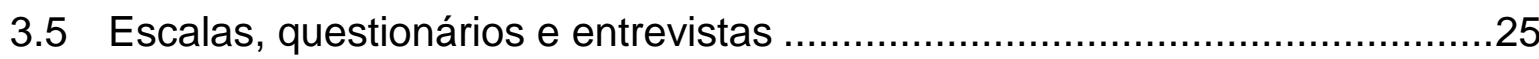

3.5.1 Índice de Qualidade do Sono de Pittsburgh.........................................25

3.5.2 Inventário de Depressão de Beck .................................................26

3.5.3 Inventário de Ansiedade de Beck ......................................................27

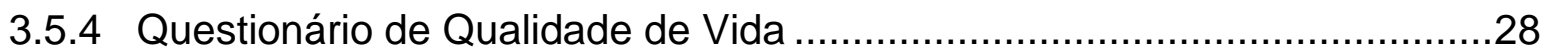

3.5.5 Entrevista Clínica Estruturada para o DSM-IV .....................................30

3.5.6 Escala de Avaliação de Mania - Modificada............................................. 31

3.5.7 Critério de Classificação Econômica Brasil.........................................32

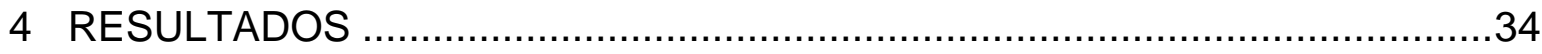

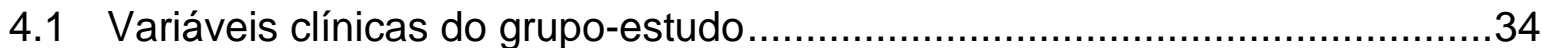

4.2 Análise das variáveis sociodemográficas ...............................................34

4.3 Análise dos sintomas depressivos, de ansiedade e de euforia ....................37

4.4 Análise da percepção da qualidade do sono ..........................................38

4.5 Análise da percepção da QV .....................................................42

4.6 Análise comparativa entre as variáveis QS, QV, sintomas depressivos, sintomas de ansiedade, idade e escolaridade

4.7 Análise comparativa entre as variáveis estado civil, nível socioeconômico, ocupação, latência, duração e eficiência do sono ......................46

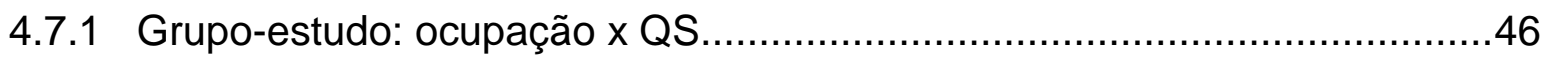

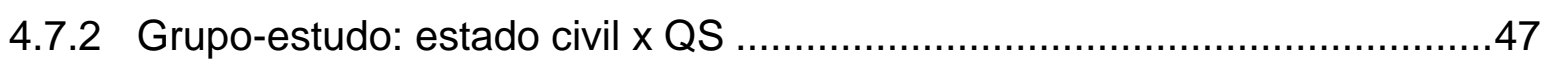

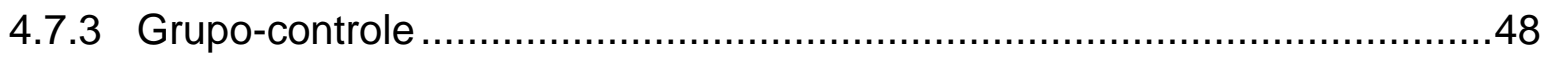

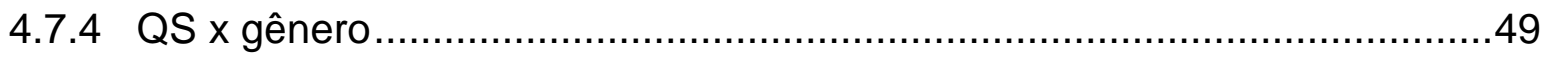

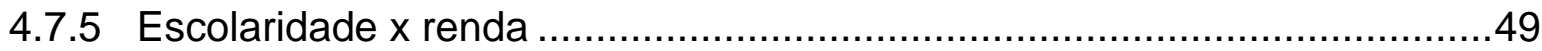

4.7.6 Latência, duração, sintomas depressivos e sintomas de ansiedade .........50

4.8 Análise dos subgrupos de maus dormidores...........................................50

4.9 Análise dos indivíduos com co-morbidade ...............................................51

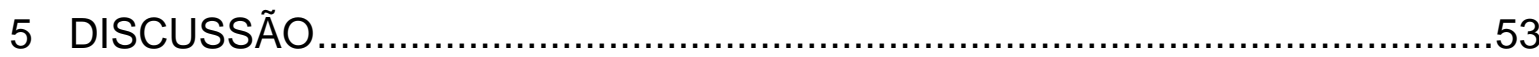

5.1 Caracterização quanto às variáveis clínicas do grupo-estudo.....................53

5.2 Caracterização quanto às variáveis sociodemográficas ............................54 
5.3 Sintomas depressivos, de ansiedade e de euforia .................................55

5.4 QS, sintomas depressivos e ansiosos ............................................. 57

$5.5 \mathrm{QV}$, sintomas depressivos e ansiosos .............................................59

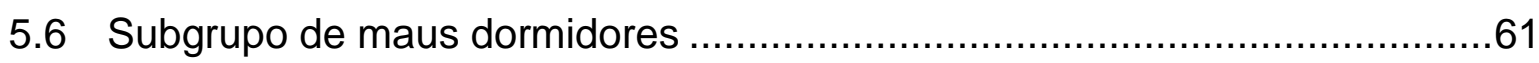

5.7 Subgrupo com co-morbidades: uma contribuição adicional à pesquisa ........61

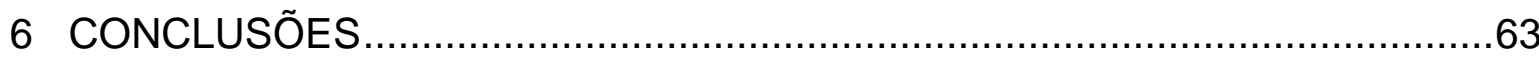

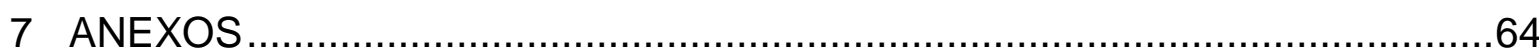

Anexo A: Protocolo de aprovação do Comitê de Ética em Pesquisa....................64

Anexo B: Termo de Consentimento Livre e Esclarecido....................................66

Anexo C: Índice de Qualidade do Sono de Pittsburgh ...................................69

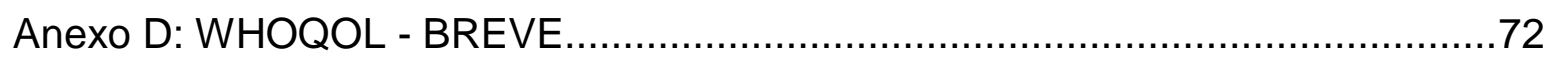

Anexo E: Escala de Avaliação de Mania Modificada (EAM-m) ...........................75

Anexo F: Roteiro de entrevista para o preenchimento do EAM-m ......................78

Anexo G: Critério de Classificação Econômica Brasil ......................................80

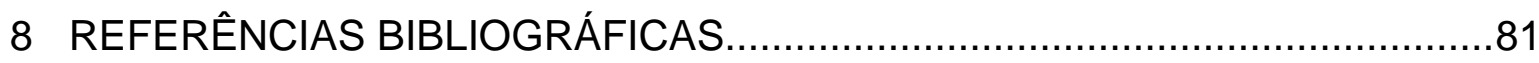




\section{Lista de Símbolos}

A2c Percentual de sujeitos do grupo-controle classificados na categoria de renda $\mathrm{A} 2$

$\mathrm{A} 2 \mathrm{E} \quad$ Percentual de sujeitos do grupo-estudo classificados na categoria de renda $\mathrm{A} 2$

B1C Percentual de sujeitos do grupo-controle classificados na categoria de renda $\mathrm{B} 1$

B1E Percentual de sujeitos do grupo-estudo classificados na categoria de renda $\mathrm{B} 1$

B2C Percentual de sujeitos do grupo-controle classificados na categoria de renda $\mathrm{B} 2$

B2 $E$ Percentual de sujeitos do grupo-estudo classificados na categoria de renda B2

$\mathrm{C}_{\mathrm{C}} \quad$ Percentual de sujeitos do grupo-controle classificados na categoria de renda $\mathrm{C}$

$\mathrm{C}_{\mathrm{E}} \quad$ Percentual de sujeitos do grupo-estudo classificados na categoria de renda $\mathrm{C}$ 
Lista de Siglas

\begin{tabular}{|c|c|}
\hline BAI & Inventário de Ansiedade de Beck \\
\hline BDI & Inventário de Depressão de Beck \\
\hline CCEB & Critério de Classificação Econômica Brasil \\
\hline DSM-IV & $\begin{array}{l}\text { (Diagnostic and Statistical Manual of Mental Disorders - } \\
\text { Fourth Edition) Manual Diagnóstico e Estatístico de } \\
\text { Transtornos Mentais } 4^{\circ} \text { Edição - Texto Revisado }\end{array}$ \\
\hline EAM-m & Escala de Avaliação de Mania Modificada \\
\hline HC-FMRP/USP & $\begin{array}{l}\text { Hospital das Clínicas da Faculdade de Medicina de } \\
\text { Ribeirão Preto da Universidade de São Paulo }\end{array}$ \\
\hline HC/FMUSP & $\begin{array}{l}\text { Hospital das Clínicas da Faculdade de Medicina da } \\
\text { Universidade de São Paulo }\end{array}$ \\
\hline HD-FMRP/USP & $\begin{array}{l}\text { Hospital Dia Psiquiátrico da Faculdade de Medicina de } \\
\text { Ribeirão Preto da Universidade de São Paulo }\end{array}$ \\
\hline OMS & Organização Mundial da Saúde \\
\hline PSQI & $\begin{array}{l}\text { (Pittsburgh Sleep Quality Index) Índice de Qualidade do } \\
\text { Sono de Pittsburgh }\end{array}$ \\
\hline QS & Qualidade do Sono \\
\hline QV & Qualidade de Vida \\
\hline SCID & $\begin{array}{l}\text { (Structural Clinical Interview for the DSM-IV) Entrevista } \\
\text { Clínica Estruturada para o DSM-IV }\end{array}$ \\
\hline TB & Transtorno Bipolar \\
\hline WHOQOL-BREVE & $\begin{array}{l}\text { World Health Organization Quality of Life - Quality of } \\
\text { Life Assessment) Questionário de Qualidade de Vida da } \\
\text { Organização Mundial da Saúde - Versão Abreviada }\end{array}$ \\
\hline
\end{tabular}




\section{Lista de Tabelas}

Tabela 1 - Categorias de renda e renda média.................................... 33

Tabela 2 - Variáveis clínicas do grupo-estudo ...................................... 34

Tabela 3 - Características sociodemográficas das variáveis numéricas idade

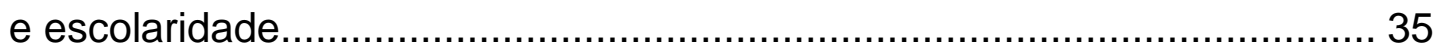

Tabela 4 - Comparação das características sociodemográficas das variáveis categóricas: gênero, estado civil, ocupação e nível socioeconômico entre os grupos.

Tabela 5 - Pontuações globais numéricas dos sintomas depressivos e de ansiedade 37

Tabela 6 - Características do sono ................................................ 38

Tabela 7 - Pontuação global da qualidade do sono ................................. 39

Tabela 8 - Freqüência relativa e absoluta da percepção subjetiva da QS .. 39

Tabela 9 - Classificação em bons e maus dormidores de acordo com a pontuação total no PSQI ................................................................. 40

Tabela 10 - Uso de medicação para dormir ....................................... 41

Tabela 11 - Sonolência diurna ...................................................... 41

Tabela 12 - Necessidade de levantar-se durante a noite para ir ao banheiro

Tabela 13 - Resultados obtidos através do WHOQOL-BREVE ................. 43

Tabela 14 - Percepção geral da QV ................................................. 43

Tabela 15 - Correlação entre as variáveis idade, QS, sintomas depressivos, sintomas de ansiedade e QV para o grupo-estudo e grupo-controle........... 45 Tabela 16 - Latência e duração do sono nos subgrupos de maus dormidores 


\section{Lista de Figuras}

Figura 1 - Distribuição das freqüências relativas das pontuações no PSQI..44 


\section{Resumo}

Angelis G. Estudo comparativo entre a percepção da qualidade do sono e Qualidade de Vida, sintomas depressivos e de ansiedade em portadores do transtorno bipolar na fase eutímica [dissertação]. São Paulo: Faculdade de Medicina, Universidade de São Paulo; 2009. 87p.

INTRODUÇÃO: O transtorno bipolar é caracterizado por episódios alternados e recorrentes de mania ou hipomania com depressão e períodos de eutimia, com prevalência entre $1 \%$ e $8 \%$ na população geral. Os transtornos mentais influenciam consideravelmente a qualidade de vida, prejudicando as relações familiares, sociais e ocupacionais. $O$ sono que influi diretamente na qualidade de vida, também pode alterar-se no transtorno bipolar. OBJETIVOS: a) Verificar se existe diferença entre a percepção da qualidade de vida e qualidade do sono em portadores de transtorno bipolar quando comparados a um grupo-controle; b) verificar a associação entre qualidade de vida e qualidade do sono em cada grupo; c) avaliar a intensidade de sintomas depressivos e de ansiedade e verificar se essas variáveis são diferentes entre os grupos; d) investigar se existe associação dos sintomas depressivos e de ansiedade na qualidade de vida e na qualidade do sono; e) verificar se a latência, duração e eficiência do sono nos maus dormidores do grupo-estudo são diferentes dos maus dormidores do grupo-controle. MÉTODOS: A pesquisa foi do tipo caso-controle e a amostra foi caracterizada como não probabilística por conveniência. Grupoestudo $(n=43)$ e grupo-controle $(n=80)$. A seleção do grupo-estudo seguiu os seguintes critérios de inclusão: pessoas com transtorno bipolar na fase estabilizada que participavam do grupo de psicoeducação em um Hospital Dia Psiquiátrico, idade entre 25 e 60 anos, diagnóstico de transtorno bipolar tipo I ou II, de acordo com os critérios diagnósticos do Manual Diagnóstico e Estatístico de Transtornos Mentais IV-Revisão, em uso de estabilizador do humor e ausência de co-morbidade psiquiátrica. Foram excluídos os controles com quaisquer diagnósticos psiquiátricos do eixo I, do Manual Diagnóstico e Estatístico de Transtornos Mentais IV-Revisão. O projeto foi aprovado pelo Comitê de Ética do Hospital das Clínicas da Faculdade de Medicina de Ribeirão Preto da Universidade de São Paulo. Os instrumentos utilizados foram: Índice de Qualidade do Sono de Pittsburgh, Inventário de Depressão de Beck, Inventário de Ansiedade de Beck, Questionário de Qualidade de Vida da Organização Mundial da Saúde, Entrevista Clínica Estruturada para o Manual Diagnóstico e Estatístico de Transtornos Mentais IV-Revisão, Escala de Avaliação de Mania Modificada e o Critério de Classificação Econômica Brasil. RESULTADOS: Encontrou-se diferença significativa em relação à qualidade do sono $(p=0,045)$. As diferenças não foram significativas para qualidade de vida $(p=0,154)$, sintomas depressivos $(p=0,480)$ e sintomas de ansiedade $(p=0,484)$. As variáveis qualidade do sono e qualidade de vida apresentaram correlação significativa tanto para 0 
grupo-estudo $(p<0,001 ; r=0,534)$ quanto para o grupo-controle $(p<0,001$; $r=0,382)$. Foram encontradas diferenças significativas na latência e duração do sono nos subgrupos de maus dormidores $(p=0,026$ e $p=0,001$; respectivamente). CONCLUSÃO: As pessoas com transtorno bipolar apresentaram percepção da qualidade de vida, intensidade de sintomas depressivos e de ansiedade semelhantes às de pessoas não afetadas por este transtorno, porém com pior qualidade do sono. Houve associação diretamente proporcional entre as variáveis: qualidade do sono e qualidade de vida. No subgrupo de maus dormidores do grupo-estudo, a latência e duração do sono estiveram aumentadas comparadas com o subgrupo de maus dormidores do grupo-controle.

Descritores: transtorno bipolar, transtornos do sono, qualidade de vida, sintomas depressivos, sintomas afetivos, sono 


\section{Summary}

Angelis G. Comparative study between the perception of quality of sleep and quality of life, depressive and anxiety symptoms in euthymic bipolar disorder (dissertation). São Paulo: "Faculdade de Medicina, Universidade de São Paulo"; 2009. 87p.

INTRODUCTION: The bipolar disorder is characterized by alternating and recurrent episodes of mania and hypomania with depression and periods of euthymia, with prevalence between 1 and $8 \%$ in the general population. The mental disorders influence the quality of life considerably, disturbing familiar, social and occupational relations. Sleep is also associated with the quality of life; moreover, it can be modified in bipolar disorder. OBJECTIVES: a) To verify if there is a difference between the perception of the quality of life and the quality of sleep in bipolar disorder when compared with a control-group; b) to verify the association between quality of life and quality of sleep in each group; c) to evaluate the intensity of depressive and anxiety symptoms and verify if these variables are different between the groups; d) to investigate possible association of depressive and anxiety symptoms in quality of life and quality of sleep; e) to verify if latency, duration and efficiency of sleep in the bad sleepers of the study-group are different from those of bad sleepers in the control-group. METHODS: The kind of research was case-control and the sample was characterized as a no-probability for convenience. Study-group $(n=43)$ and control-group $(n=80)$. The selection for the study-group had the following criteria of inclusion: patients with bipolar disorder in the stabilized phase who took part of the group of psychoeducation in a Psychiatric Hospital, age between 25 and 60, diagnostic of bipolar disorder, according to the criteria diagnostics of Diagnostic and Statistical Manual of Mental Disorders-Fourth Edition, in use of stabilizer of mood and absence of psychiatric comorbidity. The project has been approved by the Committee of Ethic of "Hospital das Clínicas da Faculdade de Medicina de Ribeirão Preto, da Universidade de São Paulo", Brazil. The instruments used in this process were: Pittsburgh Sleep Quality Index, Beck Depression Inventory, Beck Anxiety Inventory, World Health Organization Quality of Life Assessment, Clinical Interview Structuralized for the Diagnostic and Statistical Manual of Mental Disorders-Fourth Edition, Modified Scale of Mania Evaluation and Brazilian Criteria of Economic Classification. RESULTS: a significant difference in the quality of sleep $(p=0.045)$ has been found. The differences weren't significant for the variables: quality of life $(p=0.154)$, depressive symptoms $(p=0.480)$ and anxiety symptoms $(p=0.154)$. The variables quality of sleep and quality of life presented a significant correlation to both studygroup ( $p<0.001 ; r=0.534)$ and control-group $(p<0.001: r=0.382)$. Significant differences in latency and duration of sleep in the subgroup of bad sleepers ( $p=0.026$ and $p=0.001$, respectively) have been found. CONCLUSION: Patients with bipolar disorder presented perception of the quality of life, intensity of depressive and anxiety symptoms similar to those of subjects in 
the control-group not affected by this disorder. There has been a direct proportional association between the variables quality of sleep and quality of life. In the sub-group of bad sleepers in the study-group, the latency and duration of sleep had been increased compared to those in the sub-group of bad sleepers in the control-group.

Descriptors: bipolar disorder, sleep disorders, quality of life, affective symptoms, sleep 


\section{INTRODUÇÃO}

As alterações dos padrões do sono são encontradas em vários transtornos mentais, servindo de critério diagnóstico para alguns deles ${ }^{1,2}$. Em geral, trazem conseqüências negativas e desagradáveis para a vida do paciente ${ }^{1}$.

Atualmente existe uma vasta literatura sobre a relação dos distúrbios do sono com o transtorno depressivo. Estima-se que $80 \%$ dos pacientes com depressão apresentem queixas de alteração do padrão do sono, como: insônia terminal, despertares noturnos freqüentes, sono não restaurador e redução do tempo total de sono. Os exames polissonográficos confirmam tais sintomas e ainda costumam indicar alterações referentes ao sono de ondas lentas e ao sono ${ }^{*} \mathrm{REM}^{3,4,5}$. A insônia e a hipersônia fazem parte do critério diagnóstico para a depressão maior ${ }^{6}$.

Alguns estudos têm mostrado que pessoas que sofrem de insônia podem estar mais propensos à depressão, mesmo na ausência de história prévia deste transtorno ${ }^{7}$. A insônia também pode funcionar como preditor de transtorno depressivo nas pessoas com histórico de depressão $0^{8,9}$.

Por outro lado, ainda são poucos os estudos que associam distúrbios do sono e qualidade de vida no transtorno bipolar (TB). Por isto, estudos que ampliem o conhecimento sobre este assunto se fazem necessários. Atualmente sua importância tem sido reconhecida, principalmente durante os episódios eufóricos em que a necessidade de sono encontra-se diminuída e funciona como alerta para o início de uma nova crise ${ }^{10}$.

O interesse pelo tema deste trabalho surgiu da escuta de queixas dos pacientes com TB, dos grupos de psicoeducação, referentes à qualidade do sono (QS). Observou-se que eles buscavam informações que os ajudassem a melhorar a QS, preocupavam-se com uma possível recaída decorrente da 
percepção subjetiva de necessidade de sono alterada e queixavam-se das implicações nas atividades cotidianas decorrentes da percepção ruim da QS.

Alguns pesquisadores afirmam que o sono é uma necessidade vital para o organismo e contribui para o armazenamento de novas informações, atenção, visão binocular, regulação da temperatura corporal e, principalmente, para a reposição de energia ${ }^{11,12}$.

Considerando que no TB o sono pode estar alterado, fatores como ansiedade e depressão podem associar-se ao comprometimento da qualidade de vida dos sujeitos ${ }^{13,14}$.

A pesquisa abrange apenas a fase eutímica nos pacientes com TB, ou seja, aquela na qual estão estabilizados. Com isso, excluíram-se os episódios depressivos, maníacos e hipomaníacos, já que os achados do sono nessas pessoas se caracterizam de acordo com a fase da doença. Isto também permitiu delimitar o tema a ser estudado.

\subsection{Transtorno bipolar}

\subsubsection{Conceituação e classificação}

O TB é uma condição psiquiátrica complexa e heterogênea. Trata-se de uma doença crônica caracterizada por uma variedade de sintomas e marcada pela ocorrência de episódios alternados e recorrentes de mania ou hipomania com depressão e períodos de remissão, eutimia ${ }^{6}$.

De acordo com a quarta revisão do Manual Diagnóstico e Estatístico dos Transtornos Mentais (DSM-IV), o episódio depressivo maior é caracterizado por, no mínimo, duas semanas com humor deprimido, perda de interesse e prazer por todas as atividades e mais quatro sintomas dos quais podem estar presentes: alterações no sono, alterações psicomotoras, alterações no apetite ou peso, diminuição de energia, sentimentos de 
desvalia ou culpa, dificuldade para pensar ou concentrar-se, pensamentos sobre morte e ideação ou tentativa de suicídio ${ }^{6}$. Os sintomas psicóticos (delírios e alucinações), em alguns casos, podem estar presentes ${ }^{6}$.

Os episódios maníacos são definidos por um período em que o humor encontra-se alteradamente exacerbado ou irritável, com duração de uma semana ou menos, caso a hospitalização seja necessária, e mais três dos sintomas seguintes: auto-estima inflada; diminuição da necessidade de sono; fala caracterizada por difícil interrupção, alta e rápida; sensação de que o pensamento está acelerado; fuga de idéias, envolvimento excessivo em atividades que causam prazer imediato com risco potencial (dirigir em alta velocidade, promiscuidade, compras excessivas, entre outros), e sintomas psicóticos ${ }^{6}$. O humor pode apresentar-se irritável, ao invés de exacerbado, sendo assim, são necessários apenas quatro dos sintomas anteriores ${ }^{6}$.

Os episódios hipomaníacos diferenciam-se pela não necessidade de internação, ausência de delírios e de alucinações e prejuízo no funcionamento geral menos grave se comparado aos episódios maníacos ${ }^{6}$.

Nos episódios mistos, estão presentes tanto sintomas do episódio depressivo quanto do maníaco, ocorrendo por quase todos os dias e por, no mínimo, uma semana ${ }^{6}$.

O TB pode ser classificado em TB do tipo I que se caracteriza pela presença de episódios maníacos ou mistos, geralmente acompanhados por episódios depressivos maiores ${ }^{6}$. A prevalência pode variar em torno de $0,4 \%$ a $1,6 \%{ }^{6}$.

O TB tipo II é definido por um ou mais episódios depressivos maiores, com pelo menos um episódio hipomaníaco ${ }^{6}$. A prevalência é de aproximadamente $0,5 \%$.

O critério para TB com ciclagem rápida (seja do tipo I ou II) é apresentar quatro ou mais episódios no período de um ano ${ }^{6}$. Newman, Leahy, Beck, Reilly-Harrington e Gyulai (2006) afirmam que a prevalência de ciclagem rápida é maior no sexo feminino, o que pode indicar a influência dos processos reprodutivos e hormonais na regulação do humor ${ }^{15}$. 
O critério para transtorno ciclotímico requer ao menos dois anos, com vários períodos de sintomas hipomaníacos (que não satisfazem os critérios para episódio maníaco) e vários períodos de sintomas depressivos (que também não preenchem todos os critérios para episódio depressivo maior) ${ }^{6}$.

A Organização Mundial da Saúde (OMS, 2001) estima que o transtorno depressivo maior afeta aproximadamente 50 milhões de pessoas em todo o mundo e é a primeira causa de incapacitação entre os problemas de saúde; o TB é a sexta causa de incapacitação ocupacional ${ }^{16}$. Estima-se que apenas $50 \%$ dos pacientes com TB estejam em tratamento ${ }^{17}$ e que um terço deles não adere ao tratamento farmacológico, limitando seu potencial benefício $^{18,19}$. Um estudo com seguimento de 12 anos indicou que pacientes com TB ficam, em média, metade do tempo sintomáticos e com prejuízos no funcionamento geral ${ }^{20}$.

\subsubsection{Conseqüências e co-morbidades}

Os episódios depressivos afetam o relacionamento familiar, o funcionamento social, a produtividade e podem trazer conseqüências irreversíveis, como o suicídio ${ }^{16}$. O risco de suicídio é bastante alto, por volta de $15 \%$ dos pacientes com TB, principalmente nos episódios depressivos $^{16,21,22}$. Goodwin e Jamison (1990) estimam entre $20 \%$ e $56 \%$ as possibilidades de tentativa de suicídio em portadores de $\mathrm{TB}^{23}$.

Acredita-se que é considerável a co-morbidade no TB, principalmente com transtornos de ansiedade, abuso de substâncias e transtornos de personalidade ${ }^{15,24.25}$. Tais co-morbidades podem contribuir negativamente para a evolução do quadro psiquiátrico, dificultar a adesão ao tratamento, apresentar sintomas mais graves, acentuado prejuízo no funcionamento ocupacional e, conseqüentemente, pior Qualidade de Vida $(\mathrm{QV})^{15,24,25}$. 


\subsubsection{Prevalência}

Em geral, a prevalência estimada nas formas "clássicas" é de 1\% da população ${ }^{26}$. Se o diagnóstico considerar formas mais brandas do transtorno, mas não menos graves (espectro bipolar), a prevalência pode aumentar significativamente. Para alguns autores a porcentagem pode chegar a $5 \%$ da população geral ${ }^{27}$ ou mais de $8 \%{ }^{28,29}$, embora o conceito de espectro do TB ainda seja um assunto bastante polêmico.

Em relação à prevalência entre os gêneros, as pesquisas não apontam diferenças significativas, com incidência de TB aproximadamente igual em homens e mulheres ${ }^{15}$.

Estimar a idade de início é um desafio devido a problemas metodológicos como, o que considerar o início do TB: o primeiro episódio? A primeira internação ${ }^{30}$. Outros aspectos que também dificultam são: o erro no diagnóstico e viés de memória dos pacientes e familiares. Chengappa et al. (2003) apontam a idade média de início do TB por volta dos 23,5 anos ${ }^{31}$. Em geral, a maioria dos pacientes apresenta o primeiro episódio do TB no fim da adolescência e começo da idade adulta, mas ele pode manifestar-se em qualquer idade ${ }^{15,32}$.

\subsubsection{Etiologia e tratamento}

Alguns autores acreditam que a história familiar de TB pode participar dos fatores de risco para este e/ou outros transtornos psquiátricos ${ }^{6,30}$. A relação entre TB e fatores genéticos está bem estabelecida, com risco aumentado em gêmeos e em parentes de primeiro grau quando comparados com sujeitos normais ou com depressão maior ${ }^{32}$.

A etiologia do TB ainda não é bem conhecida. Vários estudos sugerem influência da predisposição genética na vulnerabilidade de 
alterações neuroquímicas, sendo o TB uma disfunção complexa ${ }^{32}$. Outros autores sugerem uma combinação de fatores, incluindo fatores ambientais, como os estressores psicossociais ${ }^{15,30}$.

O tratamento farmacológico do TB vem mostrando-se bastante eficaz e envolve o uso de estabilizadores do humor, como o lítio, o ácido valpróico, a carbamazepina e, em alguns casos, requer a utilização de outros medicamentos e/ou a sua associação ${ }^{33}$. A combinação de recursos psicoterápicos com farmacoterápicos disponíveis é o tratamento mais indicado atualmente e considerado mais eficaz ${ }^{33}$.

\subsection{O papel da psicoeducação no tratamento do transtorno bipolar}

Atualmente, vários estudos têm demonstrado a importância do tratamento psicoeducativo combinado com o farmacológico na prevenção de recaídas do $\mathrm{TB}^{33,34,35}$. Apesar de evidências da eficácia dos medicamentos utilizados no tratamento do TB, é difícil para muitos pacientes aderir à medicação, aceitar a doença, lidar com os problemas de relacionamento (familiar, conjugal), sendo que esses fatores podem contribuir para agravar o curso da doença ${ }^{15}$.

Acredita-se na importância de incluir os familiares nos grupos de psicoeducação para portadores de TB, visto que funcionam como apoio aos pacientes nos momentos de crise e, muitas vezes, são os primeiros a detectar os sintomas iniciais. Por outro lado, não é raro que os familiares neguem a doença e se tornem cúmplices no abandono do tratamento indicado ${ }^{36}$.

O tratamento psicoeducacional visa, entre outros objetivos, a aumentar o conhecimento da doença, estimular o envolvimento dos familiares, estimular a participação ativa do paciente, distinguir traços da personalidade de sintomas, aprender a reconhecer precocemente os 
sintomas de uma possível crise, estimular o retorno à vida social e ocupacional, melhorar a auto-estima, informar sobre os riscos associados ao uso de drogas e álcool, melhorar a adesão ao tratamento farmacológico e, conseqüentemente, prevenir recaídas, diminuindo o impacto negativo na $\mathrm{QV}^{33,35}$

Nessa modalidade de psicoterapia o profissional exerce uma função mais objetiva e ativa como educador e terapeuta, sendo fundamental formar um vínculo de confiança com o grupo ${ }^{37}$. Yalom e Leszcz (2006) apontam alguns fatores terapêuticos capazes de promover mudanças - que podem ser estimulados pelo psicoterapeuta ou ocorrer naturalmente durante $o$ processo $^{37}$ :

a) Instilação de esperança: os pacientes chegam ao grupo com a expectativa de serem ajudados e, ao ouvir os mais antigos contarem que já passaram por momentos difíceis e obtiveram melhoras, ficam mais esperançosos com a possibilidade de voltar à vida norma ${ }^{37}$;

b) Universalidade: sentem-se aliviados quando percebem que não estão sozinhos. Alguns dizem: "agora não me sinto mais como um patinho feio",37;

c) Compartilhamento de informações: é voltado para a explicação do processo da doença, com a intenção de desfazer as fantasias (falsas crenças). De acordo com Yalom e Leszcz (2006), "a explicação de um fenômeno é o primeiro passo para o seu controle" ${ }^{\text {,37; }}$

d) Desenvolvimento de técnicas de socialização: em que os pacientes são incentivados a compreender a possível discrepância entre sua intenção e o impacto que causam nos outros, ou seja, mediante a interação honesta com outros pacientes, fazê-los compreender que cada um tem responsabilidade pelo isolamento em que se encontra ${ }^{37}$.

Outros fatores terapêuticos, como aprendizagem interpessoal, coesão grupal, catarse, fatores existenciais e recapitulação corretiva do grupo familiar primário, também são úteis na psicoeducação ${ }^{37}$.

Por fim, mesmo sendo o TB uma doença que causa incapacitação e sofrimento, tanto na esfera psicológica quanto social e ocupacional, incluir a 
psicoeducação como medida profilática pode otimizar a eficácia do tratamento farmacológico ${ }^{33}$.

\subsection{Sono e transtorno bipolar}

As alterações do sono são encontradas com maior freqüência nos transtornos do humor. Estudos epidemiológicos indicam que de 35\% a 50\% dos indivíduos com insônia ou hipersônia também preenchem os critérios para transtornos do humor ou de ansiedade ${ }^{38}$.

Sabe-se, também, que vários medicamentos utilizados nestes transtornos provocam efeitos colaterais como alterações no sono e que os achados do sono são caracterizados de acordo com a fase do TB ${ }^{39}$.

\subsubsection{Sono no episódio maníaco}

A necessidade diminuída de sono é um dos sete critérios de diagnóstico de episódio maníaco no TB ${ }^{1}$. Dentre os aspectos importantes da relação entre sono e episódio maníaco do TB, merece destaque a considerável redução da quantidade de sono associada a uma sensação subjetiva da redução dessa necessidade. Nesta fase, o paciente parece apresentar dificuldade para dormir, quando o faz, logo desperta aparentemente revigorado, após poucas horas de sono ${ }^{10,40}$.

Alguns autores apontam que a redução da quantidade de sono pode indicar o início de um episódio maníaco ou hipomaníaco e irregularidades com a higiene do sono podem contribuir para o início dessa fase em pacientes com TB ${ }^{10,40,41}$. Harvey, Schimidt, Scarnà, Semler e Goodwin (2005) afirmam que a indução de privação do sono está associada ao início da mania ou hipomania em um número considerável de pacientes ${ }^{42}$. 
Em uma revisão de 11 estudos sobre os sintomas prodrômicos da mania, envolvendo 631 pacientes com TB, a alteração do sono foi o sintoma mais comum, indicado por $77 \%$ dos pacientes, e o sexto sintoma mais comum da depressão bipolar, relatado por $24 \%$ dos pacientes ${ }^{43}$. Este estudo é de fundamental importância, pois existem evidências de que reconhecer os primeiros sinais da mania e buscar tratamento imediatamente estão associados à redução do tempo de duração do episódio maníaco e a melhor recuperação do funcionamento ocupacional e social ${ }^{44}$.

Outro aspecto refere-se ao ciclo sono/vigília, o qual tem sido o principal componente teórico da conceitualização do TB. Existem hipóteses de que pacientes com TB possuem um componente genético que pode contribuir para a instabilidade do ritmo circadiano ${ }^{42}$.

Outros trabalhos argumentam que não é possível determinar se essa redução da quantidade do sono associada à necessidade diminuída dele é efetivamente causa da euforia ou apenas um sintoma prodrômico, já que certos comportamentos precedentes dessa fase podem induzir falta de sono como, por exemplo, abuso de substâncias psicoativas ${ }^{45}$.

Alguns relatos de estudos de caso na literatura sugerem que transtornos primários do sono, como a apnéia obstrutiva do sono, também podem contribuir para o início do episódio maníaco devido à privação de sono, já que se caracteriza por microdespertares noturnos ${ }^{46,47}$.

Acredita-se que outros aspectos integrados possam colaborar para reduzir a quantidade de sono, como: fatores fisiológicos (alterações hormonais), psíquicos (perda de alguém querido, separação conjugal) e sociais (perda ou mudança de emprego), favorecendo, assim, o início de um episódio de euforia ou hipomania ${ }^{1}$.

Um estudo prospectivo com 39 pacientes com TB apontou que um ritmo de vida estressante e conturbado é comumente observado em períodos prévios de um episódio afetivo ${ }^{48}$. Sendo que $2 \%$ desses pacientes apresentaram essas características em períodos prodrômicos de episódio de euforia, tal percentual foi significativamente mais representativo do que a freqüência observada antes de um episódio depressivo ${ }^{48}$. Esse estudo foi 
replicado de forma mais abrangente e incluiu depressão unipolar e pacientes com TB com ciclagem rápida ${ }^{49}$. Os resultados ratificaram os dados obtidos na pesquisa anterior e também mostraram que um ritmo social conturbado ocorre mais freqüentemente nos períodos que precedem um episódio maníaco do que outro episódio afetivo ${ }^{49}$. Em contrapartida, outros autores não encontraram tais associações durantes períodos prévios de episódios do $\mathrm{TB}^{50,51}$.

Contudo, um ritmo de vida conturbado associado a fatores estressantes pode, com freqüência, ocorrer durante períodos prodrômicos do TB, o que, entretanto, não autoriza inferir causa e efeito da relação entre os distúrbios do sono com o ritmo de vida e decorrentes episódios de euforia ${ }^{1}$. Além disso, é praticamente impossível assegurar se a privação do sono constitui causa ou sintoma de euforia ${ }^{10}$.

\subsubsection{Sono no episódio depressivo}

Dentre os vários critérios para o diagnóstico de transtornos depressivos, encontra-se a presença de insônia ou hipersônia em quase todos os dias ${ }^{6}$. Sabe-se, então, que os transtornos depressivos geralmente são acompanhados por alterações no sono as quais constituem um dos sintomas mais precoces e freqüentes da depressão ${ }^{8}$. Os distúrbios do sono são manifestações clínicas da depressão e cerca de $50 \%$ a $95 \%$ dos pacientes portadores de transtorno do humor apresentam queixas de sono fragmentado e superficial ${ }^{52}$.

Alguns estudos indicam que a hipersônia é um melhor indicativo de depressão bipolar do que a insônia ${ }^{53}$. Durante o episódio depressivo bipolar, os pacientes, geralmente, queixam-se de sensação de sono não restaurador, de necessidade de aumento na duração do sono noturno e de sonolência diurna ${ }^{4}$. Em contrapartida, o estudo polissonográfico em pacientes com TB mostra uma quantidade normal ou aumentada de sono, 
com padrão característico de latência REM curta e sem aumento significativo dos despertares noturnos ${ }^{4}$.

Um estudo comparativo, utilizando o Teste das Latências Múltiplas, entre a sonolência excessiva de portadores de TB e pacientes com narcolepsia não encontrou evidências de sonolência diurna excessiva nos pacientes com depressão bipolar ${ }^{54}$. Sugere-se que a hipersônia da depressão bipolar esteja relacionada de modo mais significativo com a falta de energia e fadiga do que com a sonolência diurna excessiva ${ }^{54}$.

$\mathrm{Na}$ depressão unipolar, a insônia do tipo terminal é o relato mais freqüente e a hipersônia o menos comum ${ }^{52,55}$. A redução no sono ocorre, com mais freqüência, por volta de $90 \%$ dos pacientes deprimidos, enquanto a hipersônia afeta de $15 \%$ a $30 \%{ }^{12}$. Nos pacientes com TB essa prevalência é um pouco diferenciada, pois as queixas de sonolência diurna excessiva são mais típicas da depressão bipolar do que da unipolar ${ }^{12}$.

Hantouche e Akiskal (2005) debatem as principais dificuldades em distinguir depressão unipolar de depressão bipolar. Esses autores compararam dois grupos e observaram maiores pontuações nos itens: retardo psicomotor, perda de interesse e insônia, enquanto que a principal característica na depressão bipolar foi a hipersônia ${ }^{56}$. Concluíram que, além da hipersônia, a presença de inquietação psicomotora, instabilidade afetiva, quadros mais complexos, incongruência entre o que o médico observa e 0 que o paciente relata, além de apresentações que lembrem transtornos de personalidade, podem ser sugestivos de depressão bipolar do tipo $1{ }^{56}$.

Parece haver estreita relação entre a higiene do sono inadequada e alterações no padrão de sono com os transtornos psiquiátricos ${ }^{1,3,9}$. Por isso, é importante questionar os pacientes sobre seus hábitos de sono e informálos sobre alguns aspectos que podem contribuir para melhorar sua qualidade, como, por exemplo: manter horários regulares para deitar-se e evitar o consumo de bebidas alcoólicas, café e cigarros à noite ${ }^{57}$. Dessa forma, o diálogo com o paciente e seus familiares sobre a importância do padrão do sono pode interferir de modo positivo na $\mathrm{QS}^{57}$. 


\subsubsection{Sono no período eutímico}

Os sintomas subsindrômicos entre os episódios são comuns nos portadores de TB. Dessa forma, pode-se pensar que a QS continue prejudicada ou parcialmente alterada durante os períodos eutímicos ${ }^{10}$.

Existem poucos estudos sobre a QS no período eutímico e controvérsias entre eles. Alguns apontam anormalidades na avaliação objetiva através da polissonografia ${ }^{58}$. Outros não encontraram diferenças significativas entre os portadores de TB eutímicos e os sujeitos do grupocontrole ${ }^{59}$.

Um estudo feito por Millar, Espie e Scott (2004) comparou o sono de 19 pacientes com TB tipo I em remissão com o de sujeitos controles utilizando o diário do sono e a actigrafia ${ }^{60}$. Os resultados indicaram aumento da duração do sono e maior variabilidade dos padrões do sono durante as noites aferidas ${ }^{60}$.

O estudo mais recente realizado por Harvey et al (2005) avaliou o sono através de actígrafos em pacientes com o diagnóstico principal de TB na fase eutímica $(n=20)$, pacientes com insônia $(n=20)$ e sujeitos sem queixas relacionadas ao sono $(n=20)^{42}$. Os resultados mostraram que $70 \%$ dos bipolares eutímicos apresentaram alterações clinicamente significativas no padrão do sono, sendo classificados como maus dormidores de acordo com a escala de QS utilizada ${ }^{42}$. Entretanto, cumpre ressaltar que, dentre os bipolares eutímicos, havia pacientes com co-morbidades com outros transtornos psiquiátricos, como fobia específica $(n=3)$, fobia social $(n=1)$, transtorno de ansiedade generalizada $(n=1)$ e transtorno do estresse póstraumático $(\mathrm{n}=2)$.

Acredita-se que a presença de co-morbidades possa superestimar as alterações do padrão de sono em bipolares eutímicos. O critério diagnóstico para insônia primária foi preenchido por $50 \%$ dos bipolares eutímicos ${ }^{42}$. 0 grupo de insones parece superestimar o tempo de latência do sono e subestimar o tempo total de duração do sono. Um padrão semelhante foi 
encontrado no grupo de bipolares. Essa percepção distorcida do padrão do sono, principalmente nos insones, pode contribuir para a intensificação dos sintomas de ansiedade e levar a pessoa acreditar que o seu sono está tornando-se inadequado. Assim, a ansiedade gerada pode servir para manter a insônia ${ }^{42}$.

Contudo, parece não existir um consenso bem estabelecido em relação às alterações no padrão do sono em pacientes com TB eutímicos, além disso, existem poucas pesquisas sobre este assunto. Por outro lado, é importante que o profissional especializado investigue as possíveis alterações do sono e trate-as de forma adequada para evitar o possível agravamento dos sintomas ${ }^{10}$.

\subsubsection{Qualidade do sono}

Em vários transtornos psiquiátricos, a QS pode estar alterada, inclusive no TB. Além disso, a QS geralmente está associada à $Q V^{1}$. Morawetz afirma que a insônia pode estar associada à redução da QV e à depressão ${ }^{8}$. Pessoas com insônia queixam-se de concentração e memória prejudicadas, aumento da irritabilidade, diminuição da habilidade para realizar tarefas diárias e diminuição do prazer nas relações sociais e familiares ${ }^{8}$.

Em indivíduos saudáveis, a privação média de duas horas de sono por noite também pode causar prejuízos, como dificuldades atencionais, sonolência, diminuição no tempo de reação motora, prejuízos no processamento cognitivo, dificuldade de memória e diminuição do limiar de dor ${ }^{1}$.

A QS é um fenômeno complexo, de definição e mensuração objetiva difíceis e inclui aspectos quantitativos do sono, como duração, latência e eficiência, assim como aspectos subjetivos: percepção da qualidade ou do tempo dormido ${ }^{42}$. Um exemplo prático é visto nas pessoas que se queixam 
de não conseguir dormir durante a noite, mas quando são submetidas ao exame de polissonografia, constata-se que conseguem dormir várias horas apesar do sono fragmentado ${ }^{42}$.

Entretanto, os elementos que compõem a QS e sua relativa importância podem variar entre os indivíduos. Além disso, por ser a QS amplamente subjetiva, nos exames mais objetivos, como a polissonografia, é possível correlacionar os resultados objetivos com a percepção subjetiva do sono. Embora a avaliação subjetiva não seja uma medida extremamente fiel da QS, permite verificar seu impacto na vida dos sujeitos ${ }^{61}$.

\subsection{Qualidade de Vida}

Qualidade de Vida é um conceito bastante amplo e subjetivo e vem sendo estudada por várias áreas do conhecimento, como psicologia, biologia, medicina, filosofia e sociologia. Engloba várias facetas da esfera social, psicológica, saúde física, ocupacional, espiritual e relacionamento interpessoal $^{62}$. Para o Grupo de Qualidade de Vida da divisão de Saúde Mental da OMS, QV pode ser definida como sendo a percepção que cada pessoa possui tanto de sua posição na vida dentro de um contexto cultural e de valores nos quais ela se insere, quanto em relação aos seus objetivos, expectativas e preocupações ${ }^{62}$.

Os transtornos mentais influenciam, consideravelmente, várias esferas da vida dos indivíduos: psicológica, social, ocupacional, entre outras. A QV dessas pessoas fica prejudicada, principalmente quando os sintomas da doença persistem ${ }^{16}$. Também sofrem devido à dificuldade de manter o emprego, pelo comprometimento das relações familiares e sociais e por sentirem-se vítimas de preconceitos ${ }^{16}$.

Alguns fatores comprometem ainda mais a QV dos pacientes com TB. Estima-se que pacientes com TB sofrem de oito a 10 anos antes de serem diagnosticados $^{14}$. Apenas $50 \%$ deles estão em tratamento e, 
aproximadamente, um terço destes não aderem ao tratamento farmacológico, fato que os expõe a maior suscetibilidade de novas crises ${ }^{14}$.

Outro aspecto associado ao comprometimento da QV foi identificado em alguns estudos que relacionam eventos estressantes e estilos de vida com maior instabilidade dos episódios do TB $^{63,64}$.

Sierra, Livianos e Rojo (2005) apontam que a natureza cíclica do TB, com remissões e períodos de exacerbação dos episódios do humor, pode afetar várias esferas da vida dessas pessoas, como social, psicológica, emocional e ocupacional, prejudicando significativamente a QV de maneira geral $^{65}$.

O modelo conceitual relatado por Fava (1999) com base em estudos que abrangem sintomas sub-clínicos indica que a maioria dos pacientes sofre com os sintomas do TB na maior parte do tempo e que isso afeta diretamente a $\mathrm{QV}^{66}$.

Um estudo com objetivo de avaliar a QV foi realizado com 66 pacientes bipolares divididos em grupos: pacientes no episódio misto, episódio depressivo, pacientes nos episódios maníacos/hipomaníacos e o último grupo de eutímicos ${ }^{67}$. Foram administrados dois questionários breves de auto-avaliação: o Short Form Health Survey - SF-12 (que é uma subescala sobre saúde mental do Questionário Sobre QV Forma Reduzida) e o EuroQol (questionário de QV). Os autores afirmam que não houve diferenças significativas nas pontuações de ambas as escalas quando foi comparado um grupo de pacientes no episódio misto com outro de pacientes depressivos $^{67}$. O grupo no episódio maníaco e/ou hipomaníaco obteve piores pontuações em relação aos outros grupos na escala SF-12. No grupo de pacientes no episódio maníaco e/ou hipomaníaco e em pacientes eutímicos, não se observou diferença significativa em relação às pontuações na escala de $\mathrm{QV}^{67}$. Os autores sugerem que essa discrepância entre pontuações das escalas pode dever-se à diminuição da capacidade de insight em pacientes no episódio maníaco/hipomaníaco ${ }^{65}$.

Outra pesquisa avaliou a QV em 120 pacientes com TB do tipo I (40 maníacos, 40 deprimidos e 40 eutímicos) através dos instrumentos 
WHOQOL-BREVE, Escala de Funcionamento Global, Escala de Depressão de Hamilton e Escala de Mania de Young ${ }^{68}$. Os pacientes no episódio maníaco também apresentaram pontuações na escala de QV muito próximas das pontuações de pacientes no período eutímico ${ }^{68}$. Porém, apresentaram piores pontuações na Escala de Funcionamento Global (em que o pesquisador atribui uma pontuação para o funcionamento geral do paciente), comparados com os eutímicos ${ }^{68}$.

Brissos, Dias, Carita e Martinez-Arán (2008) avaliaram a QV e algumas funções cognitivas em 30 bipolares eutímicos tipo I, 23 esquizofrênicos em remissão e 23 controles saudáveis ${ }^{69}$. Utilizaram o World Health Organization Quality of Life Measure Abbreviated Version (Questionário de Qualidade de Vida da Organização Mundial da Saúde, Versão Abreviada - WHOQOL-BREVE) ${ }^{69}$. Os pacientes bipolares e esquizofrênicos obtiveram pontuações significativamente piores nos domínios Físico, Psicológico e Relação Social do WHOQOL-BREVE comparados com os controles. Para o domínio Meio Ambiente, não houve diferença significativa entre os grupos ${ }^{69}$. Os pacientes com TB sintomáticos apresentaram piores pontuações nos domínios Físico e Meio Ambiente, que foi associado com piores desempenhos cognitivos. Os autores sugeriram que os pacientes com TB podem beneficiar-se de intervenções psicológicas para melhorar o desempenho cognitivo ${ }^{69}$.

Outro estudo sobre QV foi realizado com 90 pacientes com TB tipo I, divididos em quatro grupos: 1) totalmente em remissão, 2) menos que dois meses em remissão, 3) com sintomas maníacos persistentes e 4) de pacientes com sintomas depressivos persistentes ${ }^{70}$. Para a categorização dos grupos, os pesquisadores seguiram os critérios do Manual Diagnóstico e Estatístico de Transtornos Mentais (DSM-IV), utilizaram a escala de BechRafaelsen Mania-Melancholia Scale (Escala de Avaliação de Mania e Melancolia de Bech-Rafaelsen) para verificar sintomas de mania/hipomania e depressivos, a Global Assessment Functioning (Escala de Funcionamento Global) e a Health Related Quality of Life (Escala de Qualidade de Vida Relacionada à Saúde $)^{70}$. O grupo de pacientes com remissão completa 
obteve pontuações significativamente melhores no domínio físico, saúde geral e funcionamento social da escala de QV, comparados com o grupo com sintomas depressivos persistentes ${ }^{70}$. O grupo de pacientes com sintomas persistentes de mania obteve melhores pontuações nos domínios de saúde geral e vitalidade da escala de QV auto-administrada, comparados com o grupo com sintomas depressivos persistentes ${ }^{70}$. Entretanto, os dois grupos de pacientes com sintomas persistentes tanto de mania quanto de depressão obtiveram as piores pontuações em relação aos outros três grupos na Escala de Avaliação do Funcionamento Global - escala em que o profissional atribui uma pontuação que varia de 0 a 100 para os vários níveis do funcionamento geral dos pacientes ${ }^{70}$.

Vários estudos que compararam a QV entre grupos de pacientes com depressão bipolar e depressão unipolar encontraram piores pontuações nas escalas de pacientes com depressão bipolar ${ }^{71,72,73}$.

Apesar de não haver consenso sobre a QV em pacientes eutímicos, a maioria dos trabalhos aponta prejuízos na $\mathrm{QV}$, independentemente da fase da doença em que se encontram ${ }^{70,74,75}$.

Foram encontrados poucos artigos sobre QV em episódios de hipomania, talvez por ser pouco viável aplicar escalas auto-administráveis nesse tipo de amostra devido aos sintomas apresentados ${ }^{10}$.

Mesmo sendo razoável a quantidade de artigos disponíveis sobre QV no TB, algumas limitações foram identificadas, como amostras pequenas e a falta de critérios mais objetivos para avaliar em que fase da doença os pacientes eram classificados. Até o momento, não existe um instrumento específico para avaliar a $\mathrm{QV}$ em pacientes com TB, e conseqüentemente, os estudos são heterogêneos em relação aos instrumentos de QV utilizados, pois é empregada uma ampla variedade de escalas que dificulta a comparação com outras pesquisas ${ }^{10}$. Além disso, alguns delineamentos utilizaram outras patologias como grupo comparativo e conduziram a maioria dos estudos durante episódios depressivos ${ }^{10}$. 


\section{OBJETIVOS}

\subsection{Objetivo principal}

Verificar se existe diferença entre a percepção da QV e QS em pacientes com TB quando comparados a um grupo-controle.

\subsection{Objetivos específicos}

a) Analisar se existe associação entre QV e QS em cada grupo;

b) Avaliar a intensidade de sintomas depressivos e de ansiedade e verificar se estas variáveis são diferentes entre os grupos;

c) Investigar se existe relação dos sintomas depressivos e de ansiedade na QS e na QV;

d) Verificar se existe diferença entre os maus dormidores do grupoestudo comparados com os maus dormidores do grupo-controle

Este estudo não teve por objetivo comparar tipos e dosagens de medicações utilizadas. 


\section{MÉTODOS}

\subsection{Procedimentos}

O protocolo desta pesquisa foi aprovado pelo Comitê de Ética em Pesquisa do Hospital das Clínicas da Faculdade de Medicina de Ribeirão Preto, da Universidade de São Paulo (HC-FMRP/USP), em sua 205a Reunião Ordinária, realizada em 07/07/2005, e enquadrado na categoria "aprovado", de acordo com o processo número 5993/2005 (Anexo A).

A coleta de dados (aplicação de questionários e entrevistas) foi realizada pela pesquisadora responsável nas dependências do Hospital Dia Psiquiátrico da Faculdade de Medicina de Ribeirão Preto, da Universidade de São Paulo (HD-FMRP/USP), sob consentimento do coordenador dessa instituição.

O procedimento, objetivo, possíveis riscos e confidencialidade da pesquisa foram explicados a todos os participantes antes de assinarem 0 Termo de Consentimento Livre e Esclarecido (TCLE) (Anexo B).

Todos os instrumentos foram aplicados individualmente pela pesquisadora responsável, salvo os que, de tão simples, eram autoaplicáveis. Quando o participante não entendia o significado de alguma questão, a pesquisadora relia a pergunta de forma lenta, evitando a modificação do sentido original.

$\mathrm{Na}$ primeira etapa, o convite foi feito a todos os pacientes que participavam dos grupos de psicoeducação e os objetivos da pesquisa foram explicados. Como o grupo era aberto, ou seja, a qualquer momento um novo paciente poderia ser incluído, à medida que os novos pacientes chegavam, também eram convidados a participar da pesquisa.

Geralmente, estes pacientes chegavam ao HD-FMRP/USP encaminhados pelo HC-FMRP/USP ou por outros serviços com o 
diagnóstico de TB, sendo esse um dos pré-requisitos para participarem do grupo. Outro pré-requisito era o uso de estabilizador do humor. Posteriormente, eram avaliados pelo psiquiatra que coordena os grupos de psicoeducação para a confirmação ou não do diagnóstico.

$\mathrm{Na}$ segunda etapa, solicitou-se aos participantes da pesquisa que respondessem, individualmente, os questionários sobre QS, QV, sintomas depressivos e de ansiedade.

$\mathrm{Na}$ terceira etapa, realizaram-se as entrevistas para o preenchimento da Escala de Avaliação de Mania-Modificada e a Entrevista Clínica Estruturada para o DSM-IV a qual serviu para a comprovação ou não do diagnóstico e para investigar a presença de co-morbidade com outro transtorno psiquiátrico, além de permitirem descartar possíveis episódios depressivos, maníacos e hipomaníacos.

Dessa forma, os indivíduos foram tomados seqüencialmente e, em uma etapa posterior à aplicação de todas as escalas e entrevistas, utilizaram-se os critérios preestabelecidos para a inclusão ou exclusão dos sujeitos na amostra.

As entrevistas semi-dirigidas, como a Escala de Avaliação de Mania Modificada (EAM-m) e a Entrevista Clínica Estruturada para o DSM-IV (SCID), foram realizadas em um encontro e o tempo de aplicação foi entre uma hora e meia a duas horas. A pesquisadora recebeu treinamento para aplicar a SCID e a EAM-m no HD-FMRP/USP.

A presente pesquisa foi do tipo caso-controle. A amostra foi caracterizada como não probabilística por conveniência. Os instrumentos foram aplicados primeiramente no grupo-estudo para definir o grupo-controle com as mesmas características demográficas, mas sem a presença de TB ou outro transtorno psiquiátrico.

A tomada do grupo-controle seguiu o mesmo procedimento e as mesmas etapas utilizadas para o grupo-estudo, porém constituiu-se de funcionários da Universidade de São Paulo do campus de Ribeirão Preto. 


\subsection{Casuística}

\subsubsection{Grupo-estudo}

Foram avaliados 43 sujeitos, com TB na fase eutímica sem comorbidade, em uso de estabilizador do humor e que participavam dos grupos de psicoeducação para pacientes com TB do HD-FMRP/USP.

\subsubsection{Critérios de inclusão}

a) Ter diagnóstico de TB tipo I ou II, de acordo com os critérios diagnósticos do DSM-IV;

b) Ter consentido em participar da pesquisa e assinado o TCLE;

c) Freqüentar o grupo de psicoeducação para pacientes com TB do HD-FMRP/USP;

d) Estar na faixa etária entre 25 e 60 anos e

e) Em uso de estabilizador de humor.

\subsubsection{Critérios de exclusão}

a) Episódio atual de mania, hipomania ou depressão maior;

b) Uso de substâncias psicoativas no último ano;

c) Presença de diagnóstico de esquizofrenia ou outros transtornos psicóticos, com exceção de transtorno esquizoafetivo; 
d) História de dano cerebral, transtorno mental orgânico e doenças neurológicas.

\subsubsection{Grupo-controle}

Os pacientes foram comparados com uma amostra de 80 controles, selecionados entre a população de funcionários do campus da USP de Ribeirão Preto. Buscaram-se indivíduos com características demográficas semelhantes as do grupo-estudo, como gênero, idade, escolaridade e nível socioeconômico. Foram excluídos os controles com quaisquer diagnósticos psiquiátricos do eixo I, do DSM-IV, com história de dano cerebral ou presença de doenças neurológicas.

\subsection{Instrumentos utilizados}

Foram utilizados os seguintes instrumentos:

a) Índice de Qualidade do Sono de Pittsburgh;

b) Questionário de Qualidade de Vida da Organização Mundial da Saúde - Versão Abreviada (WHOQOL-BRVE);

c) Entrevista Clínica Estruturada para o DSM-IV;

d) Inventário de Depressão de Beck;

e) Inventário de Ansiedade de Beck;

f) Escala de Avaliação de Mania Modificada e

g) Critério de Classificação Econômica Brasil. 


\subsection{Tratamento dos dados}

Para análise estatística, foi utilizado o aplicativo computacional Statistical Package for Social Sciences (SPSS) para Windows, versão 13.0, e adotado o nível de significância $\alpha \leq 0,05$.

Primeiramente foi realizada uma análise descritiva de todas as variáveis numéricas: idade, escolaridade, sintomas depressivos, sintomas de ansiedade, QV, domínios da QV, QS, latência do sono, duração do sono e eficiência do sono. Para estas variáveis numéricas foi obtido o valor mínimo e máximo, a mediana, a média e o desvio padrão.

A análise descritiva das variáveis categóricas - gênero, estado civil, ocupação e nível socioeconômico - incluiu a freqüência relativa e absoluta. Também foram calculadas as freqüências relativas e absolutas das categorias de:

a) Sintomas depressivos e de ansiedade (mínimo, leve, moderado e grave);

b) Percepção subjetiva da QS (muito bom, bom, ruim e muito ruim);

c) Classificação de bons e maus dormidores;

d) Necessidade de uso de medicação para dormir (nenhuma, menos de uma vez por semana, uma ou duas vezes por semana e três ou mais vezes por semana);

e) Sonolência diurna (nenhuma, menos de uma vez por semana, uma ou duas vezes por semana e três ou mais vezes por semana);

f) Necessidade de levantar-se durante a noite para ir ao banheiro (nenhuma, menos de uma vez por semana, uma ou duas vezes por semana e três ou mais) e

g) Percepção subjetiva da QV (muito boa, boa, nem boa nem ruim e ruim).

Foram utilizados testes estatísticos não-paramétricos para todas as análises estatísticas inferenciais porque a maioria das variáveis do estudo não apresentava distribuição normal. 
A equivalência das variáveis gênero, idade, escolaridade e nível socioeconômico entre os grupos foi considerada como pré-requisito. O Teste de Mann Whitney foi utilizado para comparar as variáveis numéricas como idade e escolaridade.

O teste Qui-Quadrado foi utilizado para verificar se a freqüência das variáveis demográficas categorizadas gênero, nível socioeconômico e estado civil foi equivalente entre os grupos.

As variáveis sintomas depressivos, sintomas de ansiedade, QV e QS foram tratadas como numéricas para averiguação de correlação ${ }^{76}$.

Para a comparação entre os grupos das pontuações globais (variáveis numéricas) nas escalas de QV e QS, sintomas depressivos e sintomas de ansiedade, foi utilizado o teste não-paramétrico de Mann Whitney.

Utilizou-se uma automatização no Excel (correção automática), de autoria de Jefferson Luís Coutinho (Doutor em Engenharia Civil), para pontuar o Índice de Qualidade do Sono de Pittsburgh e o Questionário de Qualidade de Vida (WHOQOL-BREVE). Essa automatização possibilitou maior agilidade e menor risco de erros na correção e pontuação das escalas. Os critérios originais de correção e avaliação estabelecidos pelos autores dessas escalas foram mantidos na automatização.

Um dos critérios adotados nesta pesquisa foi avaliar pessoas com TB na fase eutímica na ausência de co-morbidade psiquiátrica. No entanto, na coleta de dados incluiu-se praticamente todos os pacientes que estavam participando dos grupos de psicoeducação, independentemente da presença de co-morbidade. Portanto, como contribuição estritamente adicional a esta pesquisa, os sujeitos que apresentavam co-morbidade e foram excluídos do grupo-estudo (13 indivíduos), também foram analisados. Por ter sido pequeno o número de elementos, não foi possível aplicar todos os testes estatísticos para as duas amostras, contudo, encontraram-se indicativos importantes para o entendimento de alguns resultados que poderão ser úteis para pesquisas posteriores. 


\subsection{Escalas, questionários e entrevistas}

A seguir, será feita uma descrição teórica dos instrumentos utilizados nesta pesquisa.

\subsection{1 Índice de Qualidade do Sono de Pittsburgh}

O Pittsburgh Sleep Quality Index - PSQI (Índice de Qualidade do Sono de Pittsburgh) foi criado e validado em 1989 por Daniel J. Buysse, Charles F. Reynolds, Timothy H. Monk, Susan R. Berman e David J. Kupfer devido à percepção de alta prevalência de queixas sobre a QS em pacientes psiquiátricos e à necessidade de um instrumento que mensurasse a QS nessa população ${ }^{61}$.

Os distúrbios do sono são encontrados em vários transtornos psiquiátricos, como depressão, esquizofrenia, transtornos de ansiedade, abuso de substâncias, entre outros. Além disso, as queixas sobre QS são comuns e os levantamentos epidemiológicos indicam altas taxas de distúrbios do sono em adultos. Outro fator importante é que uma QS pobre pode ser sintoma de um distúrbio do sono ou de outras condições médicas ou psiquiátricas ${ }^{61}$.

Este instrumento vem sendo utilizado amplamente em pesquisas internacionais e nacionais com validade e consistência adequadas, especialmente em pesquisas com distúrbios do sono ${ }^{61}$.

Consiste em um questionário auto-aplicável (Anexo C), que investiga a QS e a presença de distúrbios, no intervalo retroativo de um mês, de acordo com a perspectiva subjetiva do indivíduo. Contém 19 itens em sete sub-escalas: 1) qualidade subjetiva do sono, 2) latência do sono, 3) duração do sono, 4) eficiência habitual do sono, 5) distúrbios do sono, 6) uso de medicação para o sono e 7) sonolência diurna e distúrbios durante o dia ${ }^{61}$. A 
pontuação global pode variar de 0 a 21, sendo considerado o valor 5 para nota de corte entre os bons e maus dormidores ${ }^{61}$.

Altas pontuações globais estão relacionadas à qualidade pobre do sono e à maior severidade das disfunções do sono. Pontuações baixas $(\leq 5)$ se relacionam com melhores padrões de sono. Além de dados quantitativos, - PSQI apresenta cinco questões adicionais que possibilita, em uma breve avaliação, uma visão clínica sobre o sono do paciente ${ }^{61}$.

O PSQI foi desenvolvido para vários objetivos: realizar uma mensuração padronizada da QS, discriminar bons e maus dormidores, fornecer um inventário fácil para ser usado em pesquisa e na clínica e, por fim, fornecer uma avaliação clínica breve capaz de aferir a variedade de distúrbios que podem afetar a qualidade do sono ${ }^{61}$.

\subsubsection{Inventário de Depressão de Beck}

O Beck Depression Inventory - BDI (Inventário de Depressão de Beck) tem sido amplamente utilizado em pesquisas como instrumento de autoavaliação dos sintomas depressivos ${ }^{78,79}$. É formado por um questionário com 21 itens, cada qual avaliado em uma escala de 0 a 3 pontos (escala crescente em relação à intensidade dos sintomas) $)^{80,81,82}$.

Optou-se por esse instrumento devido à praticidade, à ampla utilização em pesquisas, além de apresentar alto grau de validade concorrente com outras avaliações clínicas de depressão, como as escalas de Hamilton e de Zung e alta consistência interna da versão em Português ${ }^{79,80}$.

Este inventário avalia a presença ou ausência de sintomas específicos de distúrbio de humor, abrangendo aspectos como tristeza, pessimismo, sensação de fracasso, de culpa e de punição, falta de satisfação, auto-depreciação, auto-acusações, idéias suicidas, crises de choro, irritabilidade, isolamento social, indecisão, distorção da imagem 
corporal, perda de interesse no trabalho, alterações no sono, fadiga, perda de apetite, perda de peso, preocupação somática e diminuição de libido ${ }^{80,82}$.

Atualmente, há diferentes sugestões para o estabelecimento dos pontos de corte entre os níveis dos sintomas depressivos utilizando o $\mathrm{BDI}^{80}$. No presente estudo serão considerados os pontos de corte apresentados por Cunha (2001) no Manual da Versão em Português das Escalas Beck ${ }^{82}$. Consideram-se sintomas depressivos mínimos ou ausentes as pontuações obtidas entre 0 e 11, sintomas depressivos leves de 12 a 19, sintomas depressivos moderados de 20 a 35 e graves de 36 a $63^{82}$.

É importante ressaltar que o BDI não foi originalmente planejado para fornecer uma avaliação diagnóstica. Este instrumento se propõe a avaliar quantitativamente aspectos específicos de depressão, ou seja, pode estimar a gravidade desses sintomas ${ }^{80}$. Entretanto, alguns autores consideram depressivos os que superam 20 pontos, desde que examinados com parcimônia e de preferência em concomitância com o diagnóstico clínico ${ }^{83}$,

Para a realização de um diagnóstico, utiliza-se a entrevista clínica, que pode ser livre, semi-estruturada ou estruturada. Neste estudo, o instrumento diagnóstico utilizado foi a SCID, posteriormente descrito.

\subsubsection{Inventário de Ansiedade de Beck}

De acordo com Gorenstein, Andrade e Zuardi ${ }^{81}$, a ansiedade é um estado emocional com componentes psicológicos e fisiológicos que constituem as experiências humanas, sendo propulsora do desempenho. Ela se torna patológica quando é desproporcional à situação que a desencadeia ou quando não há objeto específico ao qual se direcione ${ }^{81}$.

O Inventário de Ansiedade de Beck (Beck Anxiety Inventory - BAl) é uma escala de auto-relato que mede a intensidade de sintomas de ansiedade $^{82}$. Este instrumento avalia, principalmente, os aspectos somáticos, cognição, comportamento e humor relacionados à ansiedade ${ }^{81}$. 
O BAl é constituído por 21 itens, que são afirmações descritivas de sintomas de ansiedade as quais o sujeito deve avaliar com referência a si mesmo, em uma escala de 4 pontos, representando níveis de gravidade crescente de cada sintoma (absolutamente não, levemente, moderadamente e gravemente) ${ }^{81}$.

Para a correção do BAl serão considerados os seguintes pontos de corte: de 0 a 10 (mínima), 11 a19 (leve), 20 a 30 (moderada) e 31 a 63 (grave) $)^{81}$.

\subsubsection{Questionário de Qualidade de Vida}

O World Health Organization Quality of Life Assessment (Questionário de Qualidade de Vida da Organização Mundial da Saúde - WHOQOLBREVE), elaborado pela Divisão de Saúde Mental da OMS, com a intenção de ser um instrumento de aplicabilidade internacional, isto é, respeitando o construto de QV através das diferentes culturas. Para tanto, 15 centros em diferentes países participaram do projeto piloto de sua elaboração: Austrália, Croácia, França, Índia, Israel, Japão, Holanda, Panamá, Rússia, Espanha, Tailândia, Reino Unido, Estados Unidos e Zimbábue ${ }^{84}$.

Os critérios para elaborar as questões visaram: respeitar as sugestões dos pacientes e profissionais de saúde participantes dos grupos, proporcionar respostas esclarecedoras acerca da QV dos respondentes, usar linguagem simples, evitando palavras ou frases ambíguas, preferir questões curtas e ser compatíveis com uma escala de avaliação ${ }^{85}$.

Os estudos, com cerca de 1800 questões, deram origem ao WHOQOL-100. Posteriormente elaborou-se uma versão abreviada com 26 questões $^{85}$.

Será utilizada a versão breve, Questionário de Qualidade de Vida da Organização Mundial da Saúde - Versão Abreviada (WHOQOL-BREVE), testada e aprovada (Anexo D), satisfazendo os critérios psicométricos de 
consistência interna, validade discriminante, validade convergente, validade de critério e fidedignidade de teste-reteste ${ }^{85}$.

O instrumento é constituído por 26 questões, distribuídas em 6 domínios:

\section{Domínio Físico}

1. Dor e desconforto

2. Energia e fadiga

3. Sono e repouso

Domínio Psicológico

4. Sentimentos positivos

5. Pensar, aprender, memória e concentração

6. Auto-estima

7. Imagem corporal e aparência

8. Sentimentos negativos

Domínio Relações Sociais

13. Relações pessoais

14. Suporte (apoio) social

15. Atividade sexual

Domínio Meio Ambiente

16. Segurança física e proteção

17. Ambiente no lar

18. Recursos financeiros

19. Cuidados de saúde e sociais: disponibilidade e qualidade

20. Oportunidades de adquirir novas informações e habilidades

21. Participação e oportunidades de recreação/lazer

22. Ambiente físico: (poluição/ruído/trânsito/clima)

23. Transporte 
As pontuações globais na versão breve podem variar de 0 a 80 e as pontuações dos domínios de 0 a 20.

\subsubsection{Entrevista Clínica Estruturada para o DSM-IV}

A tradução adotada para a Structural Clinical Interview for the DSM-IV é Entrevista Clínica Estruturada para os Transtornos do Eixo I do DSM-IV (SCID-I) e foi realizada por Del Ben, Zuardi, Vilela e Crippa (1998). A SCID é uma entrevista semi-estruturada, utilizada para a avaliação sistemática dos principais transtornos mentais, de acordo com os critérios da quarta edição do DSM-IV ${ }^{86}$. Será utilizada a Versão Clínica, traduzida e validada para o Português, que apresenta bons índices de confiabilidade do diagnóstico psiquiátrico ${ }^{87}$.

A SCID-I tem sido utilizada em psiquiatria, saúde mental, psicologia clínica, psicologia forense, psicologia hospitalar e em coleta de dados de pesquisa nessas áreas ${ }^{86}$. Este instrumento é bastante utilizado em pesquisas em vários países e uma das vantagens é não esquecer de investigar algum critério diagnóstico importante e aumentar a consistência entre as formulações diagnósticas dos profissionais ${ }^{86}$.

O primeiro módulo da entrevista é a avaliação preliminar que visa obter informações gerais como dados demográficos, história escolar, ocupacional, estrutura, composição e história familiar, etc ${ }^{86}$. Assim, o entrevistando é encorajado a falar livremente sobre sua situação atual, incluindo a história da queixa principal, tratamento e sua condição atual. Outra função importante desse módulo é facilitar o rapport, pois inclui questões menos ameaçadoras, que permitem ao entrevistador e entrevistando construir uma relação e progredir naturalmente ${ }^{86}$. A partir da descrição inicial dos sintomas e dificuldades, o entrevistador deve indicar suas impressões diagnósticas, anotando as mais prováveis e as que possivelmente podem ser descartadas. Outras condições menos prováveis 
são possíveis, mas, notando essas alternativas, o entrevistador terá mais confiança no direcionamento que dará ${ }^{86}$.

Após a avaliação preliminar, dá-se início aos módulos, que são constituídos por questões diretas e referem-se à avaliação de conjuntos de categorias diagnósticas agrupadas nos mesmos padrões do DSM-IV ${ }^{87}$. Com o auxílio dos critérios e das instruções, o entrevistador vai codificando as respostas e assim poderá emitir um diagnóstico clínico para o caso. $\mathrm{O}$ entrevistador pode incluir suas próprias perguntas para questionar afirmações contraditórias ou confrontar negações diante de outros fatos que tenha conhecimento ${ }^{87}$.

Os critérios diagnósticos estão presentes no próprio corpo do instrumento, facilitando a elaboração do diagnóstico conforme a entrevista progride. Também é possível ignorar questões remanescentes se critérios essenciais para o diagnóstico não tenham sido preenchidos, o que permite $o$ descarte rápido de diagnósticos irrelevantes ${ }^{87}$.

Uma característica essencial da SCID é que, embora as perguntas sejam estruturadas, a pontuação se refere ao julgamento clínico do entrevistador, com relação à presença ou não de determinado critério, e não à resposta dada pelo paciente ${ }^{86}$. Daí a necessidade de treinar os entrevistadores.

\subsubsection{Escala de Avaliação de Mania - Modificada}

O único instrumento validado para avaliação de mania em língua portuguesa é a EAM-m que foi traduzida e validada a partir da Young Mania Rating Scale (Escala de Avaliação de Mania de Young), por Vilela e Loureiro $^{88}$.

De acordo com Vilela e Loureiro (2000) ${ }^{88}$, a EAM-m é um instrumento utilizado para caracterizar o comportamento de pacientes no episódio 
maníaco do TB, buscando detectar a presença de sintomas típicos desse quadro e estimar a gravidade dos sintomas.

Possui bons níveis de confiabilidade e foi validado no Brasil. A escala é composta por 11 itens, baseados em sintomas centrais de mania: (1) humor e afeto elevados; (2) energia e atividade motora elevadas; (3) interesse sexual; (4) sono; (5) irritabilidade; (6) velocidade e quantidade da fala; (7) linguagem (distúrbio do pensamento); (8) conteúdo do pensamento; (9) comportamento disruptivo agressivo; (10) aparência e (11) insight ${ }^{88}$.

Cada item apresenta 5 níveis de gravidade crescente. $O$ valor 0 significa a ausência do sintoma avaliado, enquanto o valor 4 traduz a presença mais constante do sintoma em sua forma mais grave ${ }^{88}$.

Os itens irritabilidade, velocidade e quantidade da fala, conteúdo do pensamento e comportamento disruptivo agressivo têm peso dobrado, ou seja, são pontuados em múltiplos de 2 , entre os valores de 0 e 8 . A pontuação total da escala é obtida pela soma das pontuações de cada item $^{88}$.

Para o preenchimento da escala, é necessário realizar uma entrevista semi-estruturada de aproximadamente 30 minutos. $O$ entrevistador pode seguir as perguntas-guia (Anexo E e F) e fazer outras perguntas que julgar necessário ${ }^{88}$.

A pontuação da escala é feita a partir do relato do paciente sobre a ausência ou presença dos sintomas nas últimas 48 horas, privilegiando a observação direta ${ }^{88}$.

\subsubsection{Critério de Classificação Econômica Brasil}

Para a caracterização sócio-econômica da amostra, será utilizado o Critério de Classificação Econômica Brasil (CCEB) (Anexo G), instrumento organizado pela Associação Nacional de Empresas de Pesquisa ${ }^{89}$. 
O sistema de pontuação é baseado na posse de bens de consumo duráveis, grau de instrução e outros fatores, como a presença de empregados domésticos. Dessa forma, obteve-se uma distribuição de pontos que permitiu dividir a população brasileira em cinco classes sócioeconômicas, de A a E. É importante ressaltar que o critério não estabelece diferenças ou classificações psicográficas ou culturais, uma vez que suas características são exclusivamente sócio-econômicas ${ }^{89}$.

Apesar de o estudo ter considerado a posse de diversos outros itens de produtos e serviços, optou-se por utilizar apenas os mais significativos. Pois, diversos deles, mesmo com aspectos simbólicos de modernidade muito interessantes, ainda não oferecem índice discriminador real na base total da população, não proporcionando vantagem suficiente para compensar o aumento de trabalho de coleta e manipulação de dados ${ }^{89}$.

Usando as técnicas e cálculos adequados, o Critério de Classificação Econômica Brasil permite estabelecer um parâmetro confiável de renda familiar de cada classe, tanto em termos de "faixa de renda" como de "renda média" ${ }^{89}$. Essa possibilidade tem grande utilidade para os pesquisadores, já que oferece um retrato econômico operacionalmente mais claro do que os conceitos subjetivos de classes e posse de certos bens e serviços ${ }^{89}$.

A Tabela 1 mostra a divisão em categorias de renda e a respectiva renda média, de acordo com a Associação Nacional de Empresas de Pesquisa (ANEP) ${ }^{89}$.

Tabela 1 - Categorias de renda e renda média

\begin{tabular}{cc}
\hline Classe & Renda média $(\mathrm{R} \$)$ \\
\hline A1 & 7.793 \\
A2 & 4.648 \\
B1 & 2.804 \\
B2 & 1.669 \\
C & 927 \\
D & 424 \\
E & 207
\end{tabular}

Fonte: www.anep.org.br (2008) 


\section{RESULTADOS}

\subsection{Variáveis clínicas do grupo-estudo}

A média de idade de início do TB no grupo-estudo foi de 30,44 anos com desvio padrão de 11,58.

Para o cálculo do número de crises, considerou-se a soma dos episódios depressivos, maníacos e/ou hipomaníacos, e a média foi de 4,8 crises ao longo da vida, com média de 2,2 internações.

A média do tempo de doença foi de 11,51 anos. A Tabela 2 apresenta a média, o desvio padrão, a mediana e os valores mínimo e máximo dessas variáveis.

Tabela 2 - Variáveis clínicas do grupo-estudo

\begin{tabular}{lccccc}
\hline Grupo-estudo & Mín. & Máx. & Mediana & Média & dp \\
\hline Idade de início (anos) & 13 & 57 & 28,00 & 30,44 & 11,58 \\
$\mathbf{N}^{\circ}$ de crises & 1 & 40 & 3,00 & 4,86 & 5,99 \\
$\mathbf{N}^{\circ}$ internações & 0 & 40 & 1,00 & 2,19 & 6,14 \\
Tempo de doença & 1 & 35 & 7,00 & 11,51 & 10,49 \\
Tempo uso estabilizador & 0,5 & 35 & 6,00 & 10,16 & 9,65 \\
\hline
\end{tabular}

\subsection{Análise das variáveis sociodemográficas}

Em relação às características sociodemográficas, os indivíduos do grupo-estudo tinham idade entre 25 e 60 anos, média de 42,49 anos $(\mathrm{dp}=12,00)$ e mediana de 46,00 , sendo $62,8 \%$ do gênero feminino. No grupocontrole, a idade também variou de 25 a 60 anos, sendo a média de 42,76 $(\mathrm{dp}=9,40)$ e mediana de 42,50 e $61,2 \%$ eram do gênero feminino. 
A média de anos escolares concluídos para o grupo-estudo foi de $12,86(\mathrm{dp}=2,90)$, com mediana igual a 11,00. O grupo-controle obteve uma média de 12,84 ( $\mathrm{dp}=2,76)$, com a mesma mediana.

Verificou-se, através do teste para duas amostras independentes de Mann Whitney, que as variáveis numéricas idade e escolaridade não apresentaram diferenças estatisticamente significativas entre os grupos, respectivamente $p=0,918$ e $p=0,654$.

Tabela 3 - Características sociodemográficas das variáveis numéricas idade e escolaridade

\begin{tabular}{|c|c|c|c|c|c|c|c|}
\hline Variáveis & Grupo & $\mathbf{n}$ & Mediana & Mín/Máx & Média & $d p$ & $\mathbf{p}$ \\
\hline Idade & $\begin{array}{l}\text { Estudo } \\
\text { Controle }\end{array}$ & $\begin{array}{l}43 \\
80\end{array}$ & $\begin{array}{c}46 \\
42,5\end{array}$ & $\begin{array}{l}25 / 60 \\
25 / 60\end{array}$ & $\begin{array}{l}42,49 \\
42,76\end{array}$ & $\begin{array}{c}12,00 \\
9,41\end{array}$ & 0,918 \\
\hline Escolaridade & $\begin{array}{l}\text { Estudo } \\
\text { Controle }\end{array}$ & $\begin{array}{l}43 \\
80\end{array}$ & $\begin{array}{l}11 \\
11\end{array}$ & $\begin{array}{l}4 / 16 \\
8 / 16\end{array}$ & $\begin{array}{l}12,86 \\
12,84\end{array}$ & $\begin{array}{l}2,91 \\
2,76\end{array}$ & 0,654 \\
\hline
\end{tabular}

Mann Whitney

Em uma análise categórica da variável escolaridade, obteve-se que a maioria do grupo-estudo tinha completado o ensino médio, representada por $44,2 \%$ da amostra. O ensino superior completo foi concluído por $39,5 \%$, superior incompleto 9,3\%, médio incompleto $4,7 \%$ e ensino fundamental incompleto $2,3 \%$. No grupo-controle, $41,2 \%$ tinham o ensino superior completo, $48,8 \%$ ensino médio completo, 5,0\% médio incompleto e 5,0\% fundamental completo.

Quanto ao estado civil, a maioria dos sujeitos de ambos os grupos era casada: $46,5 \%$ do grupo-estudo e $52,5 \%$ do grupo-controle. As categorias do estado civil 'separado' e 'viúvo' foram agrupadas para possibilitar a aplicação do teste estatístico Qui-Quadrado. No grupo-estudo, 16,3\% encontraram-se na categoria 'separados' e 10,0\% no grupo-controle; 30,2\% dos sujeitos do grupo-estudo eram solteiros contra $35,0 \%$ do grupo-controle. Apenas três sujeitos do grupo-estudo eram viúvos, representando $7,0 \%$ e dois do grupocontrole, $2,5 \%$.

O nível socioeconômico estava distribuído no grupo-estudo e no grupo-controle, respectivamente, da seguinte maneira, de acordo com as 
categorias de renda: $\mathrm{C}_{\mathrm{E}}=20,9 \%$ e $\mathrm{C}_{\mathrm{C}}=21,3 \% ; \mathrm{B} 2_{\mathrm{E}}=25,6 \%$ e $\mathrm{B} 2_{\mathrm{C}}=33,8 \%$; $B 1_{E}=27,9 \%$ e $B 1_{C}=35,0 \%$ e $A 22_{E}=25,6 \%$ e $A 2 C=10,0 \%$.

Todos os sujeitos do grupo-controle desempenhavam atividade profissional remunerada, enquanto, no grupo-estudo, 34,9\% eram ativos, 20,9\% aposentados (incluindo os aposentados por invalidez e por tempo de serviço), $16,3 \%$ desempregados, $16,3 \%$ do lar, $4,7 \%$ estudantes e $7,0 \%$ estavam afastados devido ao TB.

Tabela 4 - Comparação das características sociodemográficas das variáveis categóricas: gênero, estado civil, ocupação e nível socioeconômico entre os grupos

\begin{tabular}{llccc}
\hline Variáveis & Categorias & $\begin{array}{c}\text { Estudo } \\
\%\end{array}$ & $\begin{array}{c}\text { Controle } \\
\%\end{array}$ & $\mathbf{p}$ \\
\hline \multirow{2}{*}{ Gênero } & M & 37,2 & 38,8 & 0,867 \\
& F & 62,8 & 61,2 & \\
Estado & Casado & 46,5 & 52,5 & 0,445 \\
Civil & Solteiro & 30,2 & 35,0 & \\
& Separado e viúvo & 23,3 & 12,5 & \\
Ocupação & Ativo & 34,9 & 100,0 & $<0,001$ \\
& Afastado & 7,0 & & \\
& Aposentado & 20,9 & & \\
& Estudante & 4,7 & & \\
& Desempregado & 16,3 & & \\
& Do lar & 16,3 & & \\
& & & & \\
Nível socio- & A2 & 25,6 & 10,0 & \\
econômico & B1 & 27,9 & 35,0 & \\
& B2 & 25,6 & 33,8 & \\
& C & 20,9 & 21,2 & \\
\hline Qui-Quadrado & & & &
\end{tabular}

Verificou-se através do teste Qui-Quadrado que não houve diferença significativa entre os grupos para as freqüências das variáveis categóricas gênero, estado civil e nível socioeconômico. Apenas para a variável ocupação não se obteve equivalência entre os grupos. Os valores de $p$ são apresentados acima na Tabela 4. 
4.3 Análise dos sintomas depressivos, de ansiedade e de euforia

O teste de Mann Whitney não apontou diferenças significativas entre os grupos para as variáveis sintomas depressivos $(p=0,480)$ e de ansiedade $(p=0,484)$. Na Tabela 5 , consta uma descrição dos resultados referentes aos sintomas depressivos e de ansiedade no grupo-estudo e no controle.

A pontuação na EAM-m indicou ausência de sintomas de euforia para todos os sujeitos que compuseram os grupos.

Tabela 5 - Pontuações globais numéricas dos sintomas depressivos e de ansiedade

\begin{tabular}{llcccccc}
\hline Escalas & Grupo & N & Mediana & Mín./Máx. & Média & dp & p \\
\hline \multirow{2}{*}{ BDI } & Estudo & 43 & 8 & $0 / 33$ & 9,79 & 7,61 & 0,480 \\
& Controle & 80 & 7 & $0 / 32$ & 8,78 & 6,67 & \\
\multirow{2}{*}{ BAI } & & & & & & & \\
& Estudo & 43 & 6 & $0 / 34$ & 9,02 & 8,02 & 0,484 \\
& Controle & 80 & 6,5 & $0 / 36$ & 7,44 & 6,28 & \\
\hline
\end{tabular}

Mann Whitney

Em relação às categorias discretas dos sintomas depressivos para o grupo-estudo, verificou-se que a maioria - representada por $65,1 \%$ da amostra - apresentou sintomas mínimos de depressão; 25,6\% sintomas leves e 9,3\% sintomas moderados. No grupo-controle, $71,3 \%$ dos sujeitos revelaram sintomas mínimos; $23,8 \%$ leves; $5,0 \%$ moderados e 2,3\% sintomas graves.

Para os sintomas de ansiedade, a maioria dos sujeitos do grupoestudo $(72,1 \%)$ foi classificada com sintomas mínimos de ansiedade; $16,3 \%$ com sintomas leves; $9,3 \%$ com sintomas moderados e 2,3\% com sintomas graves. No grupo-controle, $73,8 \%$ dos sujeitos apresentaram sintomas mínimos de ansiedade; $22,5 \%$ sintomas leves; $2,5 \%$ sintomas moderados e $1,3 \%$ sintomas graves.

Não foi possível calcular a estatística Qui-Quadrado para essas variáveis categóricas, pois a freqüência esperada de observações em uma ou mais células era insuficiente, o que violaria as pressuposições do teste. A 
alternativa de formar agrupamentos foi abandonada porque traria forçosamente perda qualitativa.

\subsection{Análise da percepção da qualidade do sono}

A Tabela 6 mostra dados das características do sono, tais como latência, duração e eficiência obtidos, através da avaliação do PSQI. Houve diferença estatisticamente significativa para a latência $(p<0,001)$ e duração do sono $(p<0,001)$ entre os grupos.

A latência e a duração do sono estiveram significativamente aumentadas para o grupo-estudo. Por outro lado, não houve diferença significativa para a eficiência do sono entre os grupos $(p=0,083)$.

Tabela 6 - Características do sono

\begin{tabular}{|c|c|c|c|c|c|c|c|}
\hline Grupo & $\mathrm{n}$ & Variáveis & Mediana & Mín./Máx. & Média & $d p$ & $p$ \\
\hline Estudo & 43 & $\begin{array}{l}\text { Latência* } \\
\text { Duração* } \\
\text { Eficiência }\end{array}$ & $\begin{array}{c}20 \\
480 \\
94,7 \%\end{array}$ & $\begin{array}{c}10 / 90 \\
300 / 660 \\
63,6 / 98,6\end{array}$ & $\begin{array}{c}29,3 \\
475,81 \\
91,1 \%\end{array}$ & $\begin{array}{c}20,66 \\
1,58 \\
8,42\end{array}$ & $\begin{array}{c}<0,001 \\
<0,001 \\
0,083\end{array}$ \\
\hline Controle & 80 & $\begin{array}{l}\text { Latência* } \\
\text { Duração* } \\
\text { Eficiência }\end{array}$ & $\begin{array}{c}15 \\
420 \\
95,8 \%\end{array}$ & $\begin{array}{c}5 / 60 \\
270 / 570 \\
73,5 / 98,8\end{array}$ & $\begin{array}{c}16,88 \\
403,12 \\
94,3 \%\end{array}$ & $\begin{array}{c}10,83 \\
1,14 \\
4,89\end{array}$ & \\
\hline
\end{tabular}

Mann Whitney

* Em minutos

O resultado do teste de Mann Whitney indicou diferença significativa entre os grupos em relação à pontuação total no PSQI $(p=0,045)$. O grupoestudo encontrou-se discretamente mais prejudicado, com mediana igual a 6 , enquanto o grupo-controle obteve mediana 5. A pontuação nesta escala é inversamente proporcional à QS, ou seja, quanto maior a pontuação pior a QS. Esses dados estão descritos na Tabela 7. 
Tabela 7 - Pontuação global da qualidade do sono

\begin{tabular}{|c|c|c|c|c|c|c|c|}
\hline Variável & Grupo & $\mathbf{n}$ & Mediana & Mín./Máx. & Média & $d p$ & $p$ \\
\hline \multirow{2}{*}{$\begin{array}{l}\text { Pontuação } \\
\text { total da QS }\end{array}$} & Estudo & 43 & 6 & $0 / 17$ & 6,12 & 3,35 & 0,045 \\
\hline & Controle & 80 & 5 & $0 / 14$ & 5,14 & 2,94 & \\
\hline
\end{tabular}

A Tabela 8 apresenta a freqüência relativa e a absoluta das categorias da percepção subjetiva da QS. Esses dados foram obtidos a partir do item 6 do PSQI ("Durante o mês passado, como você classificaria a qualidade de seu sono?").

Tabela 8 - Freqüência relativa e absoluta da percepção subjetiva da QS

\begin{tabular}{lclcc}
\hline Grupo & $\mathbf{n}$ & Categorias & $\begin{array}{c}\text { Freqüência } \\
\%\end{array}$ & $\begin{array}{c}\text { Freqüência } \\
\text { absoluta }\end{array}$ \\
\hline Estudo & \multirow{2}{*}{43} & Muito ruim & 2,3 & 1 \\
& & Ruim & 18,6 & 8 \\
& & Bom & 55,8 & 24 \\
& & Muito bom & 23,3 & 10 \\
Controle & \multirow{2}{*}{80} & Muito ruim & 1,6 & 13 \\
& & Ruim & 19,5 & 16 \\
& & Bom & 55,3 & 44 \\
& & Muito bom & 23,6 & 19 \\
\hline
\end{tabular}

A categoria 'muito ruim' foi agrupada a 'ruim' para possibilitar uma comparação estatística das freqüências das categorias presentes na Tabela 8. Sendo assim, o teste Qui-Quadrado não apontou diferença significativa para as freqüências $(p=0,972)$ relacionadas à percepção subjetiva da QS.

Como o PSQI permite classificar os sujeitos em bons e maus dormidores, $58,1 \%$ do grupo-estudo foi classificado como mau dormidor, enquanto no grupo-controle $42,5 \%$ dos sujeitos obtiveram a mesma classificação, como mostra a Tabela 9.

Verificou-se que não houve diferença significativa quando as freqüências de bom e mau dormidor foram analisadas com o teste QuiQuadrado para amostras independentes $(p=0,098)$ e nem com o Teste Exato de Fisher $(p=0,130)$. 
Tabela 9 - Classificação em bons e maus dormidores de acordo com a pontuação total no PSQI

\begin{tabular}{lclccc}
\hline Grupo & $\mathbf{n}$ & Categorias & $\begin{array}{c}\text { Freqüência } \\
\text { relativa }\end{array}$ & $\begin{array}{c}\text { Freqüência } \\
\text { absoluta }\end{array}$ & $\mathbf{p}$ \\
\hline \multirow{2}{*}{ Estudo } & \multirow{2}{*}{43} & Mau & 58,1 & 25 & 0,098 \\
& & Bom & 41,9 & 18 & \\
Controle & \multirow{2}{*}{80} & Mau & 42,5 & 34 & \\
& & Bom & 57,5 & 46 & \\
\hline
\end{tabular}

A distribuição das freqüências das pontuações globais do PSQI, apresentada na Figura 1, mostrou que a maioria dos bons dormidores do grupo-estudo concentrou-se próxima da pontuação crítica (pontuação $\leq 5$ classificado como bom dormidor e $>5$, como mau dormidor), ou seja, esteve mais próxima dos maus dormidores. No grupo-controle, a maioria dos maus dormidores esteve mais próxima do valor crítico.

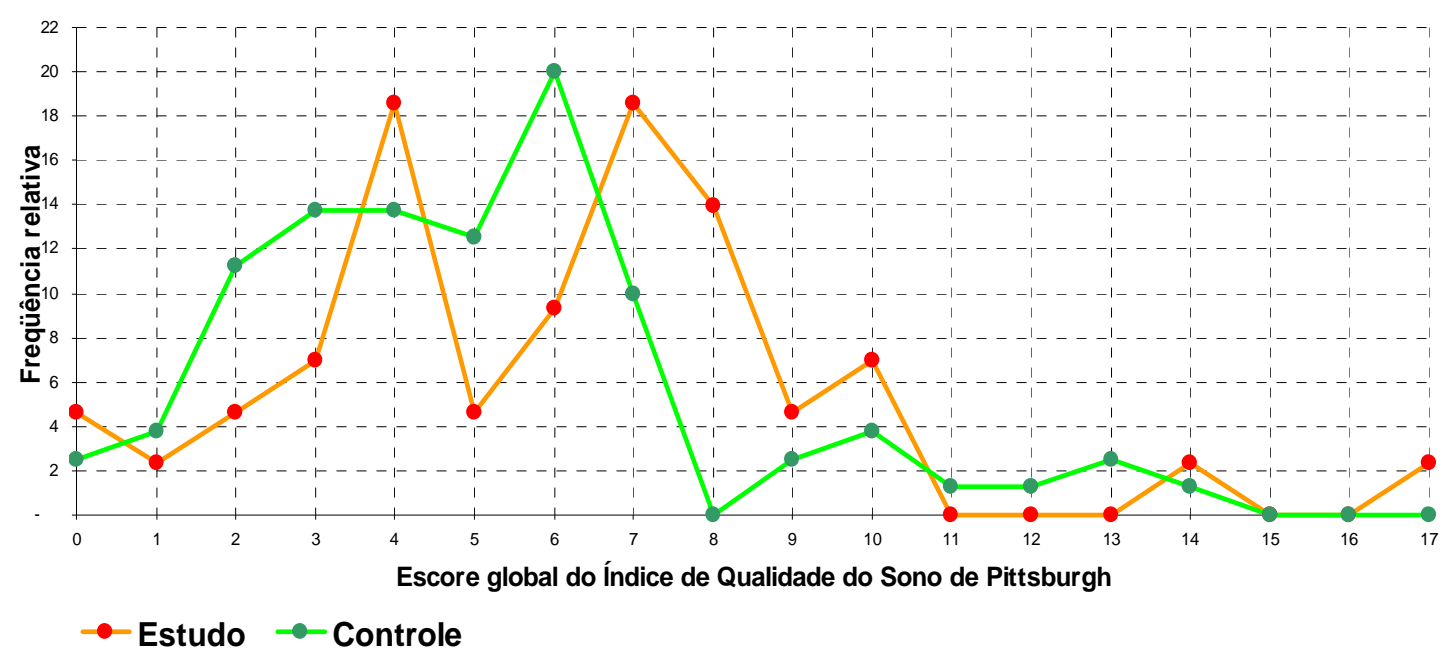

Figura 1 - Distribuição das freqüências relativas das pontuações no PSQI

Na Tabela 10, a coluna das categorias indicou a freqüência semanal do uso de medicação específica para dormir. Os resultados mostraram que $30,2 \%$ dos sujeitos do grupo-estudo usavam medicamentos para dormir três ou mais vezes durante a semana, enquanto apenas $8,8 \%$ do grupo-controle os utilizavam com freqüência semelhante. 
Tabela 10 - Uso de medicação para dormir

\begin{tabular}{lllcc}
\hline Grupo & $\mathbf{n}$ & Categoria & $\begin{array}{c}\text { Freqüência } \\
\%\end{array}$ & $\begin{array}{c}\text { Freqüência } \\
\text { absoluta }\end{array}$ \\
\hline \multirow{2}{*}{ Estudo } & \multirow{2}{*}{43} & Nenhuma & 62,8 & 27 \\
& & Menos de uma & 0 & 0 \\
& & $\begin{array}{c}\text { Uma ou duas } \\
\text { Três ou mais }\end{array}$ & 7,0 & 3 \\
& & 30,2 & 13 \\
Controle & \multirow{2}{*}{80} & Nenhuma & 86,3 & 69 \\
& & Menos de uma & 2,5 & 2 \\
& & Uma ou duas & 2,5 & 2 \\
& & Três ou mais & 8,8 & 7 \\
\hline
\end{tabular}

Qui-Quadrado

Considerando a necessidade ou não de uso de medicamentos para dormir, independentemente da freqüência do uso semanal, 37,2\% do grupoestudo utilizou medicamentos para dormir e 62,8 \% não os utilizaram. Enquanto que no grupo-controle, apenas $13,75 \%$ faziam uso destes medicamentos e $86,25 \%$ não os utilizavam. O Teste Exato de Fisher apontou diferença significativa $(p=0,005)$.

A Tabela 11 mostra a freqüência de sonolência diurna durante a semana. A maioria dos sujeitos, de ambos os grupos, não referiu problemas para manter-se acordada.

Tabela 11 - Sonolência diurna

\begin{tabular}{|c|c|c|c|c|}
\hline Grupo & $n$ & Categoria & $\begin{array}{c}\text { Freqüência } \\
\%\end{array}$ & $\begin{array}{c}\text { Freqüência } \\
\text { absoluta }\end{array}$ \\
\hline \multirow[t]{4}{*}{ Estudo } & 43 & Nenhuma & 90,7 & 39 \\
\hline & & Menos de uma & 2,3 & 1 \\
\hline & & Uma ou duas & 4,7 & 2 \\
\hline & & Três ou mais & 2,3 & 1 \\
\hline \multirow[t]{4}{*}{ Controle } & 80 & Nenhuma & 73,7 & 59 \\
\hline & & Menos de uma & 12,5 & 10 \\
\hline & & Uma ou duas & 10,0 & 8 \\
\hline & & Três ou mais & 3,8 & 3 \\
\hline
\end{tabular}

A Tabela 12, a seguir, mostra a freqüência dos grupos com relação ao quesito 'necessidade de levantar-se à noite para ir ao banheiro'. No grupoestudo, $34,9 \%$ dos sujeitos relataram levantar-se três ou mais vezes à noite 
durante a semana para ir ao banheiro, enquanto no grupo-controle apenas $15 \%$ dos sujeitos referiram essa necessidade.

Tabela 12 - Necessidade de levantar-se durante a noite para ir ao banheiro

\begin{tabular}{lllcc}
\hline Grupo & $\mathbf{n}$ & Categoria & $\begin{array}{c}\text { Freqüência } \\
\%\end{array}$ & $\begin{array}{c}\text { Freqüência } \\
\text { absoluta }\end{array}$ \\
\hline \multirow{2}{*}{ Estudo } & \multirow{2}{*}{43} & Nenhuma & 30,2 & 13 \\
& & Menos de uma & 27,9 & 12 \\
& & Uma ou duas & 7,0 & 3 \\
& & Três ou mais & 34,9 & 15 \\
Controle & \multirow{2}{*}{80} & Nenhuma & 38,8 & 31 \\
& & Menos de uma & 25,1 & 20 \\
& & Uma ou duas & 21,1 & 17 \\
& & Três ou mais & 15,0 & 12 \\
\hline
\end{tabular}

\subsection{Análise da percepção da QV}

O WHOQOL-BREVE não possibilita uma classificação categórica, apenas fornece um pontuação numérica, que pode variar entre 0 e 80 , em uma relação direta (escala crescente) com a percepção da QV. A pontuação de cada domínio vai de 0 a 20.

Em relação à pontuação total, obteve-se a mediana de 57 para 0 grupo-estudo e 61 para o controle (vide Tabela 13). Não foram observadas diferenças significativas, utilizando o teste de Mann Whitney, quando comparadas as pontuações totais numéricas das variáveis $Q V(p=0,154)$, domínio Psíquico $(0,276)$ e domínio Relações Sociais $(p=0,229)$.

Encontrou-se diferença significativa entre os grupos para as variáveis domínio Físico $(<0,001)$ e domínio Meio Ambiente $(p=0,003)$. 
Tabela 13 - Resultados obtidos através do WHOQOL-BREVE

\begin{tabular}{lllccccc}
\hline Domínio & Grupo & $\mathbf{n}$ & Mediana & Min./Máx. & Média & dp & p \\
\hline \multirow{2}{*}{ Físico } & Estudo & 43 & 14 & $10 / 20$ & 14,37 & 2,47 & $<\mathbf{0 , 0 0 1}$ \\
& Controle & 80 & 17 & $10 / 20$ & 16,15 & 2,26 & \\
Psicológico & Estudo & 43 & 15 & $8 / 19$ & 14,81 & 2,63 & 0,276 \\
& Controle & 80 & 16 & $7 / 19$ & 15,15 & 2,44 & \\
Rel. Sociais & & & & & & & \\
& Estudo & 43 & 15 & $4 / 20$ & 13,63 & 3,65 & 0,229 \\
& Controle & 80 & 15 & $5 / 20$ & 14,48 & 3,09 & \\
M.Ambiente & Estudo & 43 & 15 & $11 / 20$ & 15,44 & 2,32 & $\mathbf{0 , 0 0 3}$ \\
& Controle & 80 & 14 & $5 / 18$ & 13,94 & 2,23 & \\
Pontuação total & Estudo & 43 & 57 & $39 / 76$ & 58,26 & 9,07 & 0,154 \\
& Controle & 80 & 61 & $28 / 77$ & 59,76 & 8,33 & \\
\hline Mann Whitney & & & & & & &
\end{tabular}

Na Tabela 14 consta a descrição da freqüência para as categorias da percepção geral da QV. Esses dados foram obtidos a partir do primeiro item do questionário WHOQOL-BREVE ("Como você avaliaria sua qualidade de vida?"). A maioria dos sujeitos de ambos os grupos perceberam a QV como boa, sendo $53,5 \%$ no grupo-estudo e $70,0 \%$ no grupo-controle.

Tabela 14 - Percepção geral da QV

\begin{tabular}{llcc}
\hline & Categorias & Estudo \% & Controle \% \\
\hline \multirow{2}{*}{ Percepção da QV } & Ruim & 0 & \\
& Nem boa nem ruim & 20,9 & 6,3 \\
& Boa & 53,5 & 17,5 \\
& Muito boa & 25,6 & 6,0 \\
\hline
\end{tabular}


4.6 Análise comparativa entre as variáveis QS, QV, sintomas depressivos, sintomas de ansiedade, idade e escolaridade

Utilizou-se o teste de Correlação de Spearman para testar a correlação em cada grupo das variáveis QS, QV, sintomas depressivos, sintomas de ansiedade, idade e escolaridade.

No grupo-estudo, a variável QS apresentou correlação significativa com a QV ( $p=<0,001 ; r=-0,534)$, com os sintomas de ansiedade $(p=<0,001$; $r=0,542)$ e com sintomas depressivos $(p=0,001 ; r=0,490)$. $O$ coeficiente de correlação foi negativo, pois a ordem numérica das pontuações do PSQI com as outras escalas não segue a mesma direção. Ou seja, à medida que as pontuações no PSQI aumentaram (o que significa pior QS), as pontuações da escala de QV diminuíram. Mas, na prática, é uma correlação diretamente proporcional, visto que a QV, os sintomas depressivos e de ansiedade ficaram mais prejudicados à medida que a QS piora.

Foram encontradas correlações semelhantes para o grupo-controle. A QS esteve diretamente relacionada com a QV ( $p<0,001 ; r=-0,382)$, com sintomas depressivos $(p=0,001 ; r=0,374)$ e com sintomas de ansiedade $(p<0,001 ; r=0,473)$.

A variável sintomas depressivos, no grupo-estudo, correlacionou-se com a QV $(p<0,001 ; r=-0,736)$ e com sintomas de ansiedade $(p<0,001$; $r=0,676$ ). A variável sintomas de ansiedade correlacionou-se com $Q V$ $(p<0,001 ; r=-0,556)$.

No grupo-controle, a correlação foi significativa entre os sintomas depressivos e QV ( $p<0,001 ; r=-0,584)$, sintomas depressivos e sintomas de ansiedade $(p<0,001 ; r=0,569)$; sintomas de ansiedade e QV $(p<0,001$; $r=-0,563$ )

No grupo-estudo, as correlações (Spearman) não foram significativas entre QS e idade, QS e escolaridade, QV e idade, QV e escolaridade, sintomas depressivos e idade, sintomas depressivos e escolaridade, sintomas de ansiedade e idade, sintomas de ansiedade e escolaridade. 
Não foram encontradas correlações significativas, no grupo controle, entre as variáveis QS e idade, QS e escolaridade, QV e idade, QV e escolaridade, sintomas depressivos e idade, sintomas depressivos e escolaridade, sintomas de ansiedade e idade, sintomas de ansiedade e escolaridade.

A Tabela 15 mostra os resultados das correlações entre as variáveis para os dois grupos.

Tabela 15 - Correlação entre as variáveis idade, QS, sintomas depressivos, sintomas de ansiedade e QV para o grupo-estudo e grupo-controle

\begin{tabular}{|c|c|c|c|c|c|c|}
\hline Grupo & Variáveis & & Idade & WHOQOL & BAI & BDI \\
\hline \multirow[t]{4}{*}{ Estudo } & PSQI & $\begin{array}{l}p \\
r\end{array}$ & $\begin{array}{l}0,175 \\
0,211\end{array}$ & $\begin{array}{l}<0,001 \\
-0,534\end{array}$ & $\begin{array}{r}<0,001 \\
0,542\end{array}$ & $\begin{array}{l}\mathbf{0 , 0 0 1} \\
0,490\end{array}$ \\
\hline & BDI & $\begin{array}{l}p \\
r\end{array}$ & $\begin{array}{l}0,280 \\
0,169\end{array}$ & $\begin{array}{l}<0,001 \\
-0,736\end{array}$ & $\begin{array}{r}<0,001 \\
0,676\end{array}$ & \\
\hline & BAI & $\begin{array}{l}p \\
r\end{array}$ & $\begin{array}{l}0,150 \\
0,223\end{array}$ & $\begin{array}{l}<0,001 \\
-0,556\end{array}$ & & \\
\hline & WHOQOL & $\begin{array}{l}p \\
r\end{array}$ & $\begin{array}{r}0,766 \\
-0,047\end{array}$ & & & \\
\hline \multirow[t]{4}{*}{ Controle } & PSQI & $\begin{array}{l}p \\
r\end{array}$ & $\begin{array}{r}0,409 \\
-0,094\end{array}$ & $\begin{array}{l}<0,001 \\
-0,382\end{array}$ & $\begin{array}{r}<0,001 \\
0,473\end{array}$ & $\begin{array}{l}\mathbf{0 , 0 0 1} \\
0,374\end{array}$ \\
\hline & BDI & $\begin{array}{l}p \\
r\end{array}$ & $\begin{array}{r}0,912 \\
-0,013\end{array}$ & $\begin{array}{l}<0,001 \\
-0,584\end{array}$ & $\begin{array}{c}<0,001 \\
0,569\end{array}$ & \\
\hline & BAI & $\begin{array}{l}p \\
r\end{array}$ & $\begin{array}{r}0,758 \\
-0,035\end{array}$ & $\begin{array}{l}<0,001 \\
-0,563\end{array}$ & & \\
\hline & WHOQOL & $\begin{array}{l}p \\
r\end{array}$ & $\begin{array}{l}0,414 \\
0,093\end{array}$ & & & \\
\hline
\end{tabular}

Teste de Correlação de Spearman 
4.7 Análise comparativa entre as variáveis estado civil, nível socioeconômico, ocupação, latência, duração e eficiência do sono

Não foi possível aplicar o teste Qui-Quadrado no grupo-estudo para comparar as variáveis gênero com sintomas depressivos, gênero com sintomas de ansiedade, ocupação com sintomas depressivos, ocupação com sintomas de ansiedade, estado civil com sintomas depressivos, e estado civil com sintomas de ansiedade. Também não foi possível comparar a variável renda com outras variáveis, pois a freqüência esperada de observações para um ou mais elementos de cada uma destas variáveis foi insuficiente, violando as pressuposições do teste. No grupo-controle, diversas variáveis não foram comparadas pelo mesmo motivo.

\subsubsection{Grupo-estudo: ocupação x QS}

$\mathrm{Na}$ tentativa de compreender se a variável ocupação pode ter influenciado na QS do grupo-estudo, algumas categorias dessa variável foram agrupadas para possibilitar a aplicação do teste estatístico. Embora esse procedimento alternativo seja válido para a situação, deve-se reconhecer que ocorrem perdas qualitativas quando se agrupam duas ou mais categorias, pois a categoria resultante passa a incorporar características de outras categorias.

Assim, optou-se por agrupar os ativos, do lar e estudantes (categoria 1), por entender que possuem uma característica em comum: uma tarefa diária e metas a serem cumpridas. Os afastados foram agrupados com os aposentados (categoria 2), por não estarem oficialmente comprometidos com uma atividade laboral diária. E, por fim, os desempregados permaneceram isolados na categoria 3 . 
Os resultados não permitiram tirar conclusões, mas serviram de indicativos. Portanto, houve indicativos de que a categoria 1 apresentou maior freqüência de bons dormidores em relação à categoria $2(p=0,024)$, sendo encontrado $45,8 \%$ de bons dormidores na categoria 1 , enquanto apenas 8,3\% de bons dormidores foram encontrados na categoria 2.

A categoria 1 não diferiu da categoria 3 em relação à QS $(p=0,062)$, sendo $45,8 \%$ de bons dormidores da categoria 1 e $85,7 \%$ de bons dormidores da categoria 3 .

A categoria 3 apresentou maior freqüência de bons dormidores $(85,7 \%)$ comparada à categoria 2 (8,3\%), com $p<0,001$.

Nesse sentido, houve indícios de que a categoria 2 (aposentados e afastados) teve significativamente maior freqüência de maus dormidores, que pode ser verificado pela porcentagem obtida: 91,7\%. A freqüência de maus dormidores na categoria 1 foi de $54,2 \%$ e a na categoria 2 foi de $14,3 \%$.

Dessa forma, quando se excluíram todos os elementos da categoria 2 (afastados e aposentados) do grupo-estudo e se procedeu à comparação, entre os grupos, da QS pela pontuação global na escala, não se encontrou diferença significativa $(p=0,598)$.

Esse procedimento não foi adotado para o grupo-controle porque todos os sujeitos tinham um trabalho formal.

\subsubsection{Grupo-estudo: estado civil x QS}

A variável estado civil só pode ser testada, utilizando o teste QuiQuadrado, com a QS (bom e mau dormidor). Quando as categorias casado e solteiro foram testadas com bons e maus dormidores, não foram encontradas diferenças significativas $(p=0,073)$, tendo $70 \%$ dos casados contra $38,5 \%$ dos solteiros sido classificados como maus dormidores. 
Os casados também não diferiram dos separados (agrupados com viúvos) em relação à $Q S(p=0,584)$, tendo $60 \%$ dos separados sido classificados como maus dormidores. Quando se compararam separados (agrupados com viúvos) e solteiros, a diferença também não foi significativa $(p=0,305)$ e apontou $38,5 \%$ maus dormidores na categoria de solteiros.

\subsubsection{Grupo-controle}

\subsubsection{QS x Gênero}

Ao comparar as freqüências da variável gênero (Qui-Quadrado) com as freqüências de bons e maus dormidores da variável QS, não se observaram diferenças $(p=0,726)$. No gênero feminino, $56 \%$ foram classificados como bons dormidores e $44 \%$ como maus dormidores, enquanto, no gênero masculino, encontraram-se $60 \%$ de bons dormidores e $40 \%$ de maus dormidores.

\subsubsection{QS x estado civil}

A freqüência das categorias da variável estado civil foram comparadas com as categorias de bom e mau dormidor (Qui-Quadrado), mas não houve diferenças significativas.

Quando as categorias casado e solteiro foram testadas com bons e maus dormidores, obteve-se $\mathrm{p}=0,964$ (Qui-Quadrado), tendo $57,1 \%$ dos casados do grupo-controle sido classificados como bons dormidores e $42,9 \%$ maus dormidores. 
Entre os solteiros, $57,1 \%$ foram classificados como bons dormidores e $42,9 \%$ maus dormidores. Ao comparar solteiros com separados (agrupados com viúvos), obteve-se $p=0,875$. Entre os viúvos do grupo-controle, $60 \%$ estiveram na categoria de bons dormidores e $40 \%$ maus dormidores. Para a comparação entre as freqüências de casado com separados (agrupados com viúvo), obteve-se $p=0,869$.

\subsubsection{QS x gênero}

No grupo-estudo, as freqüências de bons e maus dormidores não foram significativamente diferentes quando comparadas com as freqüências do gênero (Qui-Quadrado $p=0,847$ ).

A mesma comparação também não foi significativa no grupo-controle (Qui-quadrado $p=0,726$ ).

\subsubsection{Escolaridade $\mathrm{x}$ renda}

No grupo-estudo, verificou-se correlação significativa entre idade e escolaridade $(p<0,001 ; r=0,517)$ e entre escolaridade e renda $(p<0,001$; $r=0,614)$.

No grupo-controle houve correlação significativa entre as variáveis escolaridade e renda $(p=0,017 ; r=0,267)$. 
4.7.6 Latência, duração, sintomas depressivos e sintomas de ansiedade

No grupo-estudo, a correlação foi significativa entre as variáveis: sintomas de ansiedade e latência ( $p=0,022 ; r=0,349)$ e sintomas depressivos e latência $(p=0,041 ; r=0,314)$.

No grupo-controle, a correlação foi significativa entre: sintomas depressivos e latência ( $p=0,026 ; r=0,249)$, sintomas depressivos e eficiência $(p=0,001 ; r=-0,356)$ e sintomas de ansiedade e eficiência $(p=0,040 ; r=$ $-0,230)$.

\subsection{Análise dos subgrupos de maus dormidores}

A Tabela 16 mostra as variáveis que diferiram significativamente entre os subgrupos de maus dormidores. A latência esteve significativamente mais prejudicada no subgrupo de maus dormidores do grupo-estudo $(p=0,026)$.

Constatou-se diferença na quantidade de horas dormidas por noite (duração do sono) entre os maus dormidores de ambos os grupos $(p=0,001)$. O subgrupo-estudo de maus dormidores apresentou maior duração do sono (mediana $=480$ minutos, aproximadamente 8 horas), enquanto que 0 subgrupo-controle obteve mediana $=360$, aproximadamente 6 horas.

Tabela 16 - Latência e duração do sono nos subgrupos de maus dormidores

\begin{tabular}{|c|c|c|c|c|c|c|c|}
\hline Variável & Grupo & $n$ & Mediana & Min/Máx & Média & $\mathrm{dp}$ & $\mathbf{P}^{*}$ \\
\hline Latência & $\begin{array}{l}\text { Estudo } \\
\text { Controle }\end{array}$ & $\begin{array}{l}25 \\
34\end{array}$ & $\begin{array}{c}30 \\
17,50\end{array}$ & $\begin{array}{c}10 / 90 \\
5 / 60\end{array}$ & $\begin{array}{l}34,40 \\
21,62\end{array}$ & $\begin{array}{l}23,91 \\
13,58\end{array}$ & 0,026 \\
\hline Duração** & $\begin{array}{l}\text { Estudo } \\
\text { Controle }\end{array}$ & $\begin{array}{l}25 \\
34 \\
\end{array}$ & $\begin{array}{l}480 \\
360 \\
\end{array}$ & $\begin{array}{l}300 / 660 \\
300 / 660 \\
\end{array}$ & $\begin{array}{l}463,20 \\
388,24 \\
\end{array}$ & $\begin{array}{c}100,28 \\
81,22\end{array}$ & 0,001 \\
\hline
\end{tabular}

*Mann Whitney

**Duração do sono em minutos 
Também foi obtida diferença significativa $(p=0,037)$, utilizando o Teste Exato de Fisher, entre os sujeitos que usavam e os que não usavam medicamentos para dormir entre os subgrupos. No grupo-estudo, $56 \%$ usavam medicamentos para dormir e no subgrupo-controle, apenas $29,4 \%$.

Do total de 25 maus dormidores do subgrupo-estudo, 14 faziam uso de medicação para dormir e representavam $56 \%$, enquanto dos 34 maus dormidores do subgrupo-controle, apenas $10(29,4 \%)$ usavam medicamento para dormir, contra 24 (70,6\%) que não usavam.

\subsection{Análise dos indivíduos com co-morbidade}

Foram excluídos 13 pacientes com TB que apresentaram comorbidade com abuso de álcool e/ou drogas (5), episódio depressivo (3), transtorno de ansiedade (1), transtorno de personalidade (2) e outras comorbidades (2).

Excluíram-se 15 sujeitos da amostra do grupo-controle porque preencheram os critérios para episódio depressivo (7), transtorno obsessivo compulsivo (2), transtorno de ansiedade (3), sintomas persecutórios (1), abuso de álcool (1) e traumatismo crânio-encefálico (1).

Resultados significativamente piores foram obtidos quando os sujeitos excluídos (devido a co-morbidades) foram comparados ao grupo de pacientes com TB sem co-morbidades. Em seguida, a Tabela 17 apresenta os dados obtidos dessa comparação. 
Tabela 17 - Subgrupo com co-morbidade

\begin{tabular}{|c|c|c|c|}
\hline Variável & $\begin{array}{l}\text { Grupo-estudo com } \\
\text { co-morbidade }\end{array}$ & $\begin{array}{c}\text { Grupo-estudo sem } \\
\text { co-morbidade }\end{array}$ & $p$ \\
\hline $\mathbf{N}$ & 13 & 43 & - \\
\hline Qualidade do sono & 10,45 & 6,12 & 0,004 \\
\hline Qualidade de Vida & 44,73 & 58,26 & $\begin{array}{c}<0,000 \\
1\end{array}$ \\
\hline Sintomas depressivos & 19,73 & 9,79 & 0,015 \\
\hline Sintomas de ansiedade & 16,91 & 9,02 & 0,005 \\
\hline
\end{tabular}

Para a variável sintomas depressivos, o posto médio para o grupoestudo foi 24,87 e 37,77 para o grupo de pacientes com co-morbidade ( $p=0,015)$, ou seja, os pacientes que apresentaram co-morbidades também tiveram pontuações mais altas (piores) na escala de sintomas depressivos.

O posto médio para a variável sintomas de ansiedade $(p=0,005)$ nos pacientes sem co-morbidade foi 24,50 e 37,23 nos pacientes com comorbidade.

$\mathrm{Na}$ variável QS, pacientes sem co-morbidade alcançaram o posto médio equivalente a 24,36 e o outro grupo, 39,77 ( $p=0,004)$. Ou seja, a QS esteve pior na presença de co-morbidade.

Por último, para a variável QV, o valor do posto médio nos pacientes sem co-morbidades foi de 12,59 e na presença de co-morbidade o valor foi de 31,31 ( $p<0,0001)$. No WHOQOL-BREVE, quanto maior a pontuação, melhor é a QV. Então, pacientes sem co-morbidades apresentaram significativamente melhores pontuações para a QV. 


\section{DISCUSSÃO}

\subsection{Caracterização quanto às variáveis clínicas do grupo-estudo}

A média de idade de início do TB do presente estudo (30,4 anos) mostrou-se um pouco acima da média de outro estudo, que indica 23,5 anos de idade ${ }^{13}$. Nesta pesquisa, considerou-se como início do TB o primeiro episódio relatado pelo paciente, caracterizado por euforia, hipomania ou depressão.

Em geral, não é simples adotar uma referência para a idade de início. Alguns estudos epidemiológicos consideram o primeiro episódio depressivo, outros, o primeiro episódio maníaco ${ }^{26}$. Por essa razão, perde-se a referência quando vários estudos são comparados. Muitas vezes, os pacientes não conseguem lembrar-se de detalhes ocorridos durante os episódios, o que também dificulta a precisão desse dado.

Quanto ao número de crises, a média foi de aproximadamente cinco ao longo da vida, sendo que existe um dado discrepante de um paciente que apresentou 40 crises e 40 internações, refletindo o possível prejuízo potencial na vida de um paciente com TB. Neste estudo, a média foi de aproximadamente cinco episódios, incluindo os depressivos e maníacos e/ou hipomaníacos, ao longo da vida dos pacientes.

Alguns autores estimam que uma pessoa acometida pelo TB com 25 anos perderá, em média, 9 anos na expectativa de vida (em decorrência de problemas cardiovasculares e outras complicações médicas), perderá 14 anos de produtividade e terá vida normal apenas durante 12 anos $^{90}$. É claro que existem diferenças do curso da doença entre os pacientes e inúmeras variáveis envolvidas nele, como, por exemplo, presença de co-morbidades, abuso de substâncias psicoativas e adesão ao tratamento farmacológico, 
que podem contribuir para agravar o prognóstico e aumentar a freqüência de episódios.

Obteve-se a média de aproximadamente duas internações ao longo da vida nos pacientes do grupo-estudo e um tempo médio de doença de 11,5 anos, variando de um a 33 anos.

Em relação ao gênero, 38,8\% dos sujeitos da amostra do grupo-estudo eram do gênero masculino e $61,2 \%$ feminino. A vasta literatura a respeito aponta que a prevalência é semelhante em homens e mulheres ${ }^{30}$. Entretanto, existem divergências entre os estudos quando se trata de espectros bipolares, sendo sugerida uma relação de 1,5 mulheres para cada homem ${ }^{30}$.

A maior prevalência do gênero feminino na amostra estudada talvez se explique pela maior iniciativa e procura por tratamento por parte das mulheres e por não ter sido aleatória a amostra do grupo-estudo.

\subsection{Caracterização quanto às variáveis sociodemográficas}

Um aspecto importante deste estudo foi a obtenção da equivalência das variáveis idade, escolaridade, gênero, estado civil e nível socioeconômico entre os grupos, isto é, essas variáveis não apresentaram diferenças significativas entre os grupos, o que permitiu denominar o grupocontrole como tal e contribuiu para diminuir as possíveis influências dessas variáveis nos resultados obtidos. Apenas a variável 'ocupação' não foi equivalente entre os grupos, dada a grande dificuldade que haveria em encontrar um grupo-controle equivalente ao grupo-estudo.

Diante disso, é possível afirmar que houve indícios de que na amostra do grupo-estudo a variável QS mostrou-se dependente da variável ocupação. Sendo que a QS do sono esteve significativamente pior na categoria 2 (aposentados e afastados). Tal fato pode ser ratificado, pois não foi encontrada diferença significativa entre os grupos, para a variável QS 
$(p=0,597)$, quando a comparação foi feita excluindo os elementos do grupoestudo pertencentes à categoria 2 (afastados e aposentados).

Apesar de não haver diferença significativa entre os grupos em relação à escolaridade e o grupo-estudo ter apresentado um nível elevado de escolaridade, apenas 34,9\% estavam economicamente ativos, incluindo vínculo empregatício formal ou autônomo. Porém, não é possível afirmar que o TB prejudicou diretamente a relação de trabalho porque não se teve um parâmetro de comparação com a população geral em relação à variável ocupação, uma vez que $100 \%$ do grupo-controle era ativo.

Por outro lado, pode-se afirmar que os sujeitos do grupo-estudo apresentavam dificuldades para conservar o emprego, visto que, a cada episódio da doença, o risco de perdê-lo crescia muito, de acordo com os dados colhidos nas entrevistas.

Quanto ao nível socioeconômico o grupo-estudo mostrou-se bem distribuído entre as categorias A2, B1, B2 e C, assim como o grupo-controle.

Foi possível comparar algumas variáveis sociodemográficas com a QS dentro de cada grupo. A variável QS possibilitou tal comparação principalmente pelo fato de compor-se de apenas duas categorias: bons e maus dormidores. Para outras variáveis, como sintomas depressivos e de ansiedade, essa comparação não foi possível por causa do número insuficiente de elementos em uma ou mais categorias.

Diante disso, os resultados sugeriram que não existe diferença significativa para as categorias da variável gênero e estado civil em relação à QS dentro de cada amostra. Ou seja, gênero e estado civil pareceram não influenciar na QS tanto no grupo-estudo quanto no grupo-controle.

\subsection{Sintomas depressivos, de ansiedade e de euforia}

É importante ressaltar que as escalas de sintomas depressivos e de ansiedade medem a intensidade desses sintomas, mas não servem de 
critérios diagnósticos para depressão ou ansiedade. Quanto aos sintomas maníacos, todos os sujeitos da amostra encontravam-se fora de períodos maníacos ou hipomaníacos.

Apesar de a mediana e a média estarem discretamente mais elevadas no grupo-estudo, a análise estatística não apontou diferenças significativas em relação aos sintomas depressivos e de ansiedade entre os grupos.

Esses dados contrariam os apresentados pela literatura ${ }^{66}$ os quais mostram que portadores do TB, mesmo no período eutímico, apresentam sintomas subclínicos de depressão e ansiedade.

Uma possível explicação para os resultados referentes aos sintomas depressivos e de ansiedade é que, em primeiro lugar, o grupo-estudo foi composto por portadores do TB na fase eutímica, sendo que os instrumentos utilizados para verificar possíveis sintomas foram criteriosamente aplicados e avaliados. O procedimento constatou que o grupo-estudo estava com o humor estabilizado e não apresentava co-morbidade com outro transtorno psiquiátrico. Além disso, todos os sujeitos do grupo-estudo que participaram da pesquisa freqüentavam um grupo de psicoeducação específico para pessoas com TB. $O$ fato de participarem desse grupo indica que estavam em busca de ajuda e de conhecimento sobre a doença para lidar melhor com as dificuldades relacionadas ao TB.

O grupo de psicoeducação tinha como objetivos: informar sobre a doença, melhorar a adesão ao tratamento farmacológico, estimular a colaboração ativa do paciente, ensinar a identificar precocemente os sintomas, prevenindo recaídas, resgatar a autonomia, restabelecer o funcionamento social, estimular o envolvimento dos familiares no tratamento dos pacientes, ajudar a distinguir traços de personalidade de possíveis sintomas e orientar quanto à importância da regularidade do ritmo de vida (incluindo orientações sobre a importância da QS).

Algumas pesquisas apontam que, apesar da eficácia do tratamento com estabilizadores do humor, muitos pacientes têm dificuldade em aceitar a doença, dificultando a adesão ao tratamento farmacológico. Além de ser comum o abuso de álcool e/ou drogas e de apresentarem dificuldades no 
relacionamento familiar. Estes fatores podem contribuir negativamente para a evolução do TB ${ }^{1}$.

Por fim, acredita-se que as técnicas de psicoeducação contribuem satisfatoriamente para melhorar o desfecho de pacientes com TB, ajudandoos a lidar com medos, baixa auto-estima e sintomas sejam depressivos ou de euforia ${ }^{2}$. Por esses motivos, o fato de os sujeitos do grupo-estudo estarem inseridos em um grupo de psicoeducação pode ter refletido nos resultados desta pesquisa, não indicando diferenças significativas em relação aos sintomas depressivos e de ansiedade quando comparados ao grupo-controle.

\subsection{QS, sintomas depressivos e ansiosos}

A avaliação da QS, de acordo com a pontuação geral do PSQI, apontou que o grupo-estudo encontra-se mais prejudicado do que o controle $(p=0,045)$. Esta diferença foi devida, principalmente, à latência do sono, que está aumentada no grupo-estudo, ou seja, este grupo demora, em média, mais tempo para pegar no sono do que o grupo-controle.

Além disso, quando se compara a necessidade de uso de medicação para dormir, independente da freqüência semanal, constatou-se que o grupo-estudo faz mais uso do que o grupo-controle. Por outro lado, a percepção subjetiva da QS não se diferenciou significativamente entre os grupos.

O teste estatístico apontou diferenças entre latência e duração do sono entre os grupos, porém a eficiência do sono não se mostrou significativamente diferente. A média de duração do sono no grupo-estudo ultrapassou a do grupo-controle. Da mesma forma, a latência foi maior no grupo-estudo comparada à do grupo-controle. $O$ teste estatístico comprovou o que se observa qualitativamente e, como a latência é maior no grupoestudo, supõe-se que ele a compense, dormindo, em média, mais tempo do 
que o grupo-controle. É diferente quando se comparam duas variáveis isoladas (latência e duração do sono) de uma variável composta que relaciona duas variáveis isoladas para um mesmo indivíduo, como a eficiência, que é o tempo dormido dividido pelo tempo total na cama.

Os resultados desta pesquisa apontaram que a latência do sono está correlacionada com os sintomas depressivos e com sintomas de ansiedade no grupo-estudo. Ou seja, quanto maior a intensidade de sintomas depressivos e de sintomas de ansiedade, mais tempo leva-se para iniciar o sono. No grupo-controle, a latência apresentou correlação significativa com sintomas depressivos e com a eficiência do sono.

No presente estudo, $58,1 \%$ dos sujeitos do grupo-estudo foram identificados como maus dormidores e $41,5 \%$ como bons dormidores, de acordo com a classificação no PSQI. No grupo-controle, 42,5\% maus dormidores e $57,5 \%$ bons dormidores, sem diferenças significativas entre os grupos. No trabalho de Harvey et $\mathrm{al}^{42}$, identificaram-se $70 \%$ de maus dormidores no grupo de portadores de TB no período eutímico. Porém, é importante ressaltar que o tamanho da amostra do estudo era pequeno, apenas 20 pacientes, além de terem sido incluídos pacientes com outros transtornos secundários ao TB, o que pode ter influenciado negativamente os resultados.

A média da pontuação no PSQI do presente estudo foi de 6,12 para o grupo-estudo e 5,14 para o grupo-controle $(p=0,045)$. Harvey et $\mathrm{al}^{42}$ encontraram a média de 7,9 no PSQI para o grupo de bipolares eutímicos média superior a da presente pesquisa - e 2,3 para o grupo-controle $(p<0,007)$. Eles também constataram maior incidência de uso de medicação para dormir (mas não foi significativa) nos pacientes com TB, tempo aumentado de latência do sono $(p<0,02)$ e maior tempo de horas dormidas medidas pelo actígrafo no grupo de bipolares eutímicos.

Os dados obtidos através do Teste de Correlação de Spearman apontaram que a QS esteve associada aos sintomas depressivos e aos sintomas de ansiedade em ambos os grupos. Ou seja, quanto mais altas 
(piores) as pontuações nas escalas que avaliam os sintomas depressivos e de ansiedade, piores as pontuações no PSQI e pior a QS.

Esses dados indicam que, apesar das pessoas tanto do grupo-estudo quanto do grupo-controle não apresentarem transtorno depressivo e/ou transtorno de ansiedade diagnosticável, a intensidade desses sintomas interfere significativamente na QS.

Por outro lado, as variáveis QS, QV, sintomas depressivos e sintomas de ansiedade não se mostraram dependentes da idade e escolaridade para as duas amostras avaliadas na ausência de transtornos diagnosticáveis. É provável, porém, que elas se comportem como variáveis dependentes na presença de um transtorno depressivo ou de ansiedade.

\subsection{QV, sintomas depressivos e ansiosos}

Apesar dos dados mostrarem a mediana no grupo-controle mais alta se comparada com a do grupo-estudo, o resultado dos testes estatísticos não apontou diferenças significativas para a QV entre os grupos.

Em relação aos domínios da QV, foram encontradas diferenças significativas para o domínio Meio Ambiente e para o domínio Físico. No domínio Meio Ambiente, os sujeitos do grupo-estudo apresentaram mediana e média mais elevadas comparadas com as do grupo-controle $(p<0,003)$. Ou seja, os pacientes com TB percebem as características do domínio Meio Ambiente como de melhor qualidade do que o grupo-controle. Uma possível explicação para este dado é que os pacientes com TB utilizam os serviços de saúde com mais freqüência e estão satisfeitos com o atendimento que recebem.

O domínio Físico esteve significativamente menor no grupo-estudo, pois a maioria dos sujeitos deste grupo referiu necessidade de tratamento médico para levar a vida diária, fator responsável pela menor pontuação obtida. 
Quanto aos sintomas depressivos e de ansiedade, tanto o grupoestudo quanto o grupo-controle apresentaram associação entre a percepção da QV com sintomas depressivos e de ansiedade. Ou seja, quanto menos sintomas depressivos e de ansiedade, melhor estava a $\mathrm{QV}$; o contrário também é válido. Essa associação apresentou-se de maneira consistente, pois o impacto na QV é evidente em pessoas depressivas. Estudos atuais mostram que pacientes deprimidos podem apresentar déficits no funcionamento geral e em alguns aspectos da vida, como, por exemplo, relações sociais, ocupacionais, desempenho acadêmico, entre outros ${ }^{91}$.

Em geral, a literatura relata que pacientes com TB na fase eutímica continuam apresentando sintomas sub-clínicos do transtorno ${ }^{65,66}$. Porém, estes estudos ${ }^{64,69,70}$ mostram algumas limitações metodológicas, como: a) ausência de grupo-controle saudável como parâmetro de comparação, b) vários estudos avaliaram pessoas com TB durante os episódios da doença e c) no período estabilizado, mas com sintomas sub-clínicos - não sendo possível distinguir se eram sintomas pródromos de uma crise. Além disso, não foi encontrada nenhuma pesquisa que tenha separado os pacientes com co-morbidades e outra dificuldade é devida à diversa quantidade de instrumentos que avaliam a QV, dificultando a comparação dos dados.

Existem outras limitações, como a ausência de uma escala de QV específica para o TB. É possível que a escala de QV genérica não consiga avaliar aspectos específicos do TB que possam influenciar a percepção da QV nestes pacientes. Por outro lado, o parâmetro seria perdido caso fosse necessário comparar a QV entre doenças independentes.

O presente estudo não ratifica os achados encontrados na literatura que apontam pior $\mathrm{QV}$ em pacientes com $\mathrm{TB}^{64,69,70}$; pois mostrou que a $\mathrm{QV}$ esteve equivalente no grupo-estudo e no controle.

Este estudo também apresentou algumas limitações como a utilização de uma amostra por conveniência por serem pacientes que freqüentavam grupos de psicoeducação. Este fato pode indicar maior iniciativa dessas pessoas em buscar tratamentos adicionais para a manutenção da estabilidade afetiva, resultando, conseqüentemente, em melhor QV. 


\subsection{Subgrupo de maus dormidores}

Esta pesquisa mostrou que os maus dormidores do grupo-estudo apresentaram QS significativamente mais prejudicada quando comparados aos maus dormidores do grupo-controle. A latência, a duração do sono e a porcentagem de sujeitos que utilizam medicamentos para dormir estiveram maiores no grupo-estudo. Há indícios de que o uso desses medicamentos pode alterar e prejudicar ainda mais o padrão de sono no subgrupo-estudo. Por outro lado, não foram observadas diferenças significativas em relação a outras variáveis, como sintomas depressivos, sintomas de ansiedade e QV entre esses subgrupos.

Cabe, diante disto, a pergunta: será que os maus dormidores do grupo-estudo estão mais susceptíveis a apresentar crises tanto eufóricas quanto depressivas?

Esta investigação não dispõe de dados suficientes para responder a esta pergunta, mas acredita-se que seria interessante o acompanhamento em longo prazo destes pacientes para tal verificação.

\subsection{Subgrupo com co-morbidades: uma contribuição adicional à pesquisa}

Visto que o objetivo desta pesquisa foi avaliar apenas os pacientes sem co-morbidade, os resultados obtidos dos pacientes com co-morbidade foram descritos e serão discutidos exclusivamente com a finalidade de contribuir adicionalmente à pesquisa.

Uma das razões para esta decisão foi o pequeno tamanho da amostra de pacientes com co-morbidade, o que inviabilizou algumas análises estatísticas, sendo assim, os resultados serviram apenas como indicativos. Por outro lado, tal análise foi importante para compreender alguns resultados 
referentes ao grupo-estudo e poderá servir de base para investigações futuras.

Sanches, Assunção e Hetem ${ }^{25}$ (2005) afirmam que a co-morbidade está relacionada à resposta insatisfatória ao tratamento farmacológico, à baixa adesão ao tratamento, à presença de sintomas mais graves, a maiores prejuízos no funcionamento geral e, conseqüentemente, a maior probabilidade de recaídas. Diante disso, a análise dos resultados desta pesquisa indicou que os pacientes que apresentaram co-morbidade psiquiátrica com TB mostraram-se significativamente mais prejudicados em relação à intensidade de sintomas depressivos e de ansiedade, QS e QV em relação ao subgrupo-estudo sem co-morbidade e ao grupo-controle.

Portanto, encontraram-se indicativos de que as variáveis estudadas (sintomas depressivos e de ansiedade, QS e QV) sofrem influências da variável co-morbidade psiquiátrica.

Assim, aparentemente, os resultados da QS da pesquisa de Harvey et $\mathrm{al}^{42}$ estiveram mais prejudicados em relação a esta pesquisa devido à inclusão de pacientes com e sem co-morbidade no grupo-estudo. 


\section{CONCLUSÕES}

De acordo com os resultados desta pesquisa, pode-se concluir que:

a) Pacientes que freqüentavam os grupos de psicoeducação no HDFMRP/USP, com TB no período eutímico, em uso de estabilizador do humor e na ausência de co-morbidade, apresentaram percepção da QV semelhante à de pessoas não afetadas por esse transtorno. A QS, entretanto, esteve mais prejudicada no grupo-estudo.

b) A QS e a QV estiveram diretamente associadas dentro de cada grupo.

c) Os pacientes do grupo-estudo apresentaram sintomas depressivos e de ansiedade em proporção aproximada à das pessoas sem transtorno mental diagnosticável.

d) Para as variáveis sintomas depressivos e sintomas de ansiedade a associação foi inversamente proporcional em relação à QS e QV. Porém, estas variáveis não se apresentaram dependentes da idade, pois não estavam associadas em ambos os grupos.

e) No subgrupo de maus dormidores do grupo-estudo, a latência e a duração do sono estavam aumentadas comparadas com o subgrupo de maus dormidores do grupo-controle. 


\section{ANEXOS}

Anexo A: Protocolo de aprovação do Comitê de Ética em Pesquisa 
HOSPITAL DAS CLÍNICAS DA FACULDADE DE MEDICINA

DE RIBEIRÃO PRETO DA UNIVERSIDADE DE SÃO PAULO

CAMPUS UNIVERSITÁRIO - MONTE ALEGRE FONE: 602-1000 - FAX (016) 633-1144

Ribeirão Preto, 06 de julho de 2005

Oficio $\mathrm{n}^{\circ} 1850 / 2005$

$\mathrm{CEP} / \mathrm{SPC}$

Prezada Senhora:

O trabalho intitulado "ESTUDO DO

PADRÃO, QUALIDADE DO SONO E QUALIDADE DE VIDA EM PESSOAS COM TRANSTORNO AFETIVO BIPOLAR DO HOSPITAL DIA DA FACULDADE DE MEDICNA DE RIBEIRÃO PRETO DA UNIVERSIDADE DE SÃO PAULO", foi analisado pelo Comitê de Ética em Pesquisa, em sua $205^{\text {a }}$ Reunião Ordinária realizada em 04/07/2005, e enquadrado na categoria: APROVADO, bem como o Termo de Consentimento Livre e Esclarecido, de acordo com o Processo HCRP $n^{\circ} 5993 / 2005$.

Aproveito a oportunidade para apresentar a Vossa Senhoria protestos de estima e considerff̣ão.

PROF. DR. SÉRGIO PEREIRA DA CUNTHA

Ccordenador do Comite de Eitica em Pesquisa do HCFMRP-USP e da FMRP-USP

Ilustríssima Senhora

GEISA DE ANGELIS

PROF. DR. RUBENS NELSON AMARAL DE A. REIMÃO (Orientador)

Faculdade de Medicina da Universidade de São Paulo

Depto. de Neurologia

Em mãos 
Anexo B: Termo de Consentimento Livre e Esclarecido

(Instruções para preenchimento no verso)

I - DADOS DE IDENTIFICAÇÃo dO SUJEITO DA PESQUISA OU RESPONSÁVEL LEGAL

Nome RG $\mathbf{N}^{\circ}$ :

Sexo: $\mathrm{M} \square \mathrm{F} \square \quad$ Data de nascimento: .................. Escolaridade:

Endereço

Cidade: № Apto:

Bairro: CEP:

Telefone(s): DDD (......)

Responsável legal

Natureza (grau de parentesco, tutor, curador etc.)

RG $\mathbf{N}^{\circ}$ :

Sexo: $\mathrm{M} \square \mathrm{F} \square \quad$ Data de nascimento: ...................

Endereço № Apto:

Bairro: Cidade: CEP:

Telefone(s): DDD (......)

\section{II - DADOS SOBRE A PESQUISA CIENTÍFICA}

1. Título do protocolo de pesquisa: Estudo do padrão, qualidade do sono e Qualidade de Vida em pessoas com transtorno afetivo bipolar do Hospital Dia da Faculdade de Medicina de Ribeirão Preto da Universidade de São Paulo.

2. Pesquisador: Geisa de Angelis Cargo/função: Psicóloga geisadeangelis@yahoo.com.br

3. Orientador: Prof. Dr. Rubens Nelson Amaral de Assis Reimão reimaorubensneuro@yahoo.com

4. Avaliação do risco da pesquisa:

$\begin{array}{llll}\text { Sem risco } & \square & \text { Risco mínimo } \square & \text { Risco médio } \\ \text { Risco baixo } & \square & \text { Risco maior } & \end{array}$

(probabilidade de que o indivíduo sofra algum dano como conseqüência imediata ou tardia do estudo)

5.Duração da pesquisa: 36 meses 
III - REgISTRO dAS EXPLICAÇÕES dO PESQUISAdOR AO PACIENTE OU SEU REPRESENTANTE LEGAL SOBRE A PESQUISA CONSIGNANDO

1. Justificativa e os objetivos da pesquisa: Os distúrbios do sono, como insônia (dificuldade de iniciar o sono ou mantê-lo durante a noite) e excesso de sono é um problema que afeta a vida das pessoas. Esta pesquisa tem o objetivo de saber como é que as pessoas com transtorno afetivo bipolar acham que está o seu sono e a sua vida nas últimas semanas. Para isso, gostaríamos de contar com sua colaboração para responder algumas perguntas.

2. Etapas que serão seguidas: Serão feitas várias perguntas sobre diferentes aspectos de sua vida: sua saúde física, sua vida emocional, seu relacionamento com amigos e familiares e seu meio ambiente. Os questionários que vamos utilizar são chamados de: Índice de Qualidade do Sono de Pittsburgh para saber como está a qualidade do sono, Inventário de Beck para Depressão e para Ansiedade (mostra alguns sinais de depressão e de ansiedade), Questionário WHOQOL-BREF para saber como está sua qualidade de vida, uma Escala de Mania (mostra se a pessoa tem sintomas de mania) e o Critério de Classificação Econômica Brasil que indica uma classificação sócio-econômica.

3. Desconfortos e riscos esperados: o Sr./a Sra. poderá se sentir emocionado (a) ao responder as perguntas sobre sua vida.

4. Benefícios que poderão ser obtidos: Esclarecimento sobre a Qualidade de Vida nos diferentes aspectos verificados e orientação para busca de situações que promovam a melhora na qualidade do sono e conseqüentemente da vida.

IV - ESCLARECIMENTOS DADOS PELO PESQUISADOR SOBRE GARANTIAS DO SUJEITO DA PESQUISA CONSIGNANDO:

1. Acesso, a qualquer momento, às informações sobre procedimentos, riscos e benefícios relacionados à pesquisa, inclusive para esclarecer quaisquer dúvidas.

2. Liberdade de retirar seu consentimento a qualquer momento e de deixar de participar do estudo, sem que isto traga prejuízo à continuidade da assistência.

3. Será mantido em sigilo o seu nome e quaisquer informações que possa identificarIhe. 
V. OBSERVAÇÕES COMPLEMENTARES: no fim da pesquisa os participantes serão informados sobre os resultados obtidos a partir dos dados que forneceram.

\section{VI - CONSENTIMENTO PÓS-ESCLARECIDO}

Declaro que, após convenientemente esclarecido pelo pesquisador e ter entendido o que me foi explicado, consinto em participar do presente Protocolo de Pesquisa.

Ribeirão Preto, de... de 2009. 


\section{Anexo C: Índice de Qualidade do Sono de Pittsburgh}

Nome:

No.

Data:

Idade:

\section{Instruções:}

As questões a seguir são referentes aos seus hábitos de sono APENAS durante o mês passado. Suas respostas devem indicar o mais corretamente possível o que aconteceu na maioria das noites do mês passado. Por favor, responda a todas as questões.

1-Durante o mês passado, a que horas você foi deitar à noite, na maioria das vezes? HORÁRIO DE DEITAR:

2-Durante o mês passado, quanto tempo (em minutos) você demorou para pegar no sono, na maioria das vezes?

QUANTOS MINUTOS DEMOROU PARA PEGAR NO SONO:

3-Durante o mês passado, a que horas você acordou de manhã, na maioria das vezes? HORÁRIO DE ACORDAR:

4-Durante o mês passado, quantas horas de sono por noite você dormiu? (pode ser diferente do número de horas que você ficou na cama)

HORAS DE SONO POR NOITE:

Para cada uma das questões seguintes, escolha uma única resposta, que você ache mais correta. Por favor, responda a todas as questões.

5-Durante o mês passado, quantas vezes você teve problemas para dormir por causa de:

a) demorar mais de 30 minutos (meia hora) para pegar no sono:

nenhuma vez

$\square \quad$ menos de uma vez por semana

$\square \quad$ uma ou duas vezes por semana

três vezes por semana

b) acordar no meio da noite ou de manhã muito cedo:

$\square \quad$ nenhuma vez

$\square \quad$ menos de uma vez por semana

$\square \quad$ uma ou duas vezes por semana

$\square \quad$ três vezes por semana

c) levantar-se para ir ao banheiro:

nenhuma vez

$\square \quad$ menos de uma vez por semana

uma ou duas vezes por semana

três vezes por semana

d) ter dificuldade para respirar:

nenhuma vez

menos de uma vez por semana

uma ou duas vezes por semana

três vezes por semana 
e) tossir ou roncar muito alto:

nenhuma vez

menos de uma vez por semana

$\square \quad$ uma ou duas vezes por semana

$\square \quad$ três vezes por semana

f)sentir muito frio:

$\square \quad$ nenhuma vez

$\square \quad$ menos de uma vez por semana

$\square \quad$ uma ou duas vezes por semana

$\square \quad$ três vezes por semana

g)sentir muito calor:

$\square \quad$ nenhuma vez

$\square \quad$ menos de uma vez por semana

$\square \quad$ uma ou duas vezes por semana

$\square \quad$ três vezes por semana

h)ter sonhos ruins ou pesadelos:

$\square \quad$ nenhuma vez

$\square \quad$ menos de uma vez por semana

$\square \quad$ uma ou duas vezes por semana

$\square \quad$ três vezes por semana

i)sentir dores:

$\square \quad$ nenhuma vez

$\square \quad$ menos de uma vez por semana

$\square \quad$ uma ou duas vezes por semana

$\square \quad$ três vezes por semana

j)quantas vezes você teve problemas para dormir por esta razão, durante o mês passado?

$\square \quad$ nenhuma vez

menos de uma vez por semana

$\square \quad$ uma ou duas vezes por semana

$\square \quad$ três vezes por semana

Outras razões, por favor descreva:

6-Durante o mês passado, como você classificaria a qualidade do seu sono?

$\square \quad$ muito boa
$\square \quad$ boa
$\square \quad$ ruim
$\square \quad$ muito ruim

7-Durante o mês passado, você tomou algum remédio para dormir, receitado pelo médico, ou indicado por outra pessoa (farmacêutico, amigo, familiar) ou mesmo por sua conta?

$\square \quad$ nenhuma vez

$\square \quad$ menos de uma vez por semana

$\square$ uma ou duas vezes por semana

$\square \quad$ três vezes por semana

Qual (is):

8-Durante o mês passado, se você teve problemas para ficar acordado enquanto estava dirigindo, fazendo suas refeições ou participando de qualquer outra atividade social, quantas vezes isto aconteceu? 
$\square \quad$ nenhuma vez

$\square \quad$ menos de uma vez por semana

$\square \quad$ uma ou duas vezes por semana

$\square \quad$ três vezes por semana

9-Durante o mês passado, você sentiu indisposição ou falta de entusiasmo para realizar suas atividades diárias?

$\square \quad$ nenhuma vez

$\square \quad$ menos de uma vez por semana

$\square \quad$ uma ou duas vezes por semana

$\square \quad$ três vezes por semana

10.Você cochila? ( ) Não ( ) Sim

Comentário do entrevistado (se houver):

Caso Sim -Você cochila intencionalmente, ou seja, por que quer?

( ) Não ( ) Sim

Comentários do entrevistado (se houver):

Para você, cochilar é:
( ) Um prazer
( ) Uma necessidade
( ) Outro - qual?
Comentários do entrevistado (se houver): 


\section{Anexo D: WHOQOL - BREVE}

\section{Instruções}

Este questionário é sobre como você se sente a respeito de sua Qualidade de Vida, saúde e outras áreas de sua vida. Por favor responda a todas as questões. Se você não tem certeza sobre que resposta dar em uma questão, por favor, escolha entre as alternativas a que lhe parece mais apropriada. Esta, muitas vezes, poderá ser sua primeira escolha.

Por favor, tenha em mente seus valores, aspirações, prazeres e preocupações. Nós estamos perguntando o que você acha de sua vida, tomando como referência as duas últimas semanas. Por exemplo, pensando nas últimas duas semanas, uma questão poderia ser:

\begin{tabular}{|c|c|c|c|c|c|}
\hline $\begin{array}{c}\text { Você recebe dos outros } \\
\text { o apoio de que necessita? }\end{array}$ & nada & $\begin{array}{c}\text { Muito } \\
\text { pouco }\end{array}$ & médio & muito & completamente \\
\cline { 2 - 7 } & 1 & 2 & 3 & $(4)$ & 5 \\
\hline
\end{tabular}

Você deve circular o número que melhor corresponde ao quanto você recebe dos outros o apoio de que necessita nestas últimas duas semanas. Portanto, você deve circular o número 4 se você recebeu "muito" apoio como abaixo.

\begin{tabular}{|c|c|c|c|c|c|}
\hline $\begin{array}{c}\text { Você recebe dos outros } \\
0\end{array}$ apoio de que necessita? & nada & $\begin{array}{c}\text { muito } \\
\text { pouco }\end{array}$ & médio & muito & completamente \\
\cline { 2 - 7 } & 1 & 2 & 3 & 4 & 5 \\
\hline
\end{tabular}

Você deve circular o número 1 se você não recebeu "nada" de apoio.

Por favor, leia cada questão, veja o que você acha e circule no número e the parece a melhor resposta.

\begin{tabular}{|c|c|c|c|c|c|c|}
\cline { 3 - 6 } \multicolumn{2}{l|}{} & muito ruim & ruim & $\begin{array}{c}\text { nem ruim } \\
\text { nem boa }\end{array}$ & boa & muito boa \\
\hline 1 & $\begin{array}{c}\text { Como você avaliaria sua } \\
\text { Qualidade de Vida ? }\end{array}$ & 1 & 2 & 3 & 4 & 5 \\
\hline
\end{tabular}

\begin{tabular}{|c|c|c|c|c|c|c|}
\cline { 2 - 6 } \multicolumn{2}{c|}{} & $\begin{array}{c}\text { muito } \\
\text { insatisfeito }\end{array}$ & insatisfeito & $\begin{array}{c}\text { nem satisfeito } \\
\text { nem } \\
\text { insatisfeito }\end{array}$ & satisfeito & $\begin{array}{c}\text { muito } \\
\text { satisfeito }\end{array}$ \\
\hline 2 & $\begin{array}{c}\text { Quão satisfeito(a) } \\
\text { você está com a } \\
\text { sua saúde? }\end{array}$ & 1 & 2 & 3 & 4 & 5 \\
\hline
\end{tabular}

As questões seguintes são sobre o quanto você tem sentido algumas coisas nas últimas duas semanas.

\begin{tabular}{|c|c|c|c|c|c|c|}
\hline \multicolumn{2}{|c|}{} & nada & $\begin{array}{l}\text { muito } \\
\text { pouco }\end{array}$ & $\begin{array}{l}\text { mais ou } \\
\text { menos }\end{array}$ & bastante & $\begin{array}{l}\text { extrema- } \\
\text { mente }\end{array}$ \\
\hline 3 & $\begin{array}{c}\text { Em que medida você acha que } \\
\text { sua dor (física) impede você de } \\
\text { fazer o que você precisa? }\end{array}$ & 1 & 2 & 3 & 4 & 5 \\
\hline & $\begin{array}{c}\text { O quanto você precisa de } \\
\text { algum tratamento médico para } \\
\text { levar sua vida diária? }\end{array}$ & 1 & 2 & 3 & 4 & 5 \\
\hline
\end{tabular}




\begin{tabular}{|c|c|c|c|c|c|c|}
\hline 5 & $\begin{array}{c}\text { O quanto você aproveita a } \\
\text { vida? }\end{array}$ & 1 & 2 & 3 & 4 & 5 \\
\hline 6 & $\begin{array}{c}\text { Em que medida você acha que } \\
\text { a sua vida tem sentido? }\end{array}$ & 1 & 2 & 3 & 4 & 5 \\
\hline 7 & $\begin{array}{c}\text { O quanto você consegue se } \\
\text { concentrar? }\end{array}$ & 1 & 2 & 3 & 4 & 5 \\
\hline 8 & $\begin{array}{c}\text { Quão seguro(a) você se sente } \\
\text { em sua vida diária? }\end{array}$ & 1 & 2 & 3 & 4 & 5 \\
\hline 9 & $\begin{array}{c}\text { Quão saudável é o seu } \\
\text { ambiente físico (clima, barulho, } \\
\text { poluição, atrativos)? }\end{array}$ & 1 & 2 & 3 & 4 & 5 \\
\hline
\end{tabular}

As questões seguintes perguntam sobre quão completamente você tem sentido ou é capaz de fazer certas coisas nestas últimas duas semanas.

\begin{tabular}{|c|c|c|c|c|c|c|}
\hline \multicolumn{2}{|c|}{} & nada & $\begin{array}{c}\text { muito } \\
\text { pouco }\end{array}$ & médio & muito & $\begin{array}{c}\text { completa- } \\
\text { mente }\end{array}$ \\
\hline 10 & $\begin{array}{c}\text { Você tem energia suficiente para } \\
\text { seu dia-a-dia? }\end{array}$ & 1 & 2 & 3 & 4 & 5 \\
\hline 11 & $\begin{array}{c}\text { Você é capaz de aceitar sua } \\
\text { aparência física? }\end{array}$ & 1 & 2 & 3 & 4 & 5 \\
\hline 13 & $\begin{array}{c}\text { Você tem dinheiro suficiente } \\
\text { para satisfazer suas } \\
\text { necessidades? }\end{array}$ & 1 & 2 & 3 & 4 & 5 \\
\hline 14 & $\begin{array}{c}\text { Quão disponíveis para você } \\
\text { estão as informações que } \\
\text { precisa no seu dia-a-dia? }\end{array}$ & 1 & 2 & 3 & 4 & 5 \\
\hline $\begin{array}{c}\text { Em que medida você tem } \\
\text { oportunidades de atividade de } \\
\text { lazer? }\end{array}$ & 1 & 2 & 3 & 4 & 5 \\
\hline
\end{tabular}

As questões seguintes perguntam sobre quão bem ou satisfeito você se sentiu a respeito de vários aspectos de sua vida nas últimas duas semanas.

\begin{tabular}{|c|l|c|c|c|c|c|}
\hline 15 & muito ruim & ruim & $\begin{array}{c}\text { nem ruim } \\
\text { nem bom }\end{array}$ & bom & $\begin{array}{c}\text { muito } \\
\text { bom }\end{array}$ \\
\hline \begin{tabular}{|l|l|c|c|c|c|}
\hline é capaz de \\
se locomover?
\end{tabular} & 1 & 2 & 3 & 4 & 5 \\
\hline 16 & $\begin{array}{c}\text { Quão satisfeito(a) você } \\
\text { está com o seu sono? } \\
\text { insatisfeito }\end{array}$ & 1 & 2 & 3 & 4 & 5 \\
\hline 17 & $\begin{array}{c}\text { Qnsatisfeito } \\
\text { Quão satisfeito(a) você } \\
\text { está com sua capaci- } \\
\text { dade de desempenhar } \\
\text { as atividades do } \\
\text { insatisfeito }\end{array}$ & $\begin{array}{c}\text { satisfeit } \\
0\end{array}$ & $\begin{array}{c}\text { muito } \\
\text { satisfeito }\end{array}$ \\
\hline
\end{tabular}




\begin{tabular}{|c|c|c|c|c|c|c|}
\hline 18 & $\begin{array}{c}\text { Quão satisfeito(a) você } \\
\text { está com sua } \\
\text { capacidade para o } \\
\text { trabalho? }\end{array}$ & 1 & 2 & 3 & 4 & 5 \\
\hline 19 & $\begin{array}{c}\text { Quão satisfeito(a) você } \\
\text { está consigo mesmo? }\end{array}$ & 1 & 2 & 3 & 4 & 5 \\
\hline 20 & $\begin{array}{c}\text { Quão satisfeito(a) você } \\
\text { está com suas relações } \\
\text { pessoais (amigos, } \\
\text { parentes, conhecidos, } \\
\text { colegas)? }\end{array}$ & 1 & 2 & 3 & 4 & 5 \\
\hline 21 & $\begin{array}{c}\text { Quão satisfeito(a) você } \\
\text { está com sua vida } \\
\text { sexual? }\end{array}$ & 1 & 2 & 3 & 4 & 5 \\
\hline 22 & $\begin{array}{c}\text { Quão satisfeito(a) você } \\
\text { está com o apoio que } \\
\text { você recebe de seus } \\
\text { amigos? }\end{array}$ & 1 & 2 & 3 & 4 & 5 \\
\hline 23 & $\begin{array}{c}\text { Quão satisfeito(a) você } \\
\text { está com as condições } \\
\text { do local onde mora? }\end{array}$ & 1 & 2 & 3 & 4 & 5 \\
\hline 24 & $\begin{array}{c}\text { Quão satisfeito(a) você } \\
\text { está com o seu acesso } \\
\text { aos serviços de saúde? }\end{array}$ & 1 & 2 & 3 & 4 & 5 \\
\hline 25 & $\begin{array}{c}\text { Quão satisfeito(a) você } \\
\text { está com o seu meio de } \\
\text { transporte? }\end{array}$ & 1 & 2 & 3 & 5 \\
\hline
\end{tabular}

A questão seguinte refere-se a com que freqüência você sentiu ou experimentou certas coisas nas últimas duas semanas.

\begin{tabular}{|c|l|c|c|c|c|c|}
\hline \multicolumn{2}{|l|}{} & nunca & $\begin{array}{c}\text { algumas } \\
\text { vezes }\end{array}$ & $\begin{array}{c}\text { freqüen- } \\
\text { temente }\end{array}$ & $\begin{array}{c}\text { muito } \\
\text { freqüente- } \\
\text { mente }\end{array}$ & sempre \\
\hline 26 & $\begin{array}{l}\text { Com que freqüência você tem } \\
\text { sentimentos negativos tais } \\
\text { como mau humor, desespero, } \\
\text { ansiedade, depressão? }\end{array}$ & 1 & 2 & 3 & 4 & 5 \\
\hline
\end{tabular}

Alguém Ihe ajudou a preencher este questionário?

Quanto tempo você levou para preencher este questionário?

Você tem algum comentário sobre o questionário? 


\section{Anexo E: Escala de Avaliação de Mania Modificada (EAM-m)}

\begin{tabular}{|l|}
\hline \multicolumn{1}{|c|}{ ITEM - Definição } \\
\hline 1. Humor e afeto elevados \\
Este item compreende uma sensação difusa e \\
prolongada, subjetivamente experimentada e \\
relatada pelo indivíduo, caracterizada por sensação \\
de bem estar, alegria, otimismo, confiança e ânimo. \\
Pode haver um afeto expansivo, ou seja, uma \\
expressão dos sentimentos exagerada ou sem \\
limites, associada à intensa relação com \\
sentimentos de grandeza (euforia). O humor pode \\
ou não ser congruente ao conteúdo do \\
pensamento.
\end{tabular}

\section{Atividade motora - energia aumentadas}

Este item compreende a psicomotricidade - e expressão corporal - apresentada pelo paciente, incluindo a sua capacidade em controlá-la, variando desde um grau de normalidade, até um estado de agitação, com atividade motora sem finalidade, não influenciada por estímulos externos. $O$ item compreende ainda o relato subjetivo do paciente, quanto à sensação de energia, ou seja, capacidade de produzir e agir.

\section{Interesse sexual}

Este item compreende idéias e/ou impulsos persistentes relacionados a questões sexuais, incluindo a capacidade do paciente em controlá-los. $O$ interesse sexual pode restringir-se a pensamentos e desejos não concretizados, em geral verbalizados apenas após solicitação, podendo chegar até a um comportamento sexual frenético e desenfreado, sem qualquer controle ou crítica quanto a riscos e normas morais.

\section{Sono}

Este item inclui a redução ou a falta na capacidade de dormir, e/ou a redução ou falta de necessidade de dormir, para sentir-se bem-disposto e ativo.

\section{Irritabilidade}

Este item revela a predisposição afetiva para sentimentos/emoções como raiva ou mau-humor apresentados pelo paciente diante de estímulos externos. Inclui baixo limiar à frustração, com reações de ira exagerada, podendo chegar a um estado constante de comportamento desafiador, querelante e hostil.
(0) Ausência de elevação do humor ou afeto

(1) Humor ou afeto discreta ou possivelmente aumentados, quando questionados

(2) Relato subjetivo de elevação clara do humor, mostra-se otimista, auto confiante, alegre; afeto apropriado ao conteúdo do pensamento

(3) Afeto elevado ou inapropriado ao conteúdo do pensamento; jocoso

(4) Eufórico; risos inadequados, cantando ( ) Não avaliado

(0) Ausente

(1) Relato subjetivo de aumento da energia ou atividade motora

(2) Apresenta-se animado ou com gestos aumentados

(3) Energia excessiva; às vezes; hiperativo; inquieto (mas pode ser acalmado)

(4) Excitação motora; hiperatividade contínua (não pode ser acalmado) ( ) não avaliado

(0) Normal; sem aumento

(1) Discreta ou possivelmente aumentado

(2) Descreve aumento subjetivo, quando questionado

(3) Conteúdo sexual espontâneo; discurso centrado em questões sexuais; auto-relato de hipersexualidade

(4) Relato confirmado ou observação direta de comportamento explicitamente sexualizado, pelo entrevistador ou outras pessoas ( ) Não avaliado

(0) Não relata diminuição do sono

(1) Dorme menos que a quantidade normal, cerca de 1 hora a menos do que seu habitual

(2) Dorme menos que a quantidade normal, mais que 1 hora a menos do que seu habitual

(3) Relata diminuição da necessidade de sono

(4) Nega necessidade de sono ( )Não avaliado

(0) Ausente

(1) Subjetivamente aumentada

(2) Irritável em alguns momentos durante a entrevista; episódios recentes (nas últimas 24 horas) de ira ou irritação na enfermaria

(3) Irritável durante a maior parte da entrevista; ríspido e lacônico o tempo todo

(4) Hostil; não cooperativo; entrevista impossível

( ) Não avaliado 


\section{Fala (velocidade e quantidade)}

Este item compreende a velocidade e a quantidade de discurso verbal apresentado pelo paciente. Inclui sua capacidade de percebê-lo e controlá-lo, por exemplo, diante de solicitações para que permaneça em silêncio ou permita que o entrevistador fale.
(0) Sem aumento

(1) Percebe-se mais falante do que o seu habitual

(2) Aumento da velocidade ou quantidade da fala em alguns momentos; verborréico, às vezes (com solicitação, consegue-se interromper a fala)

(3) Quantidade e velocidade constantemente aumentadas; dificuldade para ser interrompido (não atende a solicitações; fala junto com o entrevistador)

(4) Fala pressionada, ininterruptível, contínua (ignora a solicitação do entrevistador) ( ) Não avaliado

\section{Linguagem - Distúrbio do pensamento}

Este item refere-se a alterações da forma do pensamento, avaliada pelas construções verbais emitidas pelo paciente. O pensamento pode estar mais ou menos desorganizado, de acordo com a gravidade das alterações formais do pensamento, descritas a seguir:

- Fala indireta que demora a atingir o ponto desejado, mas eventualmente vai desde o ponto de origem até o objetivo final, a despeito da superinclusão de detalhes e observações relevantes;

- Tangencialidade: incapacidade para manter associações do pensamento dirigidas ao objetivo final desejado;

- Fuga de idéias: verbalizações rápidas e contínuas, ou jogos de palavras que produzem uma constante mudança de uma idéia para outra; as idéias tendem a estar conectadas e, mesmo em formas menos graves, podem ser difíceis de ser acompanhadas pelo ouvinte;

- Ecolalia consonante: repetição automática de palavras ou frases, com entonação e forma que produzem efeito sonoro de rima;

- Incoerência: fala ou pensamento essencialmente incompreensíveis aos outros, porque as palavras ou frases são reunidas sem uma conexão com lógica e significado, podendo chegar à incoerência gramatical e à salada de palavras.

\section{Conteúdo}

Este item compreende idéias e crenças apresentadas pelo paciente, variando, de acordo com a intensidade, de idéias novas e/ou incomuns ao paciente, ideação supervalorizada (ou seja, crença falsa, intensamente arraigada, porém susceptível à argumentação racional), a delírios (crenças falsas baseadas em inferências incorretas sobre a realidade, inconsistentes com a inteligência e antecedentes) culturais do paciente, e que não podem ser corrigidas pela argumentação). Conteúdos comumente encontrados no paciente maníaco incluem: (1) idéias místicas, de conteúdo religioso, referindo-se à atuação de entidades sobre o paciente, outras pessoas ou fatos; (2) idéias paranóides, i.e, crença de estar sendo molestado, enganado ou perseguido; (3) idéias de grandeza, i.e, concepção exagerada da própria importância, poder ou identidade, incluindo posses materiais,

\section{(0) Sem alterações}

(1) Circunstancial; pensamentos rápidos

(2) Perde objetivos do pensamento; muda de assunto freqüentemente; pensamentos muito acelerados

(3) Fuga de idéias; tangencialidade; dificuldade para acompanhar o pensamento; ecolalia consonante

(4) Incoerência; comunicação impossível ( ) Não avaliado

(0) Normal

(1) Novos interesses e planos compatíveis com a condição sócio-cultural do paciente, mas questionáveis

(2) Projetos especiais totalmente incompatíveis com a condição sócio-econômica do paciente; hiper-religioso

(3) Idéias supervalorizadas

(4) Delírios

( ) Não avaliado 
qualidades incomuns e relacionamentos especiais com personalidades famosas ou entidades místicas; (4) idéias de referência, i.e, crença de que o comportamento dos outros tem relação consigo próprio ou de que eventos, objetos ou outras pessoas possuem um significado particular e incomum para si - p. ex., freqüentemente acredita que os outros estão falando de si.

\section{Comportamento disruptivo agressivo}

Este item compreende a atitude e as respostas do paciente ao entrevistador e á situação da entrevista. O paciente pode apresentar-se desconfiado ou irônico e sarcástico, mas ainda assim respondendo aos questionamentos, ou então não cooperativo e francamente agressivo, inviabilizando a entrevista.

\section{Aparência}

Este item compreende a apresentação física do paciente, incluindo aspectos de higiene, asseio e modo de vestir-se.

\section{Insight (discernimento)}

Este item refere-se ao grau de consciência e compreensão do paciente quanto ao fato de estar doente. Varia tanto de um entendimento adequado (afetivo e intelectual) quanto à presença da doença, passando por concordância apenas diante de argumentação, chegando a uma negação total de sua enfermidade, referindo estar, em seu comportamento, normal e não necessitando de qualquer tratamento.

(0) Ausente, cooperativo

(1) Novos interesses e planos compatíveis com a condição sócio-econômica do paciente, mas questionáveis

(2) Projetos especiais totalmente incompatíveis com a condição sócio-econômica do paciente; hiper-religioso

(3) Idéias supervalorizadas

(4) Delírios

( ) Não avaliado

(0) Arrumado e vestido apropriadamente

(1) Descuidado minimamente; adornos ou roupas minimamente inadequados ou exagerados

(2) Precariamente asseado; despenteado moderadamente; vestido com exagero

(3) Desgrenhado; vestido parcialmente; maquiagem extravagante

(4) Completamente descuidado; com muitos adornos e adereços; roupas bizarras

( )Não avaliado

(0) Insight presente: espontaneamente refere estar doente e concorda com a necessidade de tratamento

(1) Insight duvidoso: com argumentação, admite possível doença e necessidade de tratamento

(2) Insight prejudicado: espontaneamente admite alteração comportamental, mas não a relaciona com a doença, ou discorda da necessidade de tratamento

(3) Insight ausente: com argumentação, admite de forma vaga alteração comportamental, mas não a relaciona com a doença e discorda da necessidade de tratamento

(4) Insight ausente: nega a doença, qualquer alteração comportamental e necessidade de tratamento

( ) Não avaliado 


\section{Anexo F: Roteiro de entrevista para o preenchimento do EAM-m}

\section{Instruções}

A entrevista de avaliação para o preenchimento do EAM-m é, a priori, não estruturada. As perguntas descritas aqui são apenas um roteiro para que, na avaliação do paciente maníaco, nenhum dos itens da EAM-m deixe de ser avaliado. Portanto, o entrevistador tem liberdade de realizar outras perguntas que julgar necessárias para a avaliação de um determinado item ou, então, omitir algumas das perguntas listadas aqui, se o paciente (ou a observação direta) já tiver oferecido informações sobre o item a que elas se referem. $A$ escala deve ser pontuada somente após o término da entrevista, e não no decorrer dela. Não é necessário que o paciente tenha todos os itens descritos em uma determinada chave de gradação, mas apenas um, o que basta para que esta chave seja marcada. Considerar a alteração que permeia a maior parte da entrevista.

\section{Entrevista}

\begin{tabular}{|l|l|}
\hline ITEM & PERGUNTAS GUIA \\
\hline Qual o seu nome completo? E a sua idade? Onde você mora? Com quem \\
você mora? Está trabalhando atualmente? (Já trabalhou anteriormente? \\
Em quê?)
\end{tabular}




\begin{tabular}{|l|l|}
\hline $\begin{array}{l}\text { 8. Conteúdo do } \\
\text { pensamento }\end{array}$ & $\begin{array}{l}\text { Ultimamente, você tem tido pensamentos diferentes ou estranhos, ou } \\
\text { idéias ou planos que antes não passavam pela sua cabeça? Quais são } \\
\text { seus planos para o futuro? (O que você tem vontade de fazer?) Nos } \\
\text { últimos dias você tem se sentido com algum talento ou habilidade que a } \\
\text { maioria das pessoas não tem? (Como você sabe disso?) Você acha que } \\
\text { as pessoas têm inveja de você? Você acredita que tem alguma coisa } \\
\text { importante para fazer no mundo? Você se considera famoso? Você tem } \\
\text { alguma relação especial com alguém importante ou famoso? }\end{array}$ \\
\hline $\begin{array}{l}\text { 9. Humor } \\
\text { elevado }\end{array}$ & $\begin{array}{l}\text { Ultimamente, como você se sente? Como tem estado o seu humor } \\
\text { (alegre, triste, irritável) (Se deprimido: Você acredita que pode } \\
\text { melhorar?) Como este sentimento tem afetado o seu dia-a-dia? (Você } \\
\text { está mais alegre [confiante ou otimista] que o habitual? Ultimamente, } \\
\text { você está tão bem ou alegre, que as outras pessoas acham que você } \\
\text { não está no seu normal? Você está tão alegre que isso Ihe trouxe } \\
\text { problemas?) [OBSERVAR] }\end{array}$ \\
\hline
\end{tabular}

\section{Encerramento}

Estas eram as perguntas que eu precisava fazer. Tem alguma que você considera importante dizer, que eu não perguntei ou algo que gostaria de perguntar.

\section{Observação}

Os itens 7, 9 e 10 da EAM-m são preenchidos a partir da observação direta.

FOLHA DE RESPOSTAS

\begin{tabular}{|l|l|}
\hline EAM-m - Item & Pontuação \\
\hline 1. Humor elevado & \\
\hline 2. Atividade e energia aumentadas & \\
\hline 3. Interesse sexual & \\
\hline 4. Sono & \\
\hline 5. Irritabilidade & \\
\hline 6. Fala (velocidade e quantidade) & \\
\hline 7. Linguagem - Distúrbio do pensamento & \\
\hline 8. Conteúdo do pensamento & \\
\hline 9. Comportamento disruptivo agressivo & \\
\hline 10. Aparência & \\
\hline 11. Insight (discernimento) & \\
\hline \multicolumn{1}{|c|}{ Pontuação total } & \\
\hline
\end{tabular}




\section{Anexo G: Critério de Classificação Econômica Brasil}

NOME:

\begin{tabular}{|l|c|c|c|c|c|}
\hline Posse de itens & Não & \multicolumn{5}{|c|}{ ITEM } \\
\cline { 3 - 6 } & tem & $\mathbf{1}$ & $\mathbf{2}$ & $\mathbf{3}$ & $\mathbf{4}$ ou + \\
\hline Televisão em cores & 0 & 2 & 3 & 4 & 5 \\
\hline Rádio & 0 & 1 & 2 & 3 & 4 \\
\hline Banheiro & 0 & 2 & 3 & 4 & 4 \\
\hline Automóvel & 0 & 2 & 4 & 5 & 5 \\
\hline Empregada Mensalista & 0 & 2 & 4 & 4 & 4 \\
\hline Aspirador de pó & 0 & 1 & 1 & 1 & 1 \\
\hline Máquina de lavar & 0 & 1 & 1 & 1 & 1 \\
\hline Videocassete e/ou DVD & 0 & 2 & 2 & 2 & 2 \\
\hline Geladeira & 0 & 2 & 2 & 2 & 2 \\
\hline $\begin{array}{l}\text { Freezer (aparelho independente } \\
\text { ou parte da geladeira) }\end{array}$ & 0 & 1 & 1 & 1 & 1 \\
\hline
\end{tabular}

Grau de instrução do chefe da família

\begin{tabular}{|l|l|}
\hline Analfabeto/Primário incompleto & 0 \\
\hline Primário Completo/Ginasial incompleto & 1 \\
\hline Ginasial Completo/Colegial incompleto & 2 \\
\hline Colegial Completo/Superior incompleto & 3 \\
\hline Superior Completo & 4 \\
\hline
\end{tabular}

CLASSIFICAÇÃO

\begin{tabular}{|c|c|}
\hline Classe & PONTOS \\
\hline A1 & $30-34$ \\
\hline A2 & $25-29$ \\
\hline B1 & $21-24$ \\
\hline B2 & $17-20$ \\
\hline C & $11-16$ \\
\hline D & $6-10$ \\
\hline E & $0-5$ \\
\hline
\end{tabular}

Fonte: ANEP- Associação Nacional de Empresas de Pesquisas. www.anep.org.br 


\section{REFERÊNCIAS BIBLIOGRÁFICAS}

1 - Krystal AD, Thakur M, Roth T. Sleep disturbance in psychiatric disorders: effects on function and quality of life in mood disorders, alcoholism and schizophrenia. Ann Clin Psychiatry. 2008;20(1):39-46.

2 - Benca RM, Okama M, Uchiyama M, Ozaki S, Nakajima T, Shibui K, Obermayer WH. Sleep and mood disorders. Sleep Med Rev. 1997;1(1):45-56.

3 - Benca RM, Obermayer WH, Tristed RA, Gillin JC. Sleep and psychiatric disorders. A meta-analysis. Arch Gen Psychiatry. 1992;49(8):651-68.

4 - Souza MM, Kaimén DRM, Reimão R. Polysomnographic evaluation of clinical patients suffering from mood disturbance. Arq Neuropsiquiatr. 2003;61(2B):387-91.

5 - Papadimitriou GN, Dikeos DG, Soldatos CR. Sleep disturbance in unipolar and bipolar depression: relationship to psychiatric family history. Neuropsychobiology. 2003;48 (3):131-5.

6 - American Psychiatry Association. Manual Diagnóstico e Estatístico de Transtornos Mentais. DSM-IV-TR ${ }^{\mathrm{TM}}$. 4.ed.rev. Porto Alegre: Artmed, 2002. p.345-417.

7 - Breslau N, Roth T, Rosenthal L, Andreski P. Sleep disturbance and psychiatric disorders: a longitudinal epidemiological study of young adults. Biol Psychiatric. 1996;15;39(6):411-18.

8 - Morawetz D. Insomnia and Depression: Which Comes First? Sleep Research Online. 2003;5(2):77-81.

9 - Riemann D, Voderholzer U. Primary insomnia: a risk factor to develop depression? J Affect Disord. 2003;76(1-3):255-59.

10 -Plante DT, Winkelman JW. Sleep disturbance in bipolar disorder. Am J Psychiatry. 2008;(15)AiA1-14.

11 -Stenuit P, Kerkhofs M. Effects of sleep restriction on cognition. Biol Psychol. 2008;77(1):81-88.

12 -Paprocki J, Rocha FL. Tratamento da insônia na depressão. In: Reimão R. Sono: estudo abrangente. 2.ed. São Paulo: Atheneu, 1996, p.246-63.

13 -Hakkaart-van Roijen L, Hoeijenbos MB, Regeer EJ, ten Have M, Nolen WA, Veraart CP, Rutten FF. The societal costs and quality of life of patients suffering from bipolar disorder in the Netherlands. Acta Psychiatr Scand. 2004;110(5)383-92. 
14 - Yatham LN, Lecrubier Y, Fieve RR, Davis KH, Harris SD, Krishnan AA. Quality of life in patients with bipolar I depression: data from 920 patients. Bipolar Disord. 2004;6(5):379-85.

15 -Newman CF, Leahy RL, Beck AT, Reilly-Harrington, Gyulai L. Transtorno Bipolar: tratamento pela terapia cognitiva. São Paulo: Roca, 2006. Cap.1, p.1-21: Transtorno bipolar: questões relacionadas com diagnóstico, epidemiologia, etiologia e prognóstico.

16 -Organização Mundial da Saúde. Relatório sobre saúde mental no mundo. Genebra: OMS, 2001 [citado 25 maio 2008]. Disponível em: http://www.who.int/whr.

17 -Lish JD, Dime-Meenam S, Whybrow PC, Price RA, Hirschfield RM. The National Depressive and Manic-Depressive Association (DMDA) survey of bipolar members. J Affect Disord. 2004;31:281-84.

18 -Lingam R, Scott J. Treatment non-adherence in affective disorders. Acta Psychiatr Scand. 2002;105:164-172.

19 -Scott J, Pope M. Nonadherence with mood stabilizers: prevalence and predictors. J Clin Psychiatry. 2002;63:384-90.

20 -Judd LL, Akiskal HS, Schettler PJ, Endicott J, Maser J, Solomon DA, Leon AC, Rice JA, Keller MB. The long term natural history of the weekly symptomatic status of bipolar I disorder. Arch Gen Psychiatry. 2002;59:530-37.

21 -Angst J, Gamma A, Benazzi F, Ajdacic V, Eich D, Rössler W. Toward a re-definition of subthreshold bipolarity: epidemiology and proposed criteria for bipolar II, minor bipolar disorders and hypomania. J Affect Disord. 2003;73(1-2): 133-46.

22 -Partinen M. Epidemiology of sleep disorders. In: Kryger $\mathrm{MH}$, Roth $\mathrm{T}$, Dement WC. Principles and practice of sleep medicine. USA: WB Saunders, 1994;437-452.

23 -Goodwin FK, Jamison KR. Manic-Depressive Illness, 2nd ed. New York: Oxford University Press, 1990.

24 -Teng CT Humes EC, Demétrio FN. Depressão e comorbidades clínicas. Rev Psiquiatr Clín. [citado em 15 maio 2008]. Disponível em: http://www.hcnet.usp.br/ipq/revista/vol32/ n3/149.html.

25 -Sanches RF, Assunção S, Helem LAB. Impacto da comorbidade no diagnóstico e tratamento do transtorno bipolar. Rev Psiquiatr Cíin. 2005;32(supl.1):71-77.

26 -Weissman MM, Bland RC, Canino GJ, Faravelli C, Greenwald S, Hwu HG, Joyce PR, Karam EG, Lee CK, Lellouch J, Lépine JP, Newman SC, Rubio-Stipec M, Wells JE, Wickramaratne PJ, Wittchen $\mathrm{H}$, Yeh EK. Cross-national epidemiology of major depression and bipolar disorder. JAMA. 1996;24-31;276(4):293-99.

27 -Akiskal HS, Bourgeois ML, Angst J, Post R, Möller H, Hischfeld R. Reevaluating the prevalence and diagnostic composition within the broad 
clinical spectrum of bipolar disorders. J Affect Disord 2000;59(suppl 1):S5-S30.

28 -Angst J. The emerging epidemiology of hypomania and bipolar II disorder. J Affect Disord. 1998 sep;50(2-3):143-51.

29 -Moreno DH. Prevalência e características do espectro bipolar em amostra populacional definida da cidade de São Paulo [tese]. Faculdade de Medicina da Universidade de São Paulo; 2003.

30 -Lima MS, Tassi J, Novo IP, Mari JJ. Epidemiologia do transtorno bipolar. Rev Psiquiatr Cin. 2005;32, supl I;15-20.

31 -Chengappa KN, Kupfer DJ, Frank E, Houck PR, Grochocinski VJ, Cluss PA, Stapf DA. Relationship of birth cohort and early age at onset of illness in a bipolar disorder: case registry. Am $J$ Psychiatry. 2003;160(9):1636-1642.

32 -Alda M. Transtorno bipolar. Rev Bras Psiquiatr. 1999; 21(Supl. 2)14-7.

33 -Colom F, Vieta E. Melhorando o desfecho do transtorno bipolar usando estratégias não farmacológicas: o papel da psiceducação. Rev Psiquiatr Clín. 2004;26(suppl III):47-50.

34 -Perry A, Tarrier N, Morriss R, McCarthy E, Limb K. Randomised controlled trial of efficacy of teaching patients with bipolar disorder to identify early symptoms of relapse and obtain treatment. BMJ. 1999;16;318(7177):149-53.

35 -Colom F, Vieta E, Martinez-Aran A, Reinares M, Goikolea JM, Benabarre A, Torrent C, Comes M, Corbella B, Parramon G, Corominas J. A randomized trial on the efficacy of group psychoeducation in the prophylaxis of recurrences in bipolar patients whose disease is in remission. Arch Gen Psychiatry. 2003;60(4):402-7.

36 -Miklowitz DJ, Hooley JM. Developing family psychoeducation treatment for patients with bipolar and other severe psychiatric disorders: a pathway from basic research to clinical trials. J Marital Fam Ther. 1998;24:419-35.

37 -Yalom ID. Leszcz M. Os fatores terapêuticos. In: Yalom ID. Leszcz M. Psicoterapia de grupo: experiência e prática. Porto Alegre: Artmed, 2006. p.23-35:

38 -Buysse DJ, Reynolds CF, Hauri PJ, Roth T, Stepanski EJ, Thorpy MJ, Bixler EO, Kales A, Manfredi RL, Vgontzas AN. Diagnostic concordance for DSM-IV sleep: a report from the APA/NIMH DSM-IV field trial. Am J Psychiatry. 1994;151(9):1351-60.

39 -De Martin NA, Winokur A. Effects of psychiatric medications on sleep and sleep disorders. Neurol Disord Drug Targets. 2007;6(1):17-29.

40 -Leibenluft E, Albert PS, Rosenthal NE, Wehr TA. Relationship between sleep and mood in patients with rapid-cycling bipolar disorder. Psychiatry Res. 1996;31;63(2-3):161-68. 
41 -Wehr TA, Sack DA, Rosenthal NE. Sleep reduction as a final common pathway in the genesis of mania. Am J Psychiatry. 1987;144:201-204.

42 -Harvey AG, Schimidt DA, Scarnà A, Semler NA, Goodwin GM. Sleeprelated functioning in euthymic patients with bipolar disorder, patients with insomnia, and subjects without sleep problems. Am J Psychiatry. 2005;162(1):50-57.

43 -Jackson A, Cavanagh J, Scott J. A systematic review of manic and depressive prodromes. J Affect Disord. 2003;74(3):209-217.

44 -Perry A, Tarrier N, Morriss R, McCarthy E, Limb K. Randomised controlled trial of efficacy of teaching patients with bipolar disorder to identify early symptoms of relapse and obtain treatment. BMJ. 1999;318(7177):149-53.

45 -Peet M, Peters ST. Drug induced mania. Drug Saf. 1995;12(2):146-53.

46 -Strakowski SM, Hudson JI, Keck PE Jr., Wilson DR, Frankenburg FR, Alperl JE, Teschke GC, Tohen M. Four cases of obstructive sleep apnea associated with treatment resistant mania. J Clin Psychiatry. 1991;52(4):156-58.

47 -Fleming JA, Fleetham JA, Taylor DR, Remick RA. A case report of obstructive sleep apnea in a patient with bipolar affective disorder. Can $J$ Psychiatry. 1985;30(6)437-39.

48 -Malkoff-Schwartz S, Frank E, Anderson B, Hlatala SA, Luther JF, Sherrill JT, Houck PR, Kupfer DJ. Social rhythm disruption and stressful life in the onset of bipolar and unipolar episodes. Psychol Med. 2000;30(5):1005-16

49 -Malkoff-Schwartz SS, Frank E, Anderson BP, Sherrill JT, Siegal L, Paterson D, Kupfer DJ: Stressful life events and social rhythm disruption in the onset of manic and depressive bipolar episodes: a preliminary investigation. Arch Gen Psychiatry. 1998;55(8):702-07.

50 -Sclare P, Creed F. Life events and the onset of mania. Br J Psychiatry. 1990;156:508-514.

51 -McPherson $H$, Herbison $P$, Romans $S$. Life events and relapse in established bipolar affective disorder. Br J Psychiatry 1993;163:381-385.

52 -Reynolds CF, Taska LS, Jarret DB, Coble PA, Kupfer DJ. REM latency in depression: is there one best definition? Biol Psychiatry. 1983;18(8):84963.

53 -Bowden CL. A different depression: clinical distinctions between bipolar and unipolar depression. J Affect Disord. 2005;84(2-3):117-25.

54 -Nofzinger EA, Thase ME, Reynolds CF, Himmelhoch JM, Mallinger A, Houck P, Kupfer DJ. Hypersomnia in bipolar depression: a comparison with narcolepsy using the multiple sleep latency test. Am J Psychiatry. 1991;148(9):1177-81. 
55 -Kales A, Bixler EO, Vela-Bueno A, Cadieux RJ, Soldatos CR, Kales JD. Biopsychobehavioral correlates of insomnia-polygraphic findings of sleep difficulty and their relationship to psychopathology. Int $J$ Neurosci 1984;23:43-55.

56 -Hantouche EG, Akiskal HS. Bipolar II vs. unipolar depression: psychopathologic differentiation by dimensional measures. J Affect Disord. 2005;84(2-3);127-32.

57 -Angelis G, Reimão R, Rossini S, Sanches RF. Implicações da qualidade do sono na Qualidade de Vida em portadores do transtorno bipolar. In: Reimão R. Sono: avanços e seus distúrbios. São Paulo: Associação Paulista de Medicina, 2005;138-39.

58 -Sitaram N, Nurnberger JI Jr, Gershon ES, Gillin JC. Cholinergic regulation of mood and REM sleep: potential model and marker of vulnerability to affective disorder. Am J Psychiatry. 1982;139(5):571-76.

59 -Knowles JB, Cairns J, MacLean AW, Delva N, Prowse A, Waldron J, Letemendia FJ. The sleep of remitted bipolar depressives: comparison with sex and age-matched controls. Can J Psychiatry. 1986;31(4):29598.

60 -Millar A, Espie CA, Scott J. The sleep of remitted bipolar outpatients: a controlled naturalistic study using actigraphy. J Affect Disord. 2004;80(23):145-53.

61 -Buysee DJ, Reynolds CF, Monk TH, Berman SR, Kupfer DJ. The Pittsburgh Sleep Quality Index: a new instrument for psychiatric practice and research. Psychiatry Research. 1988;28:193-213.

62 -Organização Mundial da Saúde (OMS), Divisão de Saúde Mental Grupo WHOQOL. Versão em português dos instrumentos de avaliação de qualidade de vida 1998 [citado 25 maio 2008] Disponível em http://www.ufrgs.br/psiq/whoqol1.html\#1.

63 -Ellicott A, Spitzer RC. A diagnostic interview. The shedule for affective disorders and schizophrenia. Arch Gen Psychiatry. 1978;35: 837-44.

64 -Robb JC, Cooke RG, Devins GM, Young LT, Joffe RT. Quality of life and lifestyle disruption in euthymic bipolar disorder. J Psychiat Res. 1997;31(5):509-17.

65 -Sierra P, Livianos L, Rojo L. Quality of life for patients with bipolar disorder: relationship with clinical and demographic variables. Bipolar Disord. 2005;7(2):159-65.

66 -Fava GA. Subclinical symptoms in mood disorders. Psychol Med. 1999;29(1):47-61.

67 -Vojta C, Kinosian B, Glick H, Altshuler L, Bauer MS. Self-reported quality of life across mood states in bipolar disorder. Compr Psychiatry. 2001;42(3):190-95.

68 -Gazalle FK, Fei BN, Hallal PC, Andreazza AC, Cunha AB, Santin A, Kapczinski F. Mismatch between self-reported quality of life and 
functional assessment in acute mania: a matter of unawareness of illness? J Affect Disord. 2007;103:247-52.

69 -Brissos S, Dias VV, Carita Al, Martinez-Arán A. Quality of life in bipolar type I disorder and schizophrenia in remission: clinical and neurocognitive correlates. Psychiatry Res. 2008;(5):14.

70 -Piccini A, Catena M, Del Debbio A, Marazziti D, Monje C, Schiavi E, Mariotti A, Bianchi C, Palla A, Roncaglia I, Carlini M, Pini S, Dell'Osso S. Health-related quality of life and functioning in remitted bipolar I outpatients. Compr Psychiatry. 2007;48(4):232-28.

71 -Yatham LN, Lecrubier Y, Fieve RR, Davis KH, Harris SD, Krishnan AA. Quality of life in patients with bipolar I depression data from 920 patients. Bipolar Disord. 2004;6(5):379-85.

72 -World Health Quality of Life - WHOQOL Group. Development of the World Health Organization WHOQOL-BREF Quality of Life Assessment. Psychological Medicine. 1998;28(3):551-8.

73 -Berlim MT, Pargendler J, Caldieraro MA, Almeida EA, Fleck MP, Joiner TE. Quality of live in unipolar and bipolar depression: are there significant differences? J Nerv Ment Disord. 2004;192(11):795-5.

74 -Namjoshi MA, Buesching DP. A review of the health-related quality of life literature in bipolar disorder. Qual Life Res. 2001;10(2):105-15.

75 -Chand PK, Mattoo SK, Sharan P. Quality of life and its correlates in patients with bipolar disorder stabilized on lithium prophylaxis. Psychiatric Clin Neurosci. 2004;58(3):311-18.

76 -Siegal S, Jr. Castellan NJ. Estatística não-paramétrica para ciências do comportamento. Porto Alegre: Artmed, 2006.

77 -Coleman RM. Diagnosis, Treatment, and follow-up of about 8,000 sleep/wake disorder patients. In Guilleminault C, Lugaresi E. Sleep/Wake Disorders. New York: Raven Press. 1983:87-97.

78 -Beck AT, Ward CH, Mendelson M, Mock J, Erbaugh G. An Inventory for measuring depression. Arch Gen Psychiatry. 1961;4:561-71.

79 -Beck AT, Steer RA, Garbin MG. Psychometric properties of the Beck depression inventory: twenty-five years of evaluation. Clinical Psychology. 1988;8:77-100.

80 -Gorestein C, Andrade LHSG. Inventário de Depressão de Beck: propriedades psicométricas da versão em português. Rev Psiquiatr Clin. 1998;25(5): 245-50.

81 -Gorenstein C, Andrade LHSG, Zuardi AW. Escalas de Avaliação Clínica em Psiquiatria e Psicofarmacologia. São Paulo: Lemos, 2000.

82 -Cunha JA. Manual da versão em português das escalas Beck. São Paulo: Casa do Psicólogo, 2001. 
83 -Kendall PC, Hollon SD, Beck AT, Hammen, Cl, Ingram RE. Issues and recommendations regarding use of the Beck Depression Inventory. Cognitive Therapy and Research. 1987;11:89-299.

84 -World Health Organization/WHO - WHOQOL Group. The development of the WHO Quality of Life Assessment Instrument: The WHOQOL. In: Orley J, Kuyken W. Quality of life assessment: international perspectives. Berlin, Springer Verlag. 1994:41-60.

85 -Fleck M, Louzada S, Xavier M, Chachamovich E, Vieira G, Santos L, Pinzon V. Aplicação da versão em português do instrumento WHOQOLBREF. Rev Saúde Pública. 2000;34(2):178-83.

86 -Tavares M. A entrevista estruturada para o DSM-IV. In Cunha JA. Psicodiagnóstico-V. Porto Alegre: Artmed, 2000; 75-87.

87 -Del-Ben CM, Vilela JA, Crippa JA, Hallak JE, Labate CM e Zuardi AW. Confiabilidade da Entrevista Clínica Estruturada para o DSM-IV "Versão Clínica" traduzida para o português. Rev Bras Psiquiatr. 2001;23(3):156-59.

88 -Vilela J, Loureiro S. Escala de Avaliação de Mania de Young - Estudo das qualidades psicométricas da versão brasileira. In: Gorenstein C, Andrade L, Zuardi A. Escalas de Avaliação Clínica em Psiquiatria e Psicofarmacologia. São Paulo: Lemos; 2000:113-24.

89 -Associação Nacional de Empresas de Pesquisa - ANEP. Critério Econômico Brasil. [acesso 10 março 2004]. Disponível em http//www.anep.org.br.

90 -Weissman MM, Bland EG, Canino GJ, Faravelli C, Greenwald S, Hwu HG, Joyce PR, Karam EG, Lee CK, Lellouch J, Lepine JP, Newman SC, Rubio -Stipec M, Wells JE, Wickramaratne PJ, Wittchen H, Yeh EK. Cross-national epidemiology of major depression and bipolar disorder. JAMA. 1996; 276(4):293-99.

91 -Berlim MT, Brenner JK, Caldieraro MAK, Pargendler JS, Fleck MPA. Qualidade de vida em pacientes deprimidos. In: Fleck MPA. A avaliação de qualidade de vida: guia para profissionais da saúde. Porto Alegre: Artmed, 2008:125-28. 